\title{
Uncovering Potential Applications of Cyanobacteria and Algal Metabolites in Biology, Agriculture and Medicine: Current Status and Future Prospects
}

OPEN ACCESS

Edited by:

Mehdi Razzaghi-Abyaneh,

Pasteur Institute of Iran, Iran

Reviewed by:

Maria de los Angeles Serradell,

Centro Científico Tecnológico (CONICET) La Plata and Instituto de

Ciencias de la Salud (UNAJ),

Argentina

Ashootosh Tripathi

University of Michigan, USA

*Correspondence: Vijay P. Singh

vijaypratap.au@gmail.com

Sheo M. Prasad

profsmprasad@gmail.com

${ }^{\dagger}$ These authors have contributed equally to this work.

Specialty section: This article was submitted to

Food Microbiology,

a section of the journal

Frontiers in Microbiology

Received: 31 May 2016 Accepted: 13 March 2017

Published: 25 April 2017

Citation:

Singh R, Parihar P, Singh M, Bajguz A, Kumar J, Singh S, Singh VP and

Prasad SM (2017) Uncovering

Potential Applications of Cyanobacteria and Algal Metabolites in Biology, Agriculture and Medicine: Current Status and Future Prospects.

Front. Microbiol. 8:515

doi: 10.3389/fmicb.2017.00515
Rachana Singh ${ }^{1 \dagger}$, Parul Parihar ${ }^{1 \dagger}$, Madhulika Singh ${ }^{1 \dagger}$, Andrzej Bajguz $^{2}$, Jitendra Kumar ${ }^{1}$, Samiksha Singh ${ }^{1}$, Vijay P. Singh ${ }^{3 *}$ and Sheo M. Prasad ${ }^{1 *}$

${ }^{1}$ Ranjan Plant Physiology and Biochemistry Laboratory, Department of Botany, University of Allahabad, Allahabad, India, ${ }^{2}$ Faculty of Biology and Chemistry, Institute of Biology, University of Bialystok, Bialystok, Poland, ${ }^{3}$ Department of Botany, Govt. Ramanuj Pratap Singhdev Post-Graduate College, Baikunthpur, Koriya, India

Cyanobacteria and algae having complex photosynthetic systems can channelize absorbed solar energy into other forms of energy for production of food and metabolites. In addition, they are promising biocatalysts and can be used in the field of "white biotechnology" for enhancing the sustainable production of food, metabolites, and green energy sources such as biodiesel. In this review, an endeavor has been made to uncover the significance of various metabolites like phenolics, phytoene/terpenoids, phytols, sterols, free fatty acids, photoprotective compounds (MAAs, scytonemin, carotenoids, polysaccharides, halogenated compounds, etc.), phytohormones, cyanotoxins, biocides (algaecides, herbicides, and insecticides) etc. Apart from this, the importance of these metabolites as antibiotics, immunosuppressant, anticancer, antiviral, anti-inflammatory agent has also been discussed. Metabolites obtained from cyanobacteria and algae have several biotechnological, industrial, pharmaceutical, and cosmetic uses which have also been discussed in this review along with the emerging technology of their harvesting for enhancing the production of compounds like bioethanol, biofuel etc. at commercial level. In later sections, we have discussed genetically modified organisms and metabolite production from them. We have also briefly discussed the concept of bioprocessing highlighting the functioning of companies engaged in metabolites production as well as their cost effectiveness and challenges that are being addressed by these companies.

Keywords: algae, biofuel, cyanobacteria, cyanotoxins, food products, pharmaceuticals

\section{INTRODUCTION}

The world population, which accounted six billion in 1999 rose to seven billion in 2011, and is estimated to touch upto nine billion by 2050 . With over increasing population, the need for resources is also increasing, which in turn increases our dependency on agricultural crops (Guihéneuf et al., 2016). However, even after over-utilization of agricultural crops for food, chemicals, and biofuels, the need of growing population has not been fulfilled. Taking into account the challenges, which are rising due to mismanagement in food and energy resources, a question arises: where we will land in the upcoming future? That is why the necessity of addressing these challenges has raised.

To achieve future food demands, cyanobacteria and algae have presented themselves as the most promising candidates because they are endowed with the complex photosynthetic system 
(Mulkidjanian et al., 2006), and can absorb a broad wavelength of the solar radiation for channelizing this energy into other chemicals (Furukawa et al., 2006; Chisti, 2007; Pisciotta et al., 2010). Another aspect which makes them more suitable is that they do not require arable lands for their growth. They can grow on residual nutrients with high productivity along with an enrichment in lipids (60-65\% of dry weight), proteins, total fibers (33-50\% higher than higher plants) and carbohydrates, which could cut out the high prices of food obtained from agriculture-based industries (Rittmann, 2008; Guihéneuf et al., 2016). Cyanobacteria and algae are the immense sources of several metabolites such as alkaloids, carbohydrates, flavanoids, pigments, phenols, saponins, steroids, tannins, terpenes, and vitamins which can be utilized in biotechnology and industrial fields (Guihéneuf et al., 2016). Some metabolites such as cyanotoxins are reported to have toxic effects, but they can be exploited for their allelochemical nature and can be introduced in agricultural fields as pesticides i.e., algicides, fungicides, weedicides, and herbicides. Apart from the toxic metabolite production, they are also enriched with several pharmacologically active compounds that have antibacterial (Volka and Furkert, 2006; Malathi et al., 2014), anticancerous (Gerwick et al., 1994; Mukund and Sivasubramanian, 2014; Semary and Fouda, 2015), antifungal (Rath and Priyadarshani, 2013; Shaieb et al., 2014), antiplasmodial (Papendorf et al., 1998), antiviral (Patterson et al., 1994; Abdo et al., 2012), and immunosuppressive (Koehn et al., 1992; Vijayakumar and Menakha, 2015) activities, which have aggravated interest in cyanobacterial and algal secondary metabolites. Thus, due to high pharmaceutical values, a new perspective of utilizing cyanobacteria and algae in the field of medicine has risen. The pathways utilized by these organisms for metabolite productions are different (Figure 1). For instance, mevalonate pathway is involved in isoprenoids synthesis in algae, but in case of prokaryotes, they are synthesized by non-mevalonate pathway.

In this article, we have summarized functions of various metabolites like phenolics, phytoene/terpenoids, phytols, sterols, free fatty acids, photoprotective compounds (MAAs, scytonemin, carotenoids, polysaccharides, halogenated compounds etc.), phytohormones and toxins obtained from cyanobacteria and algae. In addition, we have briefly mentioned usefulness of bioengineering for enhancing the production of metabolites which paves the way for their commercialization. Also we have focused on the concept of bioprocessing and new technologies that are being currently used. Besides, we have also discussed role of cyanobacteria and algae in the production of biomedicine and biofuel. In later sections, the role of algal biomass organization involved in commercializing these products has been also discussed along with the limitations and the productivity costs.

\section{AN OUTLOOK OF METABOLITES: BASICALLY WHAT THEY ARE?}

\section{Phenolics}

Polyphenols are the group of secondary metabolites such as phenolic acids, flavonoids (flavanones, flavonols, chalcones, flavones, flavan-3-ols, and flavanonols), tannins, and lignins
(Thomas and Kim, 2011; Figure 2). Among different phenolic compounds, phlorotannins (eight interconnected flavonoid rings) are the group of tannins and phloroglucinols (Wang et al., 2012) that have been isolated from brown algae (15\% of dry weight; Le Gall et al., 2015). These phlorotannins are reported to have antioxidant activities in the biological system (Ferrari et al., 2015; Gómez et al., 2016). Moreover, phenolics are characterized as stress compounds, which participate in defense mechanisms against biotic stresses like grazing (Coleman et al., 2007), settlement of bacteria (Lau and Qian, 2000), and abiotic stresses like UV irradiation (Coba et al., 2009) and metal toxicity (Connan and Stengel, 2011). Secondary metabolites are not directly involved in growth processes but some reports have suggested the participation of phlorotannins in regulating developmental processes in brown algae (Schoenwaelder and Wiencke, 2000; Gómez et al., 2016). Structurally, phenolic compounds have at least one phenolic ring and show strong biological activities, when halogenated (Cabrita et al., 2010). Metabolites like phytoalexins, lignin, flavonoids, furanocoumarins, tannins, and anthocyanins are involved in the defense system of the algae and cyanobacteria against adverse conditions (Adeyemi, 2011; Stengel et al., 2011). In addition, Microcystis aeruginosa, a cyanobacterium has been found to have inhibitory effects on growth due to the presence of polyphenols such as ellagic and gallic acids and catechin (Nakai et al., 2005). Kumar et al. (2008) have shown that main compounds of phlorotannins group are fucols, phlorethols, fucophlorethols, fuhalols, halogenated, and sulfated phlorotannins that have great potential under oxidative stress and also these compounds are capable of curing diseases caused by free radicals. Similarly, other phenolic compounds like catechin, epigallocatechin gallate, catechol, rutin, morin, caffeic acid, and hesperidin isolated from red algae have been found to exhibit anti-inflammatory activity (Ibànez and Cifuentes, 2013; Guihéneuf et al., 2016). Earlier, researchers have shown anticarcinogenic, antiviral, antibacterial, antifungal, antiinflammatory, and antitumoral properties of cyanobacteria and algae that were attributed to the presence of novel compounds such as antioxidants, phycobilins, phenols, polysaccharides, steroids, and terpenoids (Munawer and Mazharuddin, 2011; Chauhan and Kasture, 2014; Kumar et al., 2016; Table 1).

\section{Phytoene/Terpenoids}

Terpenoids are the group of organic compounds widely distributed in cyanobacteria and algae (Keeling and Bohlmann, 2012). Depending upon their five-carbon isoprene unit, terpenoids have been classified into seven groups i.e., hemiterpenes (C5), monoterpenes (C10), sesquiterpenes (C15), diterpenes (C20), triterpenes (C30), tetraterpenes (C40), and polyterpenes (>C40; Keeling and Bohlmann, 2012; Singh and Sharma, 2015; Figure 3). Terpenoids not only play an essential role during preliminary growth and development processes but also stimulate attraction of pollinators (Gershenzon and Dudareva, 2007). These attributes make them more relevant as secondary biologically active compounds (Gershenzon and Dudareva, 2007). It has been reported that terpenes can be supplemented in products for their fragrances and flavors (Kirby and Keasling, 2009; Pattanaik and Lindberg, 2015). 


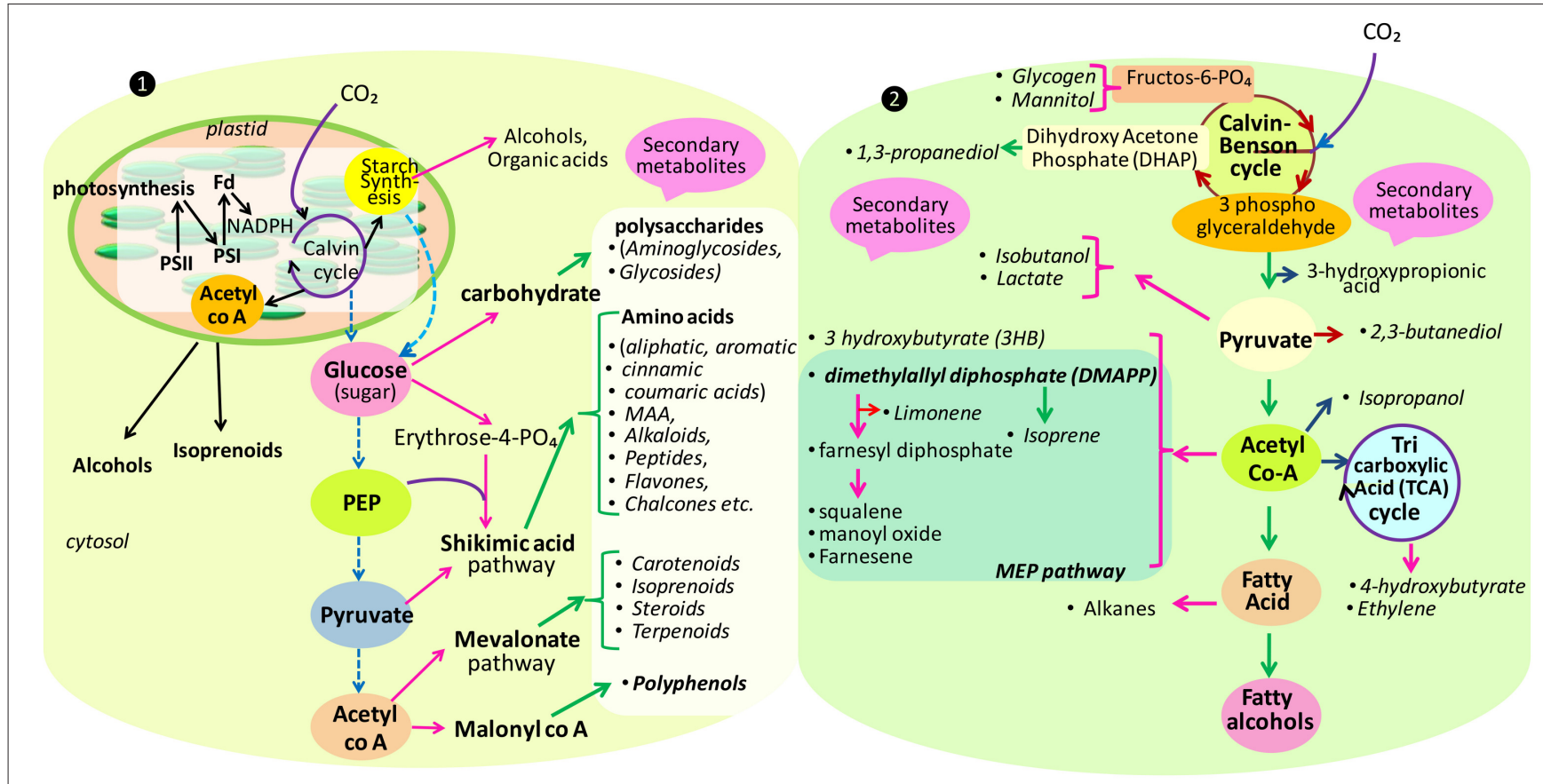

FIGURE 1 | Main pathways for the biosynthesis of some secondary as well-primary (carbohydrate, starch, alcohol, etc.) metabolites in eukaryote (1) and prokaryote (2) (modified after Burja et al., 2001; Oliver et al., 2016).

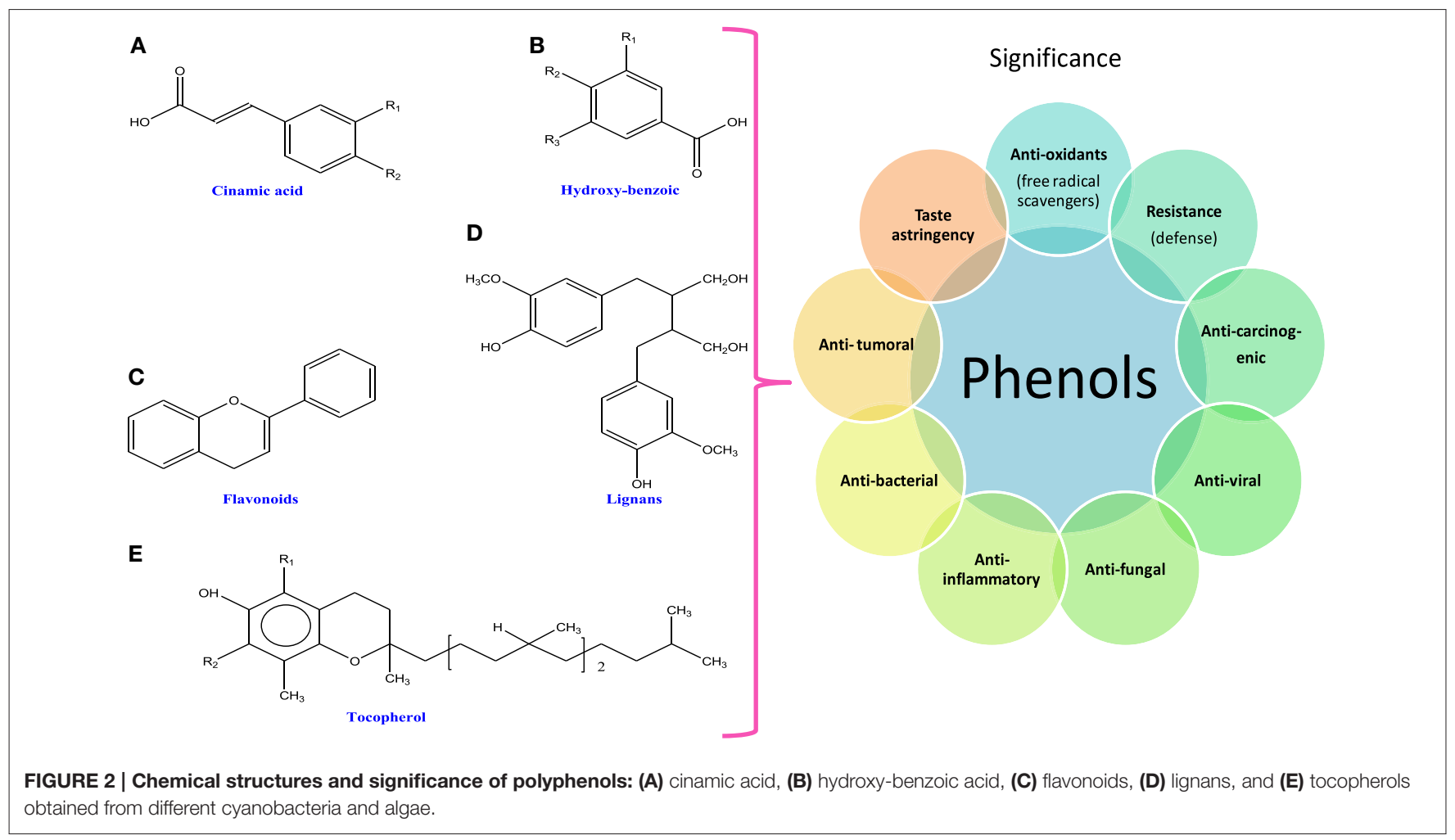

They are also emerging as advanced biofuel precursors like linear terpenes and being practiced to replace the biosynthetic diesel in the global market (Harvey et al., 2010; Pattanaik and
Lindberg, 2015; Table 1). The function of pure monoterpenes has been suggested to be antiparasitic (Goulart et al., 2004; Bedoux et al., 2014). Several cyanobacterial species have 
TABLE 1 | An overview of metabolites from cyanobacteria and algae and their potential uses.

\begin{tabular}{|c|c|c|c|}
\hline Algae/cyanobacteria & Metabolites & Uses & References \\
\hline $\begin{array}{l}\text { Arthrospira platensis, Nostoc } \\
\text { muscorum, Phormidium foveolarum, } \\
\text { and Spirulina platensis }\end{array}$ & $\begin{array}{l}\text { Phenolic } \\
\text { compounds }\end{array}$ & $\begin{array}{l}\text { - Potentially considered for pharmaceutical and } \\
\text { nutritional uses (for example as additive in the } \\
\text { preparation of functional food). } \\
\text { - Prevents vascular damage as well as cardiovascular } \\
\text { diseases progression. } \\
\text { - Provides defense by scavenging the free radicals. } \\
\text { - Acts as a UV-B screening compound, provide } \\
\text { resistance to plants against pathogens, pests, and } \\
\text { diseases. }\end{array}$ & $\begin{array}{l}\text { Rice-Evans et al., 1997; Singh et al., 2003; } \\
\text { Camera et al., 2004; Vogt, 2010; Ferrari et al., } \\
\text { 2015; Kumar et al., } 2016\end{array}$ \\
\hline
\end{tabular}

Synechocystis sp., Anabaena,
Nostoc, Spirulina, Phaeodactylum
tricornutum, P. lutheri, and Nostoc tricornutum
Fatty acids

- Highly potent to be used as liquid transport fuels.

- Consume as in diet due to high content of polyunsaturated fatty acid, protein, and vitamins.

- Provides chemical defense as it is toxic to grazers.

- Lipid extracts may be used as a herbal medicine, to treat against cancer, viruses, burns, and chronic fatigue.
Anupama and Ravindra, 2000; Jüttner, 2001; Rasmussen et al., 2008; Guedes et al., 2011; Hellier et al., 2013

\begin{tabular}{|c|c|c|c|}
\hline Synechocystis sp. & Terpenoids & $\begin{array}{l}\text { - Highly potent to be used as hydrocarbon biofuel. } \\
\text { - Provides chemical defense against herbivory, } \\
\text { fragrances, and flavors. }\end{array}$ & Kirby and Keasling, 2009; Bentley et al., 2013 \\
\hline
\end{tabular}
fragrances, and flavors.

Anabaena doliolum and Scytonema javanicum
Mycosporineglycine,

Porphyra-334, Shinorine
- Provides protection against UV-B, high temperature, and photooxidative stress.

- Acts as osmolytes and improves antioxidant status, which subsequently lowers the level of ROS.
Nostoc muscorum, Phormidium foveolarum, and Spirulina platensis

\section{Carotenoids,} $\beta$-Carotene, Lutein, Zeaxanthin Cryptoxanthin, $\alpha$-carotene, Lycopene
- Protects PSII, light harvesting complexes, and reaction center.

- Improve antioxidant status of the organisms.

- Use in food industry.

- Use to prevent cancer.

\begin{tabular}{l} 
Scytonema \\
\hline Chondrus ocellatus* \\
Synechococcus elongates PCC7942, \\
Cylindrospermopsis raciborskii \\
339-T3, Fischerella, Microcystis \\
aeruginosa NPCD-1, and Microcystis \\
panniformis SCP702
\end{tabular}

Scytonemin

- Having an unique pharmacological potential and used as anti-inflammatory and antiproliferative agent.
Oren and Gunde-Cimerman, 2007; Klisch and Häder, 2008; Singh et al., 2010

Cardozo et al., 2007; Prasanna et al., 2010; Kumar et al., 2016

\section{Carragenans, \\ - Widely used as antitumor, antiviral, anticoagulant,} Agar, and Lectins and immunomodulation agent.
- Used as a vehicle to deliver drugs.

- Exhibit antiviral, antifungal, antifouling, antiproliferative, antibacterial, anti-inflammatory activity.

- Show cytotoxic, antifeedant, insecticidal, and ichthyotoxic responses.
Anabaena vaginicola and Nostoc Phytohormones calcicola
Halogenated compounds
- Promote growth and development, enhances the production of ethylene that may be used as biofuel.

- Enhanced the production of defense enzymes and provide protection against different stresses.
Stevenson et al., 2002

Marinho-Soriano and Bourret, 2003; Jepson et al., 2004; Cardozo et al., 2007

Blunt et al., 2009; Rastogi and Sinha, 2009; Silva-Stenico et al., 2011
Takahama et al., 2003; Tarakhovskaya et al., 2007; Hashtroudi et al., 2013

\begin{tabular}{|c|c|c|}
\hline $\begin{array}{l}\text { Microcystis sp., Anabaena sp., } \\
\text { Oscillatoria sp., Anabaenopsis sp., } \\
\text { Nostoc sp., Hapalosiphon sp., and }\end{array}$ & Toxins & $\begin{array}{l}\text { - Used for development of biocides that serve as } \\
\text { antibiotics, anticancerous, and anti-inflammatory } \\
\text { agents with relevant to pharmaceutical activities. }\end{array}$ \\
\hline
\end{tabular}

Burja et al., 2001; Biondi et al., 2004; Cardozo et al., 2007; Gunasekera et al., 2008

Organisms that are eukaryotic algae are designated with "*” mark.

allelopathic property which is attributed to the presence of significant amount of geranyl acetone that inhibits the growth of neighboring cyanobacterial species (Fischer, 1991). Terpenes are hydrocarbons synthesized within the cellular system, thus may be used as fuels. Furthermore, they can be used as a blend with the fossil gasoline in the spark ignition engine (Hellier et al., 
A<smiles>C=CC(C)=CCC1=C(C)C(=O)C(OC)=C(OC)C(=O)C1=O</smiles>

Ubiquinone<smiles>CC(C)[C@H](O)/C=C\C1CCC2C3=CC=C4C[C@@H](O)CC[C@]4(C)C3CC[C@]12C</smiles>

Ergosterol

C<smiles>C/C(=C\CO)CCC[C@H](C)CCC[C@H](C)CCCC(C)C</smiles>

Phytol

D<smiles>CC1=C[C@@H](O)CC(C)(C)[C@H]1/C=C/C(C)=C/C=C/C(C)=C/C=C/C=C(C)/C=C/C=C(C)/C=C/C1=C(C)C[C@@H](O)CC1(C)C</smiles>

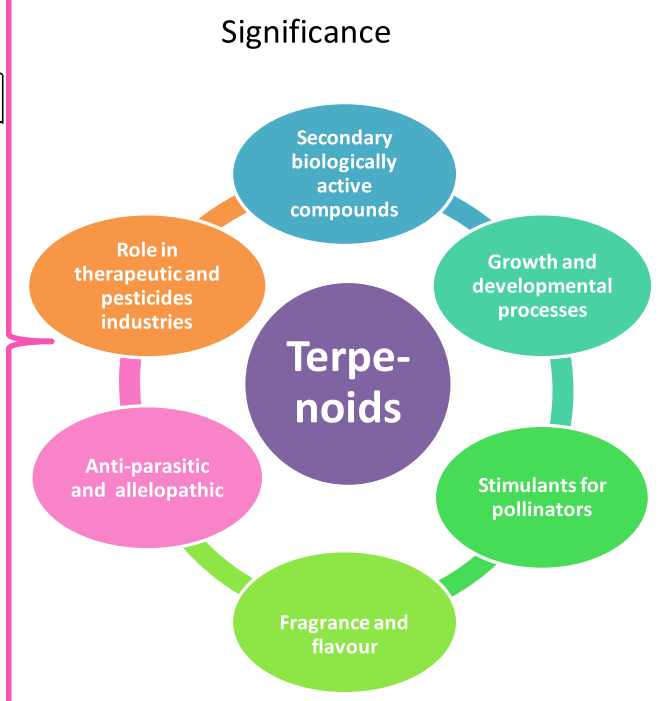

FIGURE 3 | Chemical structures and significance of terpenoid/ phytoene: (A) ubiquinone, (B) ergosterol, (C) phytol, and (D) lutein obtained from different cyanobacteria and algae.

2013). In recent years, terpenoids have gained more attention at commercial level due to their efficient roles in therapeutic and pesticide industries (de Carvalho and da Fonseca, 2006; Nichkova et al., 2009; Pattanaik and Lindberg, 2015; Table 1).

\section{Phytols}

In cyanobacteria, phytols are crucial components of chlorophyll and also cofactors for the photosynthesis (Nowicka and Kruk, 2010; Kiyota et al., 2014). A wide range of terpenoids type compounds such as carotenoids and phytols are essential for chlorophyll, quinone prenyl tails, hormones and tocopherols that are biosynthesized through methylerythritol 4-phosphate (MEP) pathway in cyanobacteria and algae (Figure 3). During synthesis of carotenoids and phytols, a prerequisite precursor of terpenoids, geranylgeranyl pyrophosphate, comes out as a by-product through the MEP pathway, (Bentley et al., 2013; Pattanaik and Lindberg, 2015). In cyanobacteria, the native form of isoprenoids often consists of phytol of chlorophyll $a$ and carotenoids and in complementary, isoprenoids also exist as cofactors of plastoquinone and phylloquinone (Kiyota et al., 2014). Studies have shown that limonene, which is a precursor for carotenoid and phytols' biosynthesis, is derived from the activity of limonene synthase enzyme. Under atmospheric pressure, limonene may be secreted from the cell without any specific treatment (Kiyota et al., 2014), which might help in enhancing its production. It has been reported that phytol may enhance an immunological response against tumor in a very beginning stage of carcinogenesis (Mukund et al., 2014). In addition, phytol may also serve as an anti-inflammatory agent (Shimizu and Tomoo, 1994; Silva-Stenico et al., 2014). Furthermore, it has been reported that phytol biosynthesis occurs in Nitzschia ovalis and Phaeodactylum tricornutum through the mevalonic acid pathway in which $\mathrm{CO}_{2}$ serves as a source of carbon (Cvejic and Rohmer, 2000; Fabris et al., 2014). In higher plants, isoprenoids, which are important for the photosynthetic machinery (phytol, plastoquinone, and carotenoids), are also produced by the MEP pathway (Kaspar, 1994; Paniagua-Michel et al., 2012; Pulido et al., 2012).

\section{Sterols}

The key role of sterols is the regulation of membrane fluidity (Piironen et al., 2000; Volkman, 2003; Silvestro et al., 2013). Sterols are produced as by-products during isoprenoids biosynthesis. Until the discovery of sterols in 1968, it was considered that sterols are not produced in cyanobacteria. Reitz and Hamilton (1968), for the first time reported the presence of sitosterol and cholesterol in Anacystis nidulans and Fremyella diplosiphon. In the same year, De Souza and Nes (1968) reported the presence of seven unsaturated sterols in Phormidium luridurn. Cyanobacteria have been reported to produce both saturated and unsaturated sterols (Kohlhase and Pohl, 1988). The unsaturated sterols viz., cholesterol, chondrillasterol, stigmasterol, sitosterol, brassicasterol, campesterol, 22dehydrocholesterol, isofucosterol, 24-ethyl-cholest-7-enol, 24-methyl-cholest-7-enol, 24-ethylcholesta-2,5-dienol, and 24ethylcholesta-5,7, 22-trienol (Levin and Bloch, 1964; De Souza and Nes, 1968; Reitz and Hamilton, 1968; Nadal, 1971; Forin et al., 1972; Seckbach and Ikan, 1972; Teshima and Kanazawa, 1972; Paoletti et al., 1976; Perry et al., 1978; Figure 3), while some saturated sterols like $4 \alpha$-methylsterols, $5 \alpha$-cholestan-3 $3 \beta$-ol, 24 -methyl- $5 \alpha$-cholestan- $3 \beta$-ol, and 24 -ethyl- $5 \alpha$-cholestan-3 $\beta$-ol have been reported from Anabaena cylindrical, A. viguirei, 
A. solitaria, Nostoc carneum, Nodularia harveyana, and Microcystis aureguinosa (De Souza and Nes, 1968; Patterson, 1971; Nishimura and Koyama, 1977). In a recent study on sterols content, Prochazkova et al. (2017) have reported the presence of sterols with a concentration up to $2.25 \mathrm{mg} / \mathrm{L}$ in water with cyanobacterial blooms.

Furthermore, in the biosynthesis of isoprenoids, wide ranges of cyclic and acyclic compounds are generated by the building block isopentenyl diphosphate leading to the formation of C30 oxygenated isoprenoid oxidosqualene. The biosynthesis of sterols takes place in the cytosol via series of chain reactions (Volkman, 2003; Fabris et al., 2014). In eukaryotic cells, sterols play essential role in various biochemical processes e.g., production of steroid hormones and also act as vital constituents of the cell membrane (Martin-Creuzburg and Von Elert, 2009). Moreover, from the nutritional point of view, sterols are good dietary sources for aqua-cultured organisms (Cardozo et al., 2007). The majority of sterols have planar structure with three $\beta$ hydroxy tetracycle containing a methyl- or ethyl-substituted hydrocarbon chain (C7-C11). They also exhibit C4, C14 methylsubstitution pattern in polycyclic form with varying degree and position of unsaturation (C5, C7, C8). The presence of fused ring system provides rigidity to sterol structure, which gives integrity as well as stability to the cell membrane and thus hold membranes together. Studies showed that the number of genes encoding enzymes such as D24-sterol C-methyltransferase, sterol-C-5-desaturase, or C-4 methyl sterol oxidase and sterolC-methyltransferase actively participate in the biosynthesis of sterols in several cyanobacteria (Kaneko and Tabata, 1997; David Nes, 2011). Even though considerable progress has been made in identifying genes required for the biosynthesis of sterols, genetic evidence for the biosynthesis of sterols is still to be identified in cyanobacteria (Volkman, 2003).

\section{Free Fatty Acids}

Among different kinds of metabolites, fatty acids are also very much important due to their key role in the metabolism. Cyanobacteria and algae contain some important fatty acids such as linolenic, linoleic, and arachidonic acids, which are prerequisite for healthy growth. Fatty acids and alcohols are the main ingredient of lipids and according to their configuration a great diversity in fats, phospholipids, glycolipids, and waxes may be found. In cyanobacteria, the structure of lipids may vary, based on the composition of vital fatty acids such as C18 linolenic and linoleic acids and their C20 derivative arachidonic and eicosapentaenoic acids (Singh et al., 2002). Several species of microalgae have capability of accumulating high amount of lipids, which could serve as good source of oil yield, as the average lipid content can vary between 1 and $70 \%$, or even can reach upto $90 \%$ of dry weight (Mata et al., 2010).

Study showed that Microcystis cell lysate efficiently suppresses pumping of ions in gills of Oreochromis mossambicus due to the presence of fatty acids (Bury et al., 1998). In cyanobacteria, biosynthesis of fatty acids takes place through the action of an enzyme fatty acid synthase that utilizes acyl carrier proteins (ACPs; Froehlich et al., 1990; Kaczmarzyk and Fulda, 2010; Liu et al., 2011). In cyanobacteria, fatty acid synthesis (FAS) is carried out by a type II fatty acid synthase complex utilizing a freely dissociable acyl carrier protein (ACPs; an essential protein cofactor; Froehlich et al., 1990; Kaczmarzyk and Fulda, 2010; Liu et al., 2011). The products of FAS are released as acyl ACPs and may serve directly as substrates for acyltransferases thereby incorporating the fatty acids into membrane lipids (Frentzen et al., 1983; Kaczmarzyk and Fulda, 2010). From the biological activity point of view, fatty acids were reported to be anticarcinogenic, antibiotic, antifungal, and antiviral (Burja et al., 2001; El-Baz et al., 2013; Table 1). Among a wide variety of fatty acids, polyunsaturated fatty acids (PUFAs) are of great concern due to their health benefits and an increasing demand in the global market (Steinhoff et al., 2014). The presence of two or more double bonds (methylene-interrupted) in fatty acids (PUFAs) makes them more valuable from nutraceutical point of view. Further, these fatty acids also show biological activities in some medical practices, which make them more valuable in curing the obesity and cardiovascular diseases (Cardozo et al., 2007; Lee et al., 2016). Moreover, they are also involved in the regulation of various cellular processes such as transport of oxygen and electron, membrane fluidity, and heat adaptation (Funk, 2001; Cardozo et al., 2007).

Glycolipids (GLs) represent a complex carbohydrate made of sugar and fat by covalent bonds which have captured the growing interest of researchers. They are located in the chloroplast and thylakoid membranes and represent important signal and regulatory molecules (Siegenthaler and Murata, 1998; Hölzl and Dörmann, 2007; Harwood and Guschina, 2009; Boudière et al., 2014). The abundantly found glycolipids in microalgae are monogalactosyl diacylglycerols (MGDGs), digalactosyl diacylglycerols (DGDGs), and sulfoquinovosyl diacylglycerols (SQDGs), which are rich in PUFAs such as arachidonic (ARA, 20:4n-6), linoleic (LA, 18:2n-6), $\alpha$ linolenic (ALA, 18:3n-3), docosahexaenoic (DHA, 22:6n-3), and eicosapentaenoic (EPA, 20:5n-3) fatty acids (Harwood and Guschina, 2009; He et al., 2011; Kim et al., 2013; da Costa et al., 2016). SQDG is a negatively charged GL having a monoglycosyl diacylglycerol with a sulfonic acid present in the 6th position of monosaccharide moiety [1,2-diacyl-3-O(6-sulfo-6-deoxy- $\alpha$-D-glucosyl)-sn-glycerol] (Reshef et al., 1997; Naumann et al., 2007). SQDGs participate in signaling and in the coordination between chloroplast lipids and cytosolic partners. MGDG, DGDG, and SQDG are chief components of the chloroplast lipids (Siegenthaler and Murata, 1998; Wang and Benning, 2012; Boudière et al., 2014). MGDG represents about $20 \%$ outer and $40-55 \%$ of the inner envelope of chloroplast and thylakoid membranes (Siegenthaler and Murata, 1998). DGDG consists of about $15-35 \%$ and SQDG about 2-40\% of total lipids in the chloroplast and thylakoid membranes (Siegenthaler and Murata, 1998). SQDGs content in microalgae is comparatively high in comparison with Arabidopsis thaliana (2-10\%; Siegenthaler and Murata, 1998; Muhlroth et al., 2013). GLs are important antitumor agents. SQDGs cause inhibitory effects on tumor cell growth and are a potent inhibitor of DNA polymerase that may result into the death of tumor cells, especially under active proliferation conditions (Hossain et al., 2005; Guschina and Harwood, 2006; Chirasuwan et al., 2007). A type of sulfate-group containing glyceroglycolipid was separated from the cyanobacterium L. lagerheimii (Gustafson et al., 1989) 
that is able to inhibit the replication of HIV. The antiviral properties of nGLs were confirmed on SQDG isolated from Spirulina platensis and Porphyridium purpureum. The sulfonate group may be responsible to carry out the antiviral activity of SQDGs (Plouguerné et al., 2014). It was suggested that lipophilic groups on SQDG interact with the positive charged side of DNA polymerase.

\section{Photoprotective Compounds}

Ultraviolet radiation (UVR) causes a wide range of harmful biological effects on living system. In cyanobacteria and algae, a number of biologically active compounds such as carotenoids, mycosporine-like amino acids (MAAs), and scytonemin have been isolated (Figure 4). They exhibit photoprotective properties under radiation stress. The biosynthesis of these compounds may be affected by different environmental stimuli including the fluctuation of light intensity, different wavelengths of UV radiation, nutrient limitation, and several other stresses (Rastogi et al., 2010). The MAAs are intracellular, colorless, small, and hydrophilic compounds. They have a great potential to dissipate excess energy in the form of heat thereby avoiding the formation of toxic oxygen radicals (Conde et al., 2000; Groniger and Hader, 2000; Whitehead and Hedges, 2005; Oren and GundeCimerman, 2007). Moreover, it has been reported that MAAs not only play protective role under radiation stress but they could protect primary and secondary consumers if consumed by them (Helbling et al., 2002; Bhatia et al., 2011; Table 1).

\section{Mycosporine-Like Amino Acids (MAAs)}

Mycosporine-like amino acids (MAAs) are a family of intracellular compounds engaged in the protection of aquatic organisms against solar radiation. Structurally, in their formation nitrogen substituent of amino acids and cyclohexenimine or cyclohexenone chromophore conjugated with one or two amino acids is involved, having absorption maxima ranging from 310 to $362 \mathrm{~nm}$ (Singh et al., 2008; Bhatia et al., 2011). MAAs are produced in several cyanobacteria, rhodophyta, and several other groups of microalgae (Sinha et al., 2007; Carreto and Carignan, 2011; Rastogi et al., 2015; Rastogi and Madamwar, 2016). They have absorption maxima in UV range (Takano et al., 1979; Bhatia et al., 2011; Kannaujiya et al., 2014). Studies have shown that MAAs originate from shikimate pathway, but the exact route of their biosynthesis is still unknown. Favre-Bonvin et al. (1987) revealed that the precursor of the six-membered carbon MAAs i.e., 3-dehydroquinate (an intermediate of the shikimate pathway) has been commercially explored for protection of skin as suncare products and other non-biological materials such as photostabilising additives in varnish, paint, and plastics (Bandaranayake, 1998). It is thought that cyanobacteria and algae are the ancestors of MAAs (Nakamura et al., 1982; Klisch and Häder, 2008), which evoke protective responses. The high molar coefficients $\left(\varepsilon=28,100-50,000 \mathrm{M}^{-1} \mathrm{~cm}^{-1}\right)$ as well as UV-absorption maxima ranging from 310 and 362 $\mathrm{nm}$ along with the photostability in both fresh and sea water in presence of photosensitizers and resistant to specifically abiotic stressors such as $\mathrm{pH}$, temperature, various solvents, and UV radiation (UVR) provide strong evidence in favor of
MAAs as photoprotective compounds (Whitehead and Hedges, 2005; Yoshiki et al., 2009; Shahidi and Zhong, 2010; La Barre et al., 2014). The protection against UV-B damage provided by MAAs mainly depends on the species and the pigments localization within. Significant, but limited, protection has been reported for various cyanobacteria with MAAs located in the cytoplasm. In case when MAAs located in the cytoplasm, according to Garcia-Pichel and Castenholz (1993) only 10-26\% of the photons are absorbed by the pigment. MAAs are thought to play an important role in photoprotection as the MAAs are located in the extracellular glycan in Nostoc commune. According to Böhm et al. (1995), pigments present in cell membranes or target absorbs two out of three photons reaches within the cell. In N. Commune, two UVA/B-absorbing pigments with absorption maxima at 312 and $335 \mathrm{~nm}$ were reported to be present in colonies when exposed to high solar radiation (Scherer et al., 1988; Ferroni et al., 2010). Out of them, one was the first mycosporine covalently linked to the oligosaccharides and was reported to be located in the extracellular glycan (Hill et al., 1994; Böhm et al., 1995). These compounds are enough capable of effectively dissipating absorbed radiation in the form of heat without producing reactive oxygen species (ROS; Conde et al., 2000). It has also been reported that MAAs provide protection from UVR not only in their producers but also to primary and secondary consumers via food chain (Helbling et al., 2002). Carreto et al. (1990) have shown that after application of 3-(3,4-dichlorophenyl)-1,1-dimethylurea (DCMU), the biosynthesis of MAAs was inhibited in the alga Alexandrium excavatum, which suggests a close relationship between the photosynthetic process and MAAs synthesis. The biosynthetic reactions of MAAs take place in two steps, the first step involves the reduction of carboxylic group of 3-dehydroquinate and the second step involves methylation of the hydroxyl group at C4 and the attachment of one (mycosporine-glycine) or two amino acids or amino alcohols (Klisch and Häder, 2008).

\section{Scytonemin}

Scytonemin (MW $544 \mathrm{Da}$ ), a photo-protective compound is a dimer of indolic and phenolic subunits. It was firstly reported in some terrestrial cyanobacterial sp. as a yellowish-brown lipid soluble pigment located in the exopolysaccharide sheath (GarciaPichel and Castenholz, 1991; Rothrock and Garcia-Pichel, 2005; Wada et al., 2013; Rastogi et al., 2015). Although, scytonemin is predominantly found in green oxidized form, it has two more forms viz., reduced (fuscorhodin; red in color) and oxidized (fuscochlorin; yellow in color; Garcia-Pichel and Castenholz, 1991; Wada et al., 2013). Recently from the organic extracts of Scytonema sp., dimethoxyscytonemin, tetramethoxyscytonemin, and scytonin pigments have been isolated (Bultel-Poncé et al., 2004; Grant and Louda, 2013; Rastogi et al., 2014). The in vivo absorption maxima of scytonemin is at $370 \mathrm{~nm}$ while purified scytonemin has absorption maximum at $386 \mathrm{~nm}$, but it also absorbs significantly at 252, 278, and $300 \mathrm{~nm}$ that's why it probably helps cyanobacteria to survive under lethal UV radiation. Studies have shown that scytonemin alone is sufficient to reduce the risk of damage caused by the most lethal UV-C radiation (Dillon and Castenholz, 1999; Rastogi 


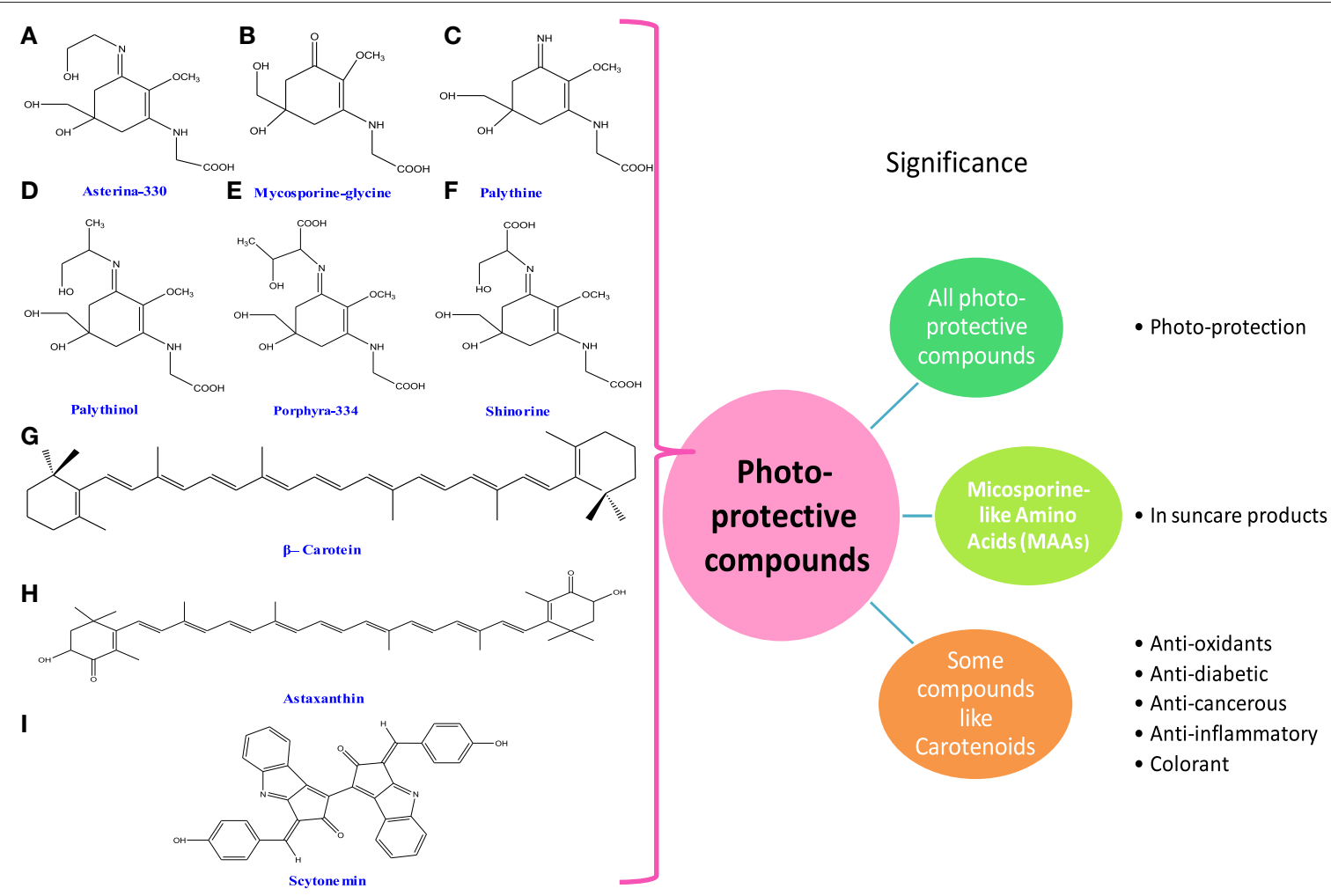

FIGURE 4 | Chemical structures and significance of photoprotective compounds: (A) asterina-330, (B) mycosporine-glycine, (C) palythine, (D) palythinol, (E) porphyra-334, (F) shinorine, (G) $\beta$-carotene, (H) astaxanthin, and (I) scytonemin obtained from different cyanobacteria and algae.

et al., 2013). Scytonemin can effectively reduce photosynthesis inhibition by UV-A radiation and also can reduce photobleaching of chlorophyll $a$ (Cockell and Knowland, 1999; Gao and GarciaPichel, 2011). The role of scytonemin as an UV-sunscreen has been confirmed in the terrestrial cyanobacterium Chlorogloeopsis sp. (Garcia-Pichel et al., 1992; Portwich and Garcia-Pichel, 2003). Scytonemin is highly stable in response to different stressors such as strong UV radiation, temperature, etc., and carry out its screening activity without any additional metabolic investment even after prolonged physiological inactivity when other ultraviolet protective mechanisms like active repair of damaged cellular components would be ineffective (Brenowitz and Castenholz, 1997). In addition, due to the higher screening potential of scytonemin, it may be used as a sunscreen in cosmetics for human beings (Rastogi et al., 2010, 2015; Table 1).

\section{Carotenoids}

A wide occurrence of carotenoid pigments is an essential phenomenon in the microorganism, animal, and plant life. Carotenoids, the accessory pigments in photosynthesis are polymers of isoprene units containing 40 carbons and up to 15 double bonds arranged in a conjugated manner (Bramley and Mackenzie, 1988; Solomons and Bulux, 1994; Yuan et al., 2015). Compounds consisting of hydrocarbons are only the carotenes, while those having oxo, hydroxyl, or epoxy groups fall under the category of xanthophyll. The number and positions of these double bonds identify the spectral properties of carotenoids, which typically absorb the light in range of 400 and $500 \mathrm{~nm}$. Among different forms of carotenoids, two major forms i.e., $\beta$ carotene and echinenone are of great importance. In addition, several others forms such as astaxanthin, $\beta$-cryptoxanthin, zeaxanthin, canthaxanthin, and 30-hydroxyechinenone have a great significance in cyanobacteria and algae (Mochimaru et al., 2005; Shah et al., 2016). They play multifunctional roles such as colorant, precursors of visual pigments, as well as contribute to improve the antioxidant status in plants and algae. The most dynamic form of carotenoids, $\beta$-carotene, and its derivative compounds also may act as the precursor for retinoic acid, retinal, and vitamin A and thus improving the nutritional value, vision, and cellular differentiation in mammals (Olson, 1993; Seino et al., 2008; Table 1). Algal $\beta$-carotene provides protection against atherosclerosis in mouse and humans (Munawer and Mazharuddin, 2011). It has been reported that in diabetic patients, $\beta$-carotene rich algae Dunaliella sp. has the potentiality of controlling cholesterol, plasma triglycerides level, and also delays development of atherosclerosis by inhibiting oxidation of low density lipoprotein (LDL) and high density lipoprotein (HDL; Sanchez and Demain, 2008; Munawer and Mazharuddin, 2011). Astaxanthin, a keto-carotenoid pigment obtained from the green alga Haematococcus pluvialis is of commercial application. Astaxanthin accumulates under unfavorable condition, when thin-walled flagellated stage of the algae changes into red thickwall resting stage and it may contribute up to $4-5 \%$ of dry weight (Froehlich et al., 1990; Ambati et al., 2014). Astaxanthin 
usually serves as food additive for salmon, trout, and shrimp for many aquacultures and also for the poultry industry and food coloring agent (Frentzen et al., 1983; Higuera-Ciapara et al., 2006; Ambati et al., 2014). Because of its strong antioxidant activity, astaxanthin is consumed as neutraceuticals in the form of encapsulated product and Haematococcus (H. pluvialis, a green alga) rich in astaxanthin is being sold in market as dietary supplement for human being (Frentzen et al., 1983; Guerin et al., 2003; Bishop and Zubeck, 2012). Sayanova and Napier (2004) have reported that astaxanthin can be effective against several diseases like cancer, diabetes, diabetic nephropathy, inflammatory diseases, as well as for syndromes like metabolic syndrome and neurodegenerative diseases.

\section{Polysaccharides}

All organisms possess biochemical structures having linearly attached 40-50 different monosaccharaides (hexoses and pentoses) connected by glycosidic linkage along with some other substituent like acyl, amino acids, or sulfates (Figure 5). These polysaccharides serve as the source of carbon and energy and are excreted during normal as well as stressful physiological processes. They are being utilized as thickening or gelling agents (Delattre et al., 2009, 2011; Kraan, 2012). In addition, they have immunomodulatory, antibacterial, anticoagulant, antimutagenic, radioprotective, anti-oxidative, antiulcer, anticancer, and anti-inflammatory properties (Kraan, 2012; Misurcova et al., 2015; de Jesus Raposo et al., 2015). Cyanobacteria and algae have been suggested to synthesize polysaccharides and the polysaccharides produced by microalgae ranges from $\sim 0.5 \mathrm{~g} / \mathrm{L}$ up to $20 \mathrm{~g} / \mathrm{L}$ (Markou and Nerantzis, 2013). The process how these polysaccharides are produced and extracted from microalga and cyanobacteria has been reviewed by Delattre et al. (2016). Different types of polysaccharides are obtained from both cyanobacteria and algae; some of them are discussed in the following sections.

\section{Phycocolloids}

Phycocolloids are unique type of polysaccharides synthesized by various species of seaweeds. Among different types of phycocolloids, carrageenan, agar, and alginates are of great importance due to their multifunctional uses (Figure 5 and Table 1). The significant roles of polysaccharides as antioxidants, antiviral, antitumoral, and anticoagulant have been welldocumented in cyanobacteria and algae (Smit, 2004; Kilınç et al., 2013; Minicante et al., 2016). Agar and carrageenan, the sulfated polysaccharides are extracted from red algae, while alginates, that are binary polyurodine consisting of guluronic and mannuronic acids have been isolated from brown algae (Smit, 2004; Kılınç et al., 2013). Multifunctional uses of phycocolloids as emulsifier, viscosifier, and gelling agent are attractive for scientists and industry (Cardozo et al., 2007).

\section{Carrageenan}

Carrageenans are high molecular weight compounds that are formed through the replicating disaccharide units with modifications in 4-linked $\alpha$-galactopyranose and/or 3,6anhydro-D-galactopyranose and 3-linked $\beta$-D-galactopyranose

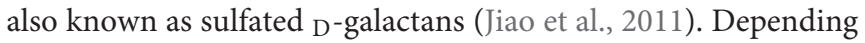
upon the existence of sulfate groups such as 3,6-anhydrogalactose on the 4-linked residue and their amount and allocation, they can further form a diverse range of carrageenans (Pereira et al., 2009; Blanco-Pascual et al., 2014). For instance, $\lambda$-carrageenan consists of three sulfate groups per disaccharide unit where the third sulfate group is present at the $\mathrm{C} 6$ position of the 4-linked residue, but these 4-linked residues lack 3,6-anhydride bridge (Jiao et al., 2011). In nature, $\lambda$-carrageenan is produced by red algae Chondrus and Gigartina (Zhou et al., 2006). The viscous property of carrageenan makes it more valuable in dairy industry, meat processing, and other miscellaneous products like toothpaste, air freshener gels, and pet food (Table 1).

\section{Agar}

Agar may be isolated by the boiling of certain species of algae, which results into the breaking of the cell wall and release of two structural polysaccharides. Furthermore, the binding of these two polysaccharides results in agar formation, which is dried in the oven and grounded into a fine powder that is ideal for storage (Cardozo et al., 2007). Seaweed galactans, which are collectively known as agar, contains $\alpha(1 \rightarrow 4)-3,6$-anhydro-L-galactose and $\beta(1 \rightarrow 3)$-D-galactose (Cardozo et al., 2007). Despite the fact that the biosynthetic pathway of agar is well-known (Hammingson et al., 1996; Siow et al., 2013), the processes implicated in converting precursors i.e., mannose and glucose into an agar via

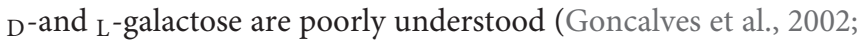
Siow et al., 2013). In food industries, agar is commonly used as emulsifying, stabilizing, and thickening agent. It is also used as a mild laxative component in pharmaceutical products. Moreover, in microbiology agar may serve as a growth medium for bacteria and fungi in Petri dishes due to its solidifying nature, which is ideal for experiments incubated at human body temperature.

\section{Alginate}

Alginate, also called alginic acid or algin, is widely found in cyanobacteria and algae and mainly made up of linear polysaccharides, which contain $\alpha-\mathrm{L}$-guluronic acid and 1,4-linked $\beta$-D-annuronic (Cardozo et al., 2007). Alginates are derivatives of alginic acid extracted from brown algae such as Laminaria and are extensively used in cosmetics, pharmaceuticals, insecticides, paints, and printers' ink (Raja et al., 2013). Moreover, in the textile industry, for sizing the cotton yarns alginate is being used as a gelling agent. Brown algae, being the good source of alginates, are very popular in several food and pharmaceutical industries (Raja et al., 2013).

\section{Lectins}

Among extensive range of biologically active compounds, it is necessary to emphasize on lectins. Lectins or agglutinins are synthesized in cyanobacteria and algae and are the complex form of proteins, having the ability to bind directly with carbohydrates without changing the property of carbohydrate to which they bound (Lam and Ng, 2011). Although, lectins adopt the ordinary process of binding, the significance of sugar may not be the same (Lam and Ng, 2011). Their specificity of carbohydrates binding makes them valuable candidates for application in histo-chemical 


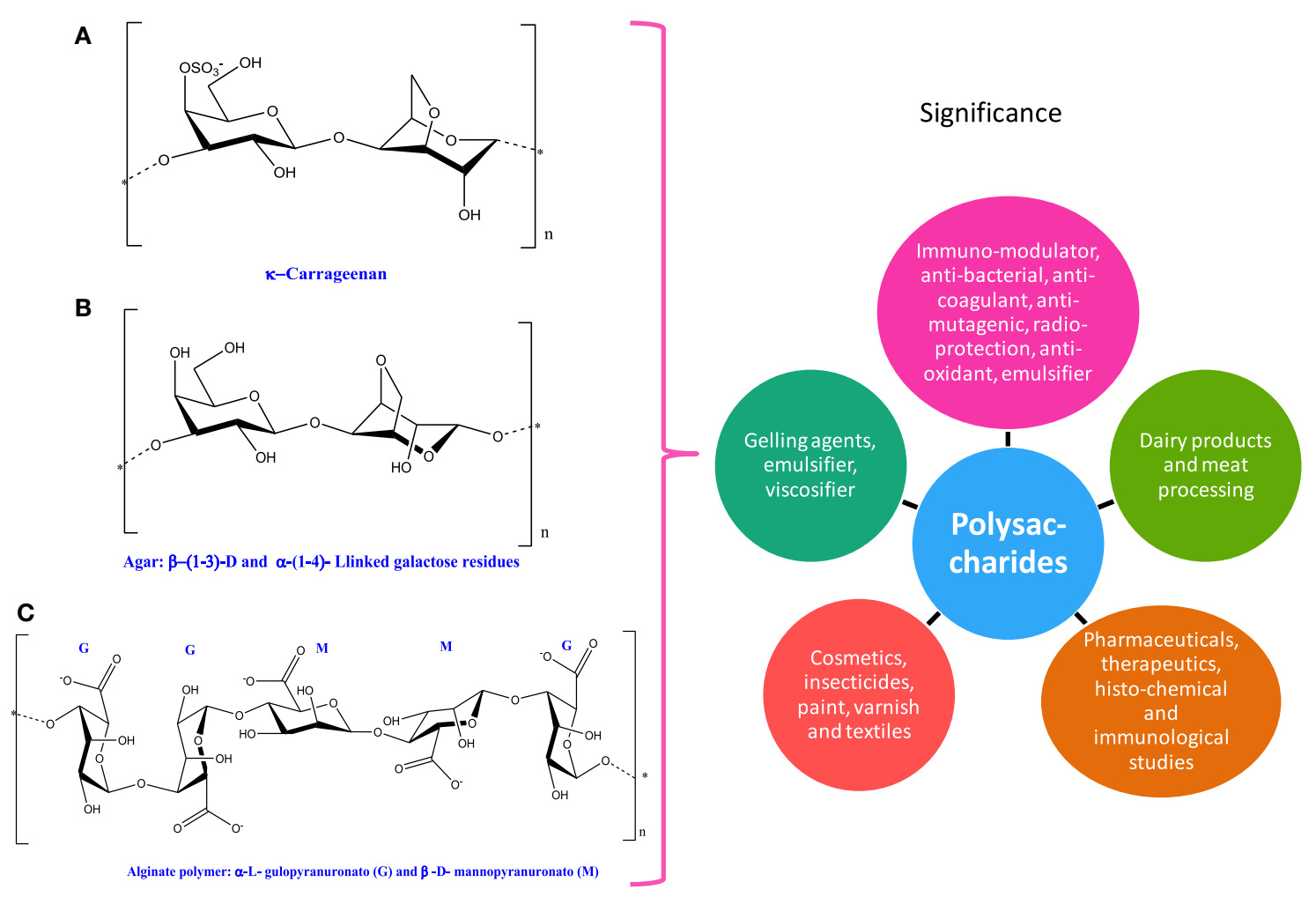

FIGURE 5 | Chemical structures and significance of phycocolloid compound: (A) carrageenan, (B) agar, and (C) alginate polymer obtained from different cyanobacteria and algae.

and immunological studies and also in identifying sugar type on the cell surface. In biological sciences particularly in medicine, lectins are valuable for identification of diseases pertaining to the modification in the synthesis of glycan, such as the typing of blood group on the basis of the secretor status and malignancy (Rudiger and Gabius, 2001; Kumar et al., 2012). Lectins are commonly used as therapeutic agents because they have unique ability of binding epithelium of intestine and enhance diffusion of drugs (Chowdary and Rao, 2004). Keeping their therapeutic importance into consideration, numerous lectins, i.e., scytovirin, microvirin, agglutinin, and cyanovirin- $\mathrm{N}$ have been isolated from several cyanobacteria such as Scytonema varium, Mycrocystis sp., Nostoc ellipsosporum, and Oscillatoria agardhii (Bewley et al., 1998; McFeeters et al., 2007; Ziemert et al., 2010; Mandal and Rath, 2014). Furthermore, lectins are used in anticipating transmission of HIV due to the interaction of glycans with HIV gp120 and thus, exhibit a great potential for antiviral activities (Bewley et al., 2004; Huskens et al., 2010).

\section{Halogenated Compounds}

Halogenated compounds have been isolated mainly from phaeophyceae and rhodophyceae, dispelling the general rumors that they are only man-made. The wide occurrence of halogenated compounds in cyanobacteria and algae may be characterized as acetogenins, phenols, terpenes, indoles, fatty acids, and volatile halogenated compounds (i.e., dibromomethane, chloroform, and bromoform; Butler and
Carter-Franklin, 2004; Figure 6). They are very important from the pharmacological point of view as they show biological activities like antiproliferative, antifungal, antibacterial, antiviral, antifeedant, antifouling, anti-inflammatory, cytotoxic, ichthyotoxic, insecticidal, and antitumoral (Vairappan et al., 2001; Cabrita et al., 2010; Table 1). A lot of biologically active peptides, aeruginosin, and cyanopeptolin, which are the protease inhibitors, have been well-recognized in several cyanobacteria and have great role in agrochemistry and pharmacy (SilvaStenico et al., 2011). Moreover, the diverse ranges of halogenated alkanes such as $\mathrm{CH}_{3} \mathrm{Cl}, \mathrm{CH}_{3} \mathrm{Br}, \mathrm{CH}_{3} \mathrm{I}, \mathrm{CH}_{2} \mathrm{Br}_{2}$, and $\mathrm{CHBr}_{3}$ are produced by the brown alga Macrocycstis pyrifeara (Manley et al., 1992; Dembitsky and Tolstikov, 2003). Similarly, different genera of brown algae such as Eisenia arborea, Egregia menziesii, Custoseria osmundacea, Laminaria farlowii, and Prochlorococcus marinus also produce $\mathrm{CH}_{3} \mathrm{I}, \mathrm{CHBr}_{3}$, and $\mathrm{CH}_{2} \mathrm{Br}_{2}$ (Manley et al., 1992; Dembitsky and Tolstikov, 2003; Hughes et al., 2011).

\section{Phytohormones}

It has been established that different genera of cyanobacteria and algae significantly accumulate and release a diverse group of phytohormones including auxins, gibberellins (GA), cytokinins (CKs), and ethylene (ET) that are involved in plants' growth and development (Stirk et al., 2002; Hussain and Hasnain, 2011; Gayathri et al., 2015). Phytohormones such as indole-3-acetic acid (IAA) and CKs, excreted by symbiotic cyanobacteria are consumed by the host plants during their 


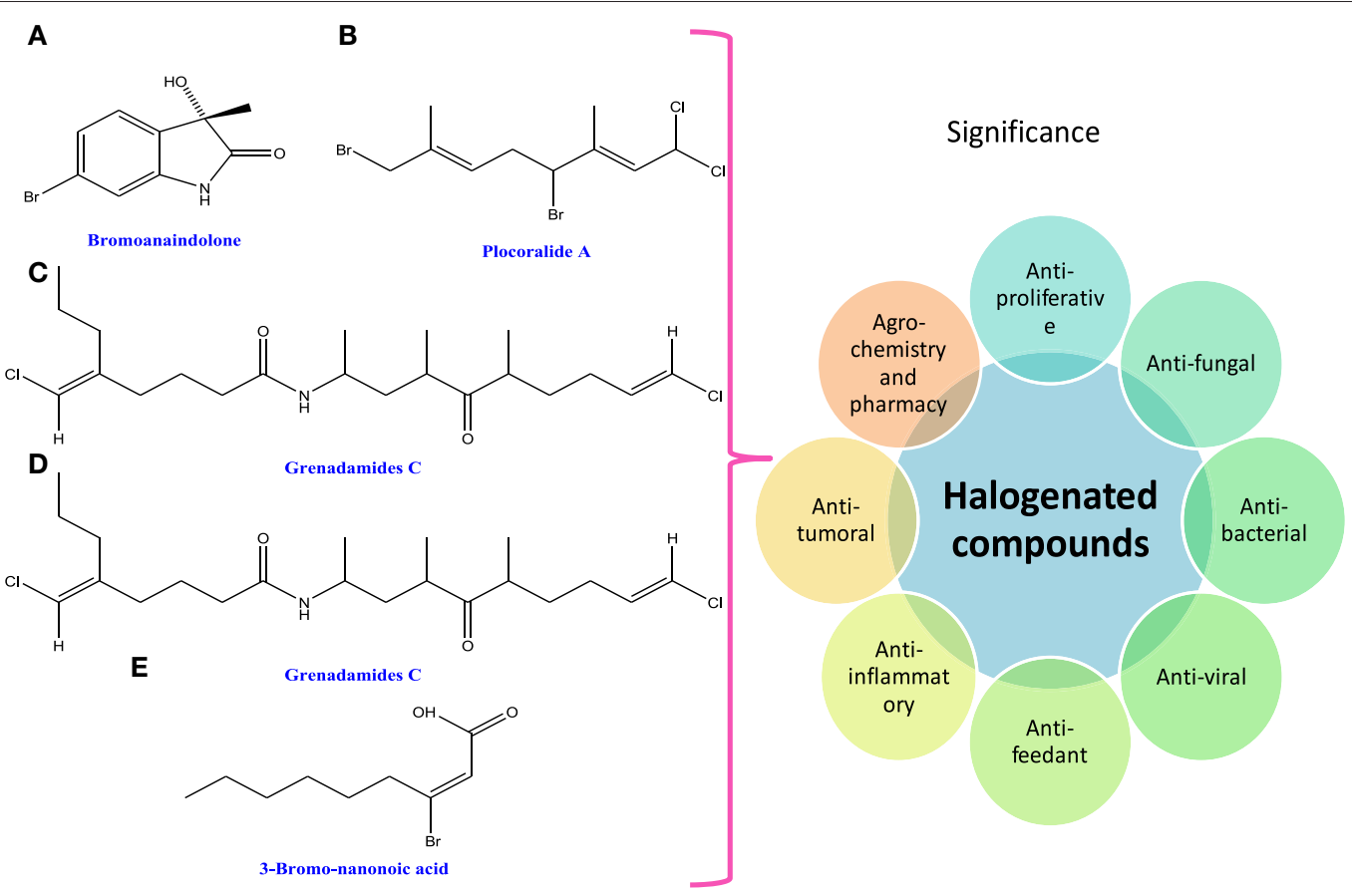

FIGURE 6 | Chemical structures and significance of halogenated compound: (A) bromoanaindolone, (B) plocoralide A, (C) grenadamides B, (D) grenadamides $\mathrm{C}$, and $\mathbf{E}$ ) 3-bromo-nanonoic acid polymer obtained from different cyanobacteria and algae.

growth and developmental processes (Hussain and Hasnain, 2010). Furthermore, the study by Hussain et al. (2013) showed that endophytic Nostoc strains have the capability to produce equal amount of phytohormones (IAA and CKs) in root cells of both rice and wheat and in the same study they showed that ipt gene is mostly activated during the production of CKs and IAA in Nostoc sp. After knocking out this gene, a significant decrease in CKs and IAA accumulation was noticed. The basic reason of the deactivation of the ipt gene is homologous recombination in the background of Nostoc sp., after that, the synthesis of zeatin was drastically reduced followed by a significant decrease in the growth of the mutant strain. Numerous plant growth regulators (PGRs) such as amino acids, sugars, vitamins that may upregulate the growth of the vascular plant, have been isolated from different genera of cyanobacteria and algae (Misra and Kaushik, 1989; Karthikeyan et al., 2007; Table 2). It is evident that among different phytohormones only two i.e., auxins and CKs perform their action at very low concentrations. Moreover, Stirk et al. (2002) and Stirk et al. (2009) also reported that Cyanophyta and Chlorophyta exhibited CK-like activity, which could be beneficial to agricultural crops. Moreover, algae and cyanobacteria are the great sources of numerous oxylipins, including jasmonic acid and its volatile methyl ester. The presence of these hormones has been observed in various microautotrophs such as green algae (Dunaliella tertiolecta, Dunaliella salina, and Chlorella sp.), euglenophyta (Euglena gracilis), red alga (Gelidium latifolium), and cyanobacteria (Spirulina sp.; Karthikeyan et al., 2007). In brown algae Ectocarpus siliculosus, IAA has been shown to play the regulatory role in the induction of signaling pathway and also in relaying cell-cell positional information (Le Bail et al., 2010). In another study, it was noticed that cleavage of specific cyclic epoxy-xanthophylls may have a crucial role in initiating the formation of abscisic acid (ABA; Rock and Zeevaart, 1991). In cyanobacteria, ABA functions under salt stress condition while in other class of algae it functions as a stress molecule under drought, nutrient, osmotic, oxidative, and salt stresses (Kobayashi et al., 1997; Yoshida et al., 2003, 2004; Lu et al., 2014). In the alga, Nannochloropsis oceanic, under nitrogen deprivation, the biosynthetic pathway of CKs and ABA was found to be transcriptionally down-regulated and up-regulated, respectively. Recently, it was found that ethylene (ET), produced by a green alga Spirogyra pratensis regulates the cell development process, revealing that ET has emerged before land colonization (Ju et al., 2015). In two green algae, Chlamydomonas sp. and Chlorella sp. both Gibberellic acid (GA) GAs and ET have been found to be involved in growth, senescence and different biological activities (Yordanova et al., 2010; Park et al., 2013; Tate et al., 2013). These phytohormones, obtained from the diverse algae and cyanobacteria, may be applied commercially in agricultural land to enhance the crop productivity (Table 2 ).

\section{Cyanotoxins}

A wide group of toxins, which are a part of secondary metabolites, are secreted by different marine as well as fresh water algae and cyanobacteria. The excess level of nutrients like nitrogen and phosphorus creates algal blooms, which result into serious problems of water quality by producing different form of toxins (Codd et al., 2005). Studies showed that five active groups of toxins including neurotoxins (anatoxins and saxitoxins), 
TABLE 2 | An overview of various phytohormones produced by algae and their potential implication in microbial biotechnology.

\begin{tabular}{|c|c|c|c|c|}
\hline Phytohormones & Cyanobacteria/algae & Relevant findings in microalgae & $\begin{array}{l}\text { Potential implication for } \\
\text { microalgal biotechnology }\end{array}$ & References \\
\hline $\begin{array}{l}\text { Abscisic acid } \\
\text { (ABA) }\end{array}$ & $\begin{array}{l}\text { Anabaena variabili, Ascophyllum } \\
\text { nodosum }{ }^{\star} \text {, Chlamydomonas } \\
\text { reinhardtii*, Chlorella minutissima*, } \\
\text { Chondracanthus* sp., }_{\text {Coscinodiscus granii }} \text {, Draparnaldia } \\
\text { mutabilis*, Dunaliella* sp., Gelidium } \\
\text { sp., Gracilaria* sp., Gracilariopsis* } \\
\text { sp., Hypnea* sp., Nannochloropsis } \\
\text { oceanic*, Nostoc muscorum, } \\
\text { Porphyra* sp., Trichormus variabilis, } \\
\text { Synechococcus leopoliensis }\end{array}$ & $\begin{array}{l}\text { Exogenous ABA decreases growth } \\
\text { rate in Nannochloropsis oceanica* } \\
\text { and Coscinodiscus granii* } \\
\text { Exogenous ABA improves stress } \\
\text { tolerance to dehydration in } \\
\text { Haematococcus pluvialis*, higher } \\
\text { salinity in Dunaliella sp., }{ }^{*} \text { and } \\
\text { Chlamydomonas reinhardtii*; } \\
\text { nitrogen deprivation in } \\
\text { Nannochloropsis oceanica*; } \\
\text { osmotic stress in Chlamydomonas } \\
\text { reinhardtii* }\end{array}$ & $\begin{array}{l}\text { Improvement in stress } \\
\text { tolerance. }\end{array}$ & $\begin{array}{l}\text { Boyer and Dougherty, 1988; } \\
\text { Hirsch et al., 1989; Kentzer and } \\
\text { Mazur, 1991; Zahradnıckova } \\
\text { et al., 1991; Marš́álek et al., } \\
\text { 1992; Tominaga et al., 1993; } \\
\text { Kobayashi et al., 1997; Yoshida } \\
\text { et al., 2003; Hartung, 2010; } \\
\text { Yokoya et al., 2010; Lu et al., } \\
\text { 2014; Stirk et al., 2014 }\end{array}$ \\
\hline Auxins & $\begin{array}{l}\text { Anabaena sp., Chlorella } \\
\text { minutissima*, Chlorella } \\
\text { pyrenoidosa*, Chondracanthus* }^{\star} \\
\text { sp., Chroococcidiopsis sp., } \\
\text { Ectocarpus siliculosus*, Gelidium }{ }^{\star} \\
\text { sp., Gracilaria* sp., Gracilariopsis* } \\
\text { sp., Hypnea* sp., Nostoc sp., } \\
\text { Oscillatoria sp., Phormidium sp., } \\
\text { Porphyra* sp., Prionitis lanceolate*, } \\
\text { Scenedesmus armatus*, } \\
\text { Synechocystis sp. }\end{array}$ & 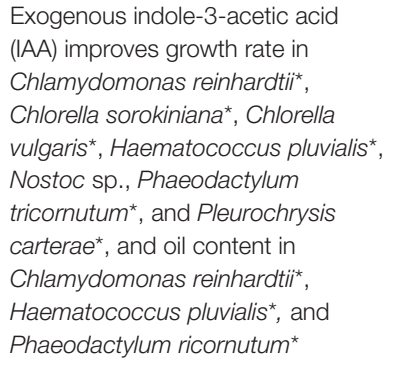 & $\begin{array}{l}\text { Elevation of microalgal } \\
\text { growth rate, biomass } \\
\text { production, oil content, and } \\
\text { stress tolerance. }\end{array}$ & $\begin{array}{l}\text { Ashen et al., 1999; Mazur et al., } \\
\text { 2001; Sergeeva et al., 2002; Le } \\
\text { Bail et al., 2010; Hussain et al., } \\
\text { 2010; Maor, 2010; Yokoya et al., } \\
\text { 2010; Mazhar et al., 2013; Park } \\
\text { et al., 2013; } \\
\text { Piotrowska-Niczyporuk and } \\
\text { Bajguz, 2014; Stirk et al., } 2014\end{array}$ \\
\hline Cytokinins (CK) & $\begin{array}{l}\text { Anabaena sp., Calothrix sp., } \\
\text { Chlorella minutissima*, } \\
\text { Chlorogloeopsis sp., } \\
\text { Chondracanthus* sp., } \\
\text { Chroococcidiopsis sp., Ecklonia* } \\
\text { sp., Ecklonia maxima*, Gelidiums } \\
\text { sp., Gigartina clathrate*, Gracilaria* } \\
\text { sp., Gracilariopsis* sp., Hypnea* } \\
\text { sp., Laminaria pallid*, } \\
\text { Nannochloropsis oceanic*, } \\
\text { Oscillatoria sp., Phormidium sp., } \\
\text { Porphyra* sp., Rhodospirillum sp., } \\
\text { Synechocystis sp. }\end{array}$ & $\begin{array}{l}\text { Exogenous CK improves cell cycle } \\
\text { progression in Nannochloropsis } \\
\text { oceanica*; growth rate in } \\
\text { Chlamydomonas reinhardtii*, } \\
\text { Nannochloropsis oceanica*, and oil } \\
\text { content in Chlamydomonas } \\
\text { reinhardtii*, Haematococcus } \\
\text { pluvialis*, and Phaeodactylum } \\
\text { tricornutum* } \\
\text { Elevated temperature led to } \\
\text { increase in CK contents in Ecklonia } \\
\text { maxima* and Macrocystis pyrifera* }\end{array}$ & $\begin{array}{l}\text { Elevation of microalgal } \\
\text { growth rate, oil content, and } \\
\text { stress tolerance. }\end{array}$ & $\begin{array}{l}\text { Jennings, 1969; Tian et al., } \\
\text { 2006; Tsavkelova et al., 2006; } \\
\text { Hussain et al., 2010; Stirk et al., } \\
\text { 2011; Park et al., 2013; Lu et al., } \\
\text { 2014; Stirk et al., 2013, } 2014\end{array}$ \\
\hline Ethylene (ET) & $\begin{array}{l}\text { Anabaena sp., Calothrix sp., } \\
\text { Chlorella pyrenoidosa*, } \\
\text { Cylindrospermum sp., Ecklonia } \\
\text { maxima*, Nostoc sp., Padina } \\
\text { arborescent* sp., Porphyra tenera*, } \\
\text { Scytonema sp., Synechococcus sp. }\end{array}$ & $\begin{array}{l}\text { ET take part in programmed cell } \\
\text { death of microalgae in } \\
\text { Chlamydomonas reinhardtii* }\end{array}$ & $\begin{array}{l}\text { Enhancement of microalgal } \\
\text { growth rate as well as } \\
\text { biomass productivity. }\end{array}$ & $\begin{array}{l}\text { Watanabe and Kondo, 1976; } \\
\text { Kreslavsky et al., 1997; } \\
\text { Tsavkelova et al., 2006; } \\
\text { Yordanova et al., } 2010\end{array}$ \\
\hline Gibberellins (GA) & $\begin{array}{l}\text { Anabaenopsis sp., } \\
\text { Chlamydomonas reinhardtii } \\
\text { Chlorella* sp., Cylindrospermum } \\
\text { sp., Ecklonia radiate*, Hypnea } \\
\text { musciformis*, Nannochloropsis } \\
\text { oceanic*, Phormidium foveolarum }\end{array}$ & $\begin{array}{l}\text { Exogenous GA stimulates } \\
\text { astaxanthin biosynthesis in } \\
\text { Haematococcus pluvialis* } \\
\text { Exogenous GA improves growth } \\
\text { rate in Chlamydomonas reinhardtii* }\end{array}$ & $\begin{array}{l}\text { Increased algal growth rate } \\
\text { and biomass productivity. } \\
\text { Target chemical production. }\end{array}$ & $\begin{array}{l}\text { Jennings, 1968; Gupta and } \\
\text { Agarwal, 1973; Tsavkelova et al., } \\
\text { 2006; Park et al., 2013; Stirk } \\
\text { et al., 2013; Voß et al., } 2014\end{array}$ \\
\hline
\end{tabular}

Organisms that are eukaryotic algae are designated with "**" mark.

cytotoxins (cylindrospermopsin), hepatotoxins (nodularin and microcystins) dermatotoxins and irritant toxins or endotoxins (lypopolysaccharides and lipopolysaccharides) produced by cyanobacteria and algae are of great concern due to their serious impact on human health (Wiegand and Pflugmacher, 2005; Gacsi et al., 2009; Figure 7 and Table 3). Toxins released from freshwater and marine algae can accumulate upto some extent in several aquatic organisms especially in fish, mollusks and seafood (Landsberg, 2002; Cazenave et al., 2005). Bioaccumulation of these compounds can severely affect health of domestic animals, humans and wildlife thereby causing several toxicological effects like toxicity within the cell (cytotoxic), skin (dermatotoxicity), hepatotoxicity, and neurotoxicity (Kujbida et al., 2006). The most common freshwater algal toxins such as anatoxin-a, 


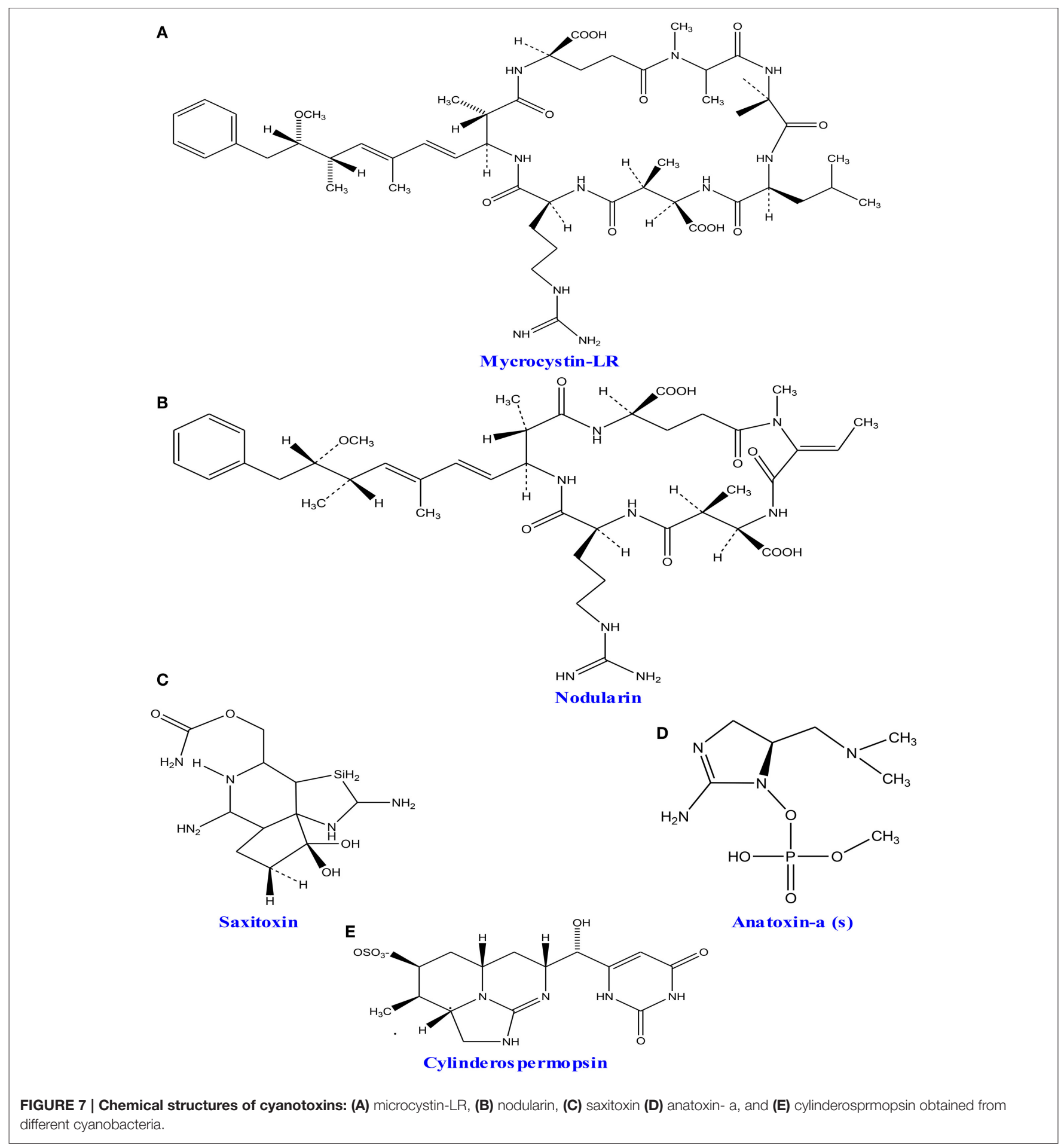

cylindrospermopsin, microcystins, and saxitoxins are obtained from cyanobacterial strains viz., Anabaena, Microcystis, Nostoc, and Oscillatoria sp. (Codd et al., 2005). Cylindrospermopsin is another toxin which is an alkaloid produced (with strain-specific production; Valerio et al., 2005) in the cyanobacterial strains of Aphanizomenono valisporum (in Australia and Israel), Cylindrospermopsis raciborskii (in Australia, Hungary, and the
United States), Umezakia natans (in Japan), and Anabaena sp. (Torokne et al., 2004; Neumann et al., 2007). Neurotoxins have been classified into three main classes (i) anatoxin-a, the first powerful cyanotoxin (Koskinen and Rapoport, 1985), (ii) saxitoxin from Anabaena circinalis (a cyanobacterium) in Australia and Aphanizomenon flosaquae (a cyanobacterium) in North America (Mahmood and Carmichael, 1986; Fergusson 
TABLE 3 | An overview of cyanotoxins produced by algae and cyanobacteria and their potential impacts on other organisms.

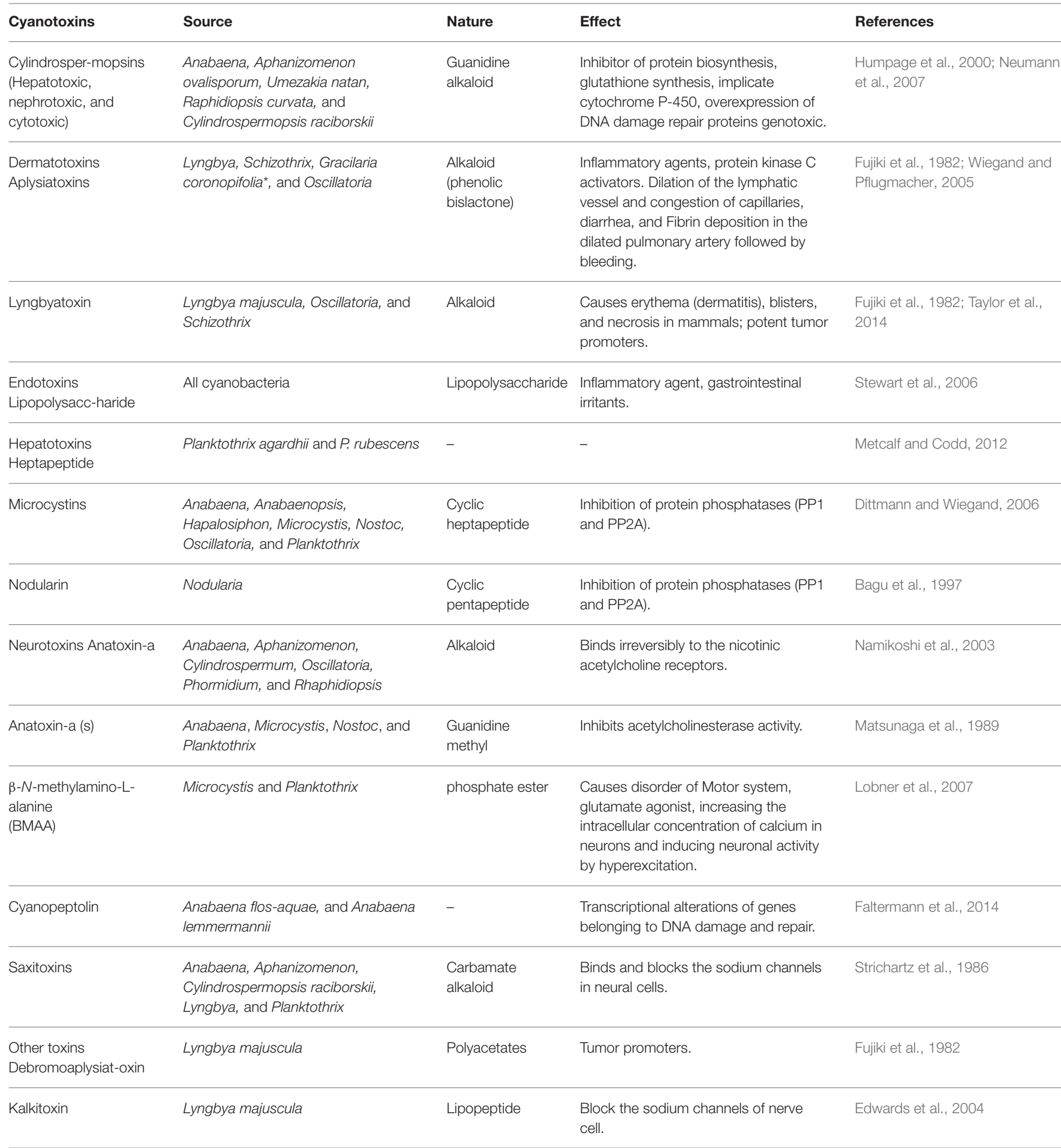

Organisms that are eukaryotic algae are designated with "*” mark.

and Saint, 2000; Al-Tebrineh et al., 2010) that cause widespread animal mortality; and (iii) anatoxin-a(s) that acts as a potent irreversible acetyl cholinesterase inhibitor (Devic et al., 2002).

These toxins are secreted by cyanobacteria and algae that exert negative impacts on herbivorous zooplanktons (Hansson et al.,
2007) and causes serious health hazard by making the water unfit for drinking (Stewart et al., 2006). Among five groups of toxins: hepatotoxin and neurotoxin are the most dangerous to humans as well as animals due to their accumulation in liver and kidney (Wiegand and Pflugmacher, 2005). 


\section{A GROWING WORLDWIDE MARKET FOR CYANOBACTERIAL AND ALGAL METABOLITES}

\section{In Cosmetics and Other Uses}

In view of the wide application of algal and cyanobacterial secondary metabolites, photoprotective compounds are being used in several skin care products like anti-aging creams, regenerants, anti-irritant, antioxidants, and anti-inflammatory drugs (Shilpa et al., 2010; Rastogi and Incharoensakdi, 2014; Suh et al., 2014). Some aquatic organisms like Alaria esculenta (brown algae), Ascophyllum nodosum (brown algae), Chlorella vulgaris (green algae), Chondrus crispus (red algae), Dunaliella salina (green algae), Mastocarpus stellatus (red algae), Nannochloropsis oculata (algae), and Spirulina platensis (blue-green algae) have occupied an important position in the skin care market (Stolz and Obermayer, 2005). Chlorella extracts have been used commercially in cosmetics, having collagen stimulating property (Kim et al., 2008). Since last two decades, cases of non-melonoma skin cancer (NMSC) have increased (Halpern and Kopp, 2005) and usage of sunscreen is considered beneficial in these cases (Maier and Korting, 2005) by the health care professionals (Halpern and Kopp, 2005; Seite and Fourtanier, 2008; Diffey, 2009). Due to high demands for safe and best sunscreens in cosmetic industries, exploitation of cyanobacteria has become promising, as MAAs and scytonemin can be used as efficient natural UV blockers in these formulations. They not only prevent damage from the UV radiation but also protect the skin effectively from other problems. These MAAs have absorption maxima in UV range therefore, being used at large scale in various industries (Conde et al., 2000; Whitehead and Hedges, 2005). Some derivatives of MAAs such as tetrahydropyridines have been developed and are applied as sunscreen (Dunlap et al., 1998; Bhatia et al., 2011). Besides this, in paints, plastic, and varnishes industries, MAAs have been widely applied for the manufacturing of photostabilizing agents (Bandaranayake, 1998; Bhatia et al., 2011). Moreover, it was demonstrated that the fusion of two MAAs (shinorine+P334), isolated from red alga Porphyra umbilicalis, has suppressed efficiently the negative consequences of UV on human skin (Daniel et al., 2004). A study demonstrated a kinase activity in scytonemin (a photoprotective compound), which may be useful in curing the disorders of proliferation and inflammation (Stevenson et al., 2002). Scytonemin (GarciaPichel et al., 1992) prevents up to $90 \%$ of solar UV radiation from entering the cell. In addition, scytonemin has antioxidant activity as well as functions as a radical scavenger to prevent cellular damage resulting from ROS produced due to UVradiation exposure (Matsui et al., 2012; Rastogi et al., 2015). The third most important photoprotective compounds are carotenoids, especially $\beta$-carotene, which protects skin against UV-induced photooxidation (Aust et al., 2005; Wertz et al., 2005). Moreover, it has been reported that ketocarotenoidastaxanthin has vital role in preventing pathological damages in human like photooxidation, inflammation in the cell, prostate and mammary carcinogenesis, aging, ulcers due to Helicobacter pylori infection, and skin aging problems (Bennedsen et al., 1999; Guerin et al., 2003; Cardozo et al., 2007). It is proven to be an excellent and more powerful antioxidant than that of vitamins $\mathrm{C}$ and $\mathrm{E}$ or other carotenoids, while preserving the essential lipids and proteins of human lymphocytes due to its superoxide dismutase and catalase enzyme activities (Bolin et al., 2010; Vílchez et al., 2011). In addition to this, polysaccharides like alginate, fucoidan, and laminaran derived from brown algae, such as Fucus vesiculosus and Turbinaria conoides, have antioxidative properties (Jea et al., 2009) and can be applicable to prevent skin aging and cutaneous disorders.

Skin whitening has become common tradition all over the world, mainly in Asia (Li E. P. H. et al., 2008). This is because white skin has become a parameter of beauty in Asian culture. In this case, the most common approach for skin whitening is the use of tyrosinase inhibitors (Wang et al., 2011) as the enzyme catalyzes the rate-limiting step of pigmentation. Thomas and Kim (2013) have reported that Fucoxanthin isolated from Laminaria japonica suppress tyrosinase activity in melanogenesis in UVB-irradiated mice and UVB-irradiated guinea pigs. Further they have reported that, oral treatment with fucoxanthin suppressed skin mRNA expression linked to melanogenesis, thereby suggesting that fucoxanthin have the capability to negatively regulate the melanogenesis at the transcriptional level. Another brown algal secondary metabolite i.e., Phloroglucinol have tyrosinase inhibitory activity due to their ability to chelate copper (Babitha and Kim, 2011). At industrial scale, they may be widely used in drugs, food additives, and cosmetics (Jha and Zi-rong, 2004). Overall, photoprotective compounds, which do exhibit biological activities, may be used in further research emphasizing their biotechnological applications in order to improve human health. Another important compound agar obtained from algae, has industrial applications in casting, adhesives, coating, printing, dyeing, and culture media (Cardozo et al., 2007). In addition, a unique compound of monoterpenes group- $\beta$-phellandrene, made up of 10 -carbon has a great commercial potential including personal care, cleaning products, and pharmaceutics (Bentley et al., 2013).

\section{In Defense}

Fluctuation in environmental conditions may cause enhancement in ROS production which may damage cells oxidatively. Simultaneously, photosynthetic organisms have developed several strategies to avoid negative consequences of ROS. In this context, PUFAs have been shown to provide protection to the cell against oxidative damage (Kumar et al., 2012). Kumar et al. (2012) have also demonstrated that decline in PUFAs and an enhancement in the activities of antioxidants (i.e., catalase and superoxide dismutase) were sufficient to manage oxidative stress under metal stress. Phycocyanobilins, structurally very close to bilirubin, are regarded as efficient quenchers of different oxygen derivatives (Wagner et al., 1993; Kumar et al., 2016). Therefore, it is thought that phycocyanobilins would have great antioxidant potential since they could protect the living cell against severe oxidative stress (Hirata et al., 2000). Similarly, MAAs may provide protection to the cell by improving the antioxidant status and quenching the superoxide anions and other oxygen derivatives (Suh et al., 
2003; De la Coba et al., 2007). From nutrition point of view, a cyanobacterium Spirulina can be consumed orally i.e., directly without any processing and is very beneficial to human health including augmentation of the immune system, antioxidant activity, anticancer, and antiviral effects, thereby regulating the hyperlipidemia and cholesterol level, which consequently provide protection to the cell against various disorders such as allergies, obesity, immunomodulation, hepatotoxicity, inflammation, arthritis, and diabetes (Deo et al., 2014; Mishra et al., 2014).

\section{In Biofuels}

In the present scenario, energy crisis and global warming have become two burning problems for the human beings. They have occurred due to the disturbance in equilibrium between industrialization, availability of fossil fuel, and population growth. Hence, the identification of alternative and environment friendly renewable energy sources has gained momentum. In this race, presently the algal biofuel has been recognized as a feasible alternative of renewable energy source for sustainable energy production, which has the potential to replace the fossilbased fuels. Cyanobacteria are capable of converting nearly $10 \%$ of the solar energy into biomass, while the other algae and energy crops such as sugarcane and corn have the ability to convert only 5 and $1 \%$ of solar energy into biomass, respectively. In this way, the photosynthetic prokaryotes like cyanobacteria and microalgae have emerged as useful tools for producing biodiesel, which is cost-effective and eco-friendly to a large extent (Li Q. et al., 2008). The oil obtained from microalgae constitutes $16-68 \%$ of dry weight and the yield of oil is recorded up to $136,900 \mathrm{~L} / \mathrm{ha}$ as compared to the other plant crops, which ranges from 172 to $5950 \mathrm{~L} /$ ha (Chu, 2012). Several metabolites like carbohydrates, lipids and fatty acids, important constituents of biofuels, are produced during the Calvin cycle in cyanobacteria and algae. Another process is fermentation, in which a huge amount of carbohydrates can be transformed into bioethanol, fatty acids into acetate, and butyrate into propionate at commercial level. In addition, lipids can also be converted into biodiesel (Parmar et al., 2011; Table 1). Moreover, some green algae like, Botryococcus (Rao et al., 2012), Chlorella (Münkel et al., 2013), Scenedesmus (Xia et al., 2013), Chlamydomonas (Nakanishi et al., 2014), Dunaliella (Moheimani, 2013), and Nannochloropsis (Bartley et al., 2013) may provide raw materials for production of biodiesel. High growth rate, high lipid content, resistant nature under different environmental stimuli and no seasonal limitations on culturing of cyanobacteria and algae make them promising tool for the production of biodiesel at low cost (Chisti, 2007; Ho et al., 2010, 2014). It is necessary to check lipid composition of algae because the content of lipid provides excellency of biodiesel, which can be used for efficient combustion process and also in heating power of engines (Talebi et al., 2013; Wang et al., 2014).

\section{Biofuel Production}

Biofuel production is a complex process that consists of following stages: (1) microalgae cultivation, (2) harvesting, drying, and cell disruption (cells separation from the growth medium), (3) lipid extraction for biodiesel production through transesterification, and (4) starch hydrolysis, fermentation, and distillation for bioethanol production (Figure 8). There are two major phases for biofuel production i.e., upstream and downstream processes. The upstream stage mainly puts emphasis on different cultivation technologies to maximize biomass quality and quantity, whereas the downstream phase is engaged in harvesting technologies and sustainable biofuel production. So far, various potential sources of biofuel such as biomethane, biohydrogen and bioethanol have been identified for the production of biodiesel. In this way, fatty acids, which have high energy carbon-hydrogen and carbon-carbon bonds, could have a great potential for their application in renewable energy regime either as an additive or major constituent of petroleum (Rupilius and Ahmad, 2006). Several genetically modified cyanobacterial strains e.g., Anabaena sp. PCC7120, Synechococcus elongatus PCC7942, and Synechocystis sp. PCC6803 have been recognized as native producers of hydrocarbons. Furthermore, Tan et al. (2011) have shown that genetically engineered cyanobacterial system may produce various components of biofuels i.e., hydrocarbons and fatty alcohols through photosynthesis. In a study, Liu and Curtiss (2012) have developed a genetic approach termed as "thermorecovery" which helps in liberating free fatty acids that are precursors for biofuel production at commercial level by lysing cultures of cyanobacteria and hydrolysis of membrane lipids.

The major limitations for biofuel production from cyanobacteria and algae are low concentration of biomass and low oil content in the culture. Furthermore, smaller

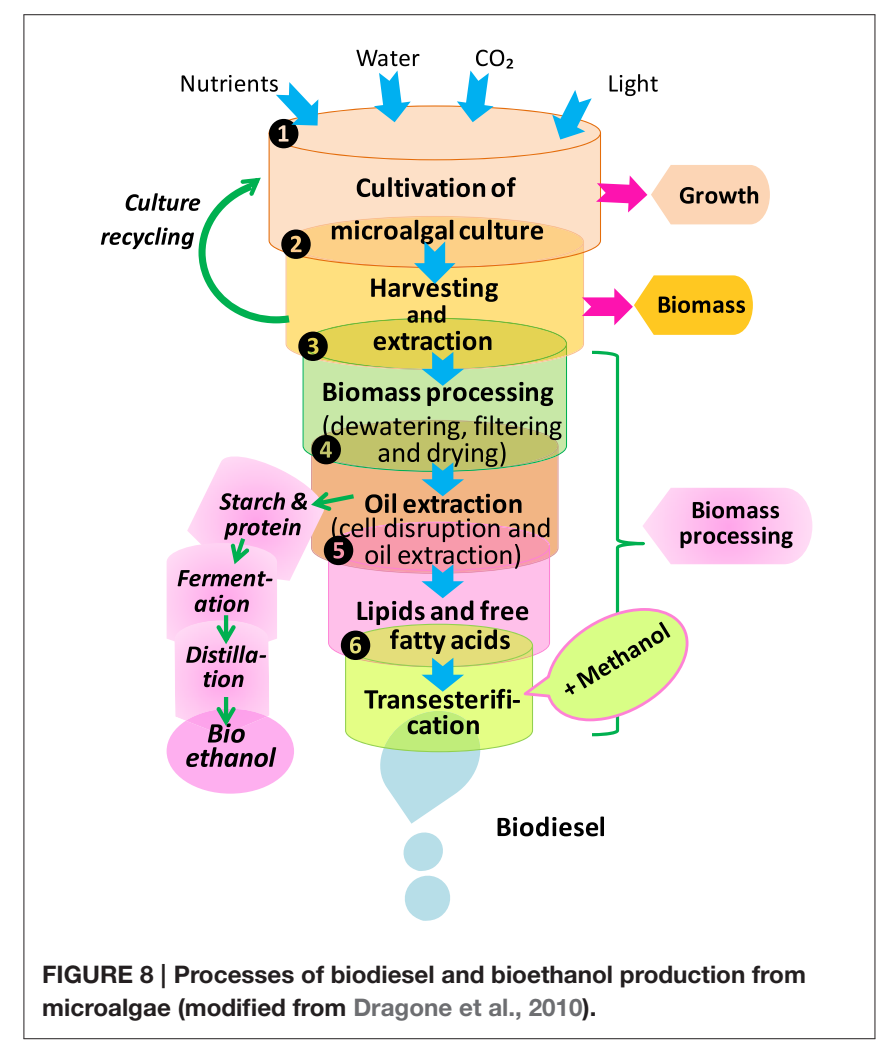


size of microalgae makes them quite costly for harvesting. Moreover, harvesting and drying of algal biomass from high quantity/volume of water are an energy consuming process. The infrastructure and resources needed in the production of large-scale microalgal biomass are costly. The costs of exhaustive management and the equipment for photobioreactor systems are prohibitive, particularly for thousands of hectares of clear containment vessels with accompanying pumps and plumbing needed. In case of large pond, the production appears to be more expensive. Overall, microalgal farming is much more costly and complicated in comparison to the conventional agriculture practices. These difficulties can be overcomed by upgrading the harvesting technologies. Recently, some cost effective technologies have been suggested for microalgal biofuel production:

1. by developing biorefinery or coproduct strategies,

2. by designing high photosynthetic efficient photobioreactors,

3. by developing cost-effective technologies for biomass harvesting and drying,

4. by developing genetic engineering technology to modify the metabolic pathways for microalgal biomass and lipid production and,

5. to understand the symbiotic interactions between microalgae (cyanobacteria and algae) and bacteria, which also affects the biomass as well as lipid production in microalgae.

\section{Bioethanol}

Bioethanol production can be carried out using first, second as well as third generation feedstock. The first generation feedstock includes cereals and legumes like sugar beet, corn, wheat etc. while, the second generation feedstock includes materials rich in lignocellulose like waste or forest residue and the third generation feedstock includes algae. Sugar obtained from molasses, sugarcane, sugar beet is directly fermented by yeast for ethanol production, but they have low conversion costs. It has been suggested that ethanol production from second generation feedstock is more suitable due to less energy requirement and chemical inputs like from 1 ton of sugar beet only 25 gallons (gal) of ethanol is produced, similarly, from 1 ton of sweet sorghum only 20 gallons of ethanol is produced yearly (Sarkar et al., 2012). However, due to their harvesting, purification and treatments needs, their production becomes challenging and less economical, which has shifted the focus toward the third generation feedstock that are easy in cultivation along with high cultivation and less harvesting time. Apart from the convenience in biomass cultivation, the ethanol yield from algal system is very high, which is 5,000-15,000 gal/acre or $46,760-140,290$ $\mathrm{L} /$ ha, while from sugar beet it is $536-714 \mathrm{gal} / \mathrm{acre}$ or 5,010 $6680 \mathrm{~L} / \mathrm{ha}$, from corn $370-430 \mathrm{gal} / \mathrm{acre}$ or $3,460-4,020 \mathrm{~L} / \mathrm{ha}$ and that from sweet sorghum it is $326-435 \mathrm{gal} / \mathrm{acre}$ or 3,0504,070 L/ha (Chaudhary et al., 2014). The wide variety of algal species such as Scenedesmus, Chlorella (Ho et al., 2013), and Chlamydomonas (Kim et al., 2006) can accumulate a substantial quantity of carbohydrates in their biomass. Due to the high starch content (ca. 37\% dry weight), Chlorella vulgaris is a good source of ethanol with 65\% conversion efficiency (Hirano et al., 1997). The process for ethanol production involves biomass grounding and then the starch/carbohydrate is converted into sugars, mixed up with yeast and water and kept in large warm tanks called fermenters (Demirbas, 2001). The breakdown of sugar as well as its conversion into ethanol is carried out by yeast (McKendry, 2002). After this, the product undergoes distillation process to remove impurities like water that will be present in the diluted alcohol products (10-15\% ethanol). The concentrated ethanol obtained after the process is separated and condensed in liquid form that can be used as petrol substitute (Demirbas, 2001; Machado and Atsumi, 2012). On the other hand, ethanol can also be produced via dark fermentation process from microalgae with the maximum productivity of $450 \mathrm{mmol} \mathrm{g}^{-1}$ dry weight (Ueno et al., 1998). Moreover, carbohydrates found in cyanobacteria and algae are primarily made up of cellulose (lacks lignin) and starch, which are easily converted to simple sugars for fermentation as compared to the lignocellulosic biomass (John et al., 2011; Ho et al., 2013). Therefore, numerous studies have suggested use of microalgae for biodiesel production that is quite high in comparison to bioethanol production. It seems that in future, production of bioethanol using microalgae will offer a reasonable alternative source (John et al., 2011; Ho et al., 2013).

\section{In Agriculture as Biocides}

Cyanobacteria and algae are also useful in agriculture sector. Several cyanotoxins, which are derived from cyanobacteria, exhibit various bioactivities and may serve as biocides. These biocides show growth inhibitory response on microorganisms including bacteria, viruses, fungi, and some invertebrates such as crustaceans, bivalves, and also some vertebrates like fish, birds, and mammals (Misra and Kaushik, 1989; Schwartz et al., 1990; Burja et al., 2001). These cyanotoxins have a great potential for developing an active biological compound that could be applied in crop fields as insecticides, herbicides, algicides, and fungicides due to their allelopathic effects (Biondi et al., 2004; Ishibashi et al., 2005; Berry et al., 2008; Rastogi and Sinha, 2009; Table 1). Numerous problems have been reported to arise from application of synthetic pesticides and thus production of biocides with low environmental risk is needed (Isman, 2006). Comparing the ecological impact of synthetic pesticides and biocides, it could be concluded that they have low negative ecological impact and simultaneously maintain growth of producers. Study has demonstrated that cyanotoxins such as microcystins, anatoxin-a and cylindrospermopsin, which are obtained from cyanobacterial strains of Microcystis, Anabaena, and Cylindrospermopsis, respectively showed greater mortality rate and larvicidal activity (Berry et al., 2008). Thus, application of these cyanotoxins could help in restoring the ecological sustainability (Rastogi and Sinha, 2009).

\section{In Medicine}

During the last decades, several bioactive compounds having anti-inflammatory and anticancer property, enzymes and antibiotics have been isolated from cyanobacteria and algae (Burja et al., 2001; Gunasekera et al., 2008; Kwan et al., 
2008; Rastogi and Sinha, 2009), which suggest that these organisms may be a great market in developing the important and biotechnologically applicable compounds. Recently, two bioactive compounds viz., dragonamide $\mathrm{C}$ and dragonamide $\mathrm{D}$ have been isolated from a cyanobacterium Lyngbya sp. (Gunasekera et al., 2008) showing anticancerous activity similar to that of recorded with dragonamides, while dragonamide $\mathrm{A}, \mathrm{B}$, and $\mathrm{E}$ showed in vitro activity against leishmaniasis (Jiménez and Scheuer, 2001; McPhail et al., 2007; Balunas et al., 2010). Along with dragonamides, dragomabin was isolated from Lyngbya sp. which possesses the best differential toxicity between mammalian cells and parasite. In 2010, Sanchez et al. isolated and identified a series of almiramides A-C from Lyngbya majuscule which showed a strong in vitro antiparasitic activity against leishmania. Similarly, cryptophycins isolated from Nostoc sp. exhibited cytotoxic properties, which provide good opportunities in manufacturing anticancerous drugs (Moore et al., 1996). About twenty-six cryptophycin forms were isolated by Moore group from Nostoc sp. GSV 224 (Chaganty et al., 2004). Of the various forms, cryptophycin 52 form was reported to be the most successful and evaluated in phase II clinical trials for curing the platinum resistant ovarian cancer and advanced lung cancer (Edelman et al., 2003; D'Agostino et al., 2006). In other findings, borophycin (polyketide) obtained from cyanobacteria, Nostoc linckia and Nostoc spongiaeforme exhibited antitumor activity against cancer (Hemscheidt et al., 1994; Torres et al., 2014). Recently, National Cancer Institute (NCR) has announced that a fat soluble photosynthetic pigment, $\beta$-carotene is anticarcinogenic in nature. Besides this, it is also effective in reducing the risk of heart diseases by controlling the cholesterol level. Thus, the natural $\beta$-carotene can be superior in terms of its anticarcinogen and antiheart disease properties. Due to these desirable medical properties, the demand of natural $\beta$-carotene is increasing in the market. Medically Arthrospira sp. is very important as it is a rich source of $\gamma$-linolenic acid (GLA), which plays vital role in lowering blood pressure by regulating the lipid metabolism.

Omega-3 ( $\omega-3)$ fatty acids are PUFAs and essential components for the growth of higher eukaryotes (Ward and Singh, 2005). Omega-3 fatty acids are an important structural component of human cell membranes, principally neuronal cells (Brunner, 2006). The use of EPA (eicosapentaenoic acid) and DHA (docosahexaenoic acid) supplements are known to prevent cardiovascular inflammatory conditions (Sijtsma and Swaaf, 2004). In case of cardiovascular health, it is believed that regular consumption of $\omega-3$ fatty acids reduces the risk of cardiac arrhythmia, hypertension, myocardial infarction, and thrombosis because $\omega-3$ fatty acids increase the highdensity lipoprotein/low-density lipoprotein (HDL/LDL) ratio thereby decreasing the total cholesterol/HDL ratio (Horrocks and Yeo, 1999). Additionally, omega-3 fatty acids also have positive effect on brain functioning of human beings along with the nervous system (Simopoulos et al., 2009). For the healthy development of fetal brain, the sufficient intake of EPA and DHA is essential in pregnant women (Damude and Kinney, 2008). In infants, for normal growth and functional development, arachidonic acid (ARA), a type of omega-6 fatty acid and DHA are necessary (Dyerberg et al., 1995).
Interestingly, an increased DHA consumption may also reduce the severity of depression (Hibbeln and Salem, 1995). The immuno-modulatory effects have been observed (Simopoulos, 1991; Calder, 1996), when they used $\omega-3$ fatty acids in the treatment of inflammatory conditions such as asthma, Crohn's disease, cystic fibrosis, lupus, psoriasis, rheumatoid arthritis, and ulcerative colitis (Simopoulos, 1991; Calder, 1996). According to Hodge et al. (1996) the ingestion of fish oil for more than once a week in children, had a lower probability of suffering from asthma.

Carotenoids are essential for healthy eyes. The two major carotenoids, i.e., lutein and zeaxanthin inhibit photooxidative damage to human retina by accumulating in the macula of retina (Neelam et al., 2005). Astley et al. (2004) showed that occurrence of light mediated diseases can be reduced by antioxidant activity of carotenoids. In addition, several epidemiological evidences show that high dietary intake of carotenoids decrease the risk of cancer, as lycopene has been suggested to be effective against prostate cancer (Ben-Dor et al., 2005).

The highly purified agar (also called agarose in neutral fractions) is used as anticoagulants, bulking agents, capsules, laxatives, suppositories, and tablets, which are useful from pharmaceutical point of view (Cardozo et al., 2007). Moreover, agar is employed for cancer cell therapy because it can persuade the apoptosis of these cells in vitro (Chen et al., 2004).

Algae are good sources of lectins that have specific role in advanced medical sciences. Some examples are blood group typing and definition of secretor status, detection of disease-related alterations of glycan synthesis, quantification of aberrations of cell surface glycan presentation and malignancy (Rudiger and Gabius, 2001). Besides this, they deliver vaccines across the mucosal surfaces and binds there due to their bioadhesive property (Jepson et al., 2004). A detail outline for use of cyanobacteria and algae as medicine is given in Table 4.

\section{In Food and Food Colorant}

Among diverse metabolites procured from cyanobacteria and algae, fatty acids particularly PUFAs have gained much consideration due to their nutritional importance. Cyanobacteria and algae produce an enormous amount of PUFAs and thus, are contributing in manufacturing of fats and oils at commercial level as alternative sources of animal and plants' oil. Apart from this, PUFAs especially EPA and DHA, are being implicated in the prevention of cardiovascular disease. The oil extracted from Crypthecodinium cohnii contains $40-50 \%$ DHA but no EPA or other long chain poly unsaturated fatty acids (LC-PUFA) and DHA is very important for brain and eye development in infants (Kroes et al., 2003; Ward and Singh, 2005). Since, in an aquatic ecosystem fishes and other herbivores have lesser capability of producing PUFAs, they obtain them from cyanobacteria and microalgae, which are rich sources of different kinds of fatty acids. Property of excess fatty acid production by cyanobacteria and microalgae makes them suitable candidates for aquaculture (Tonon et al., 2002; Guedes et al., 2011). The microalgal fatty acids consisted of triacylglycerides (TAG), a class of lipid mainly used by oleaginous eukaryotic micro-organisms for storage of their fatty acids under stress conditions (Ratledge, 2004). TAG offers the option to partially replace the functions of currently 
TABLE 4 | Various therapeutic agents produced by cyanobacteria and algae and their potential uses.

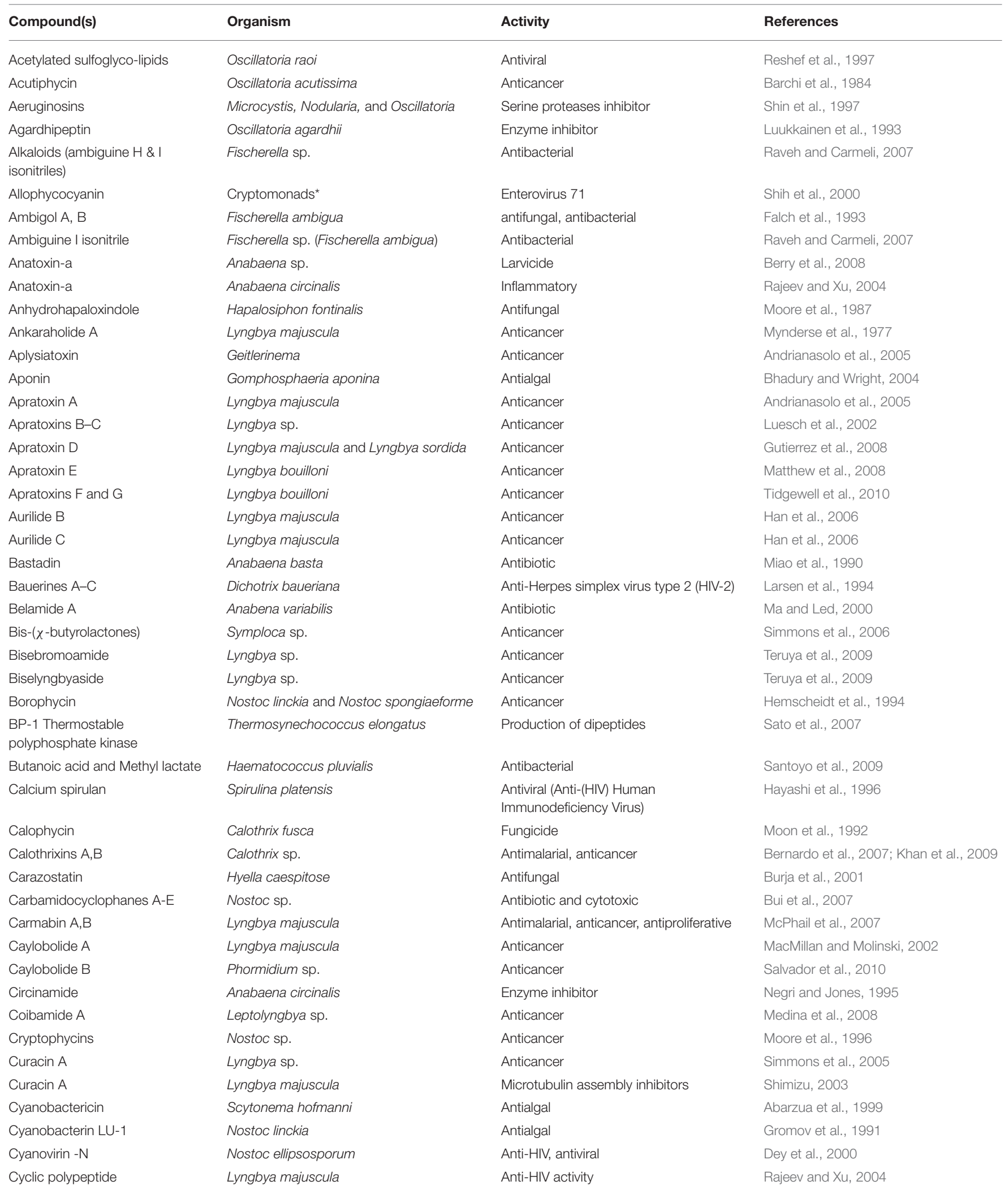


TABLE 4 | Continued

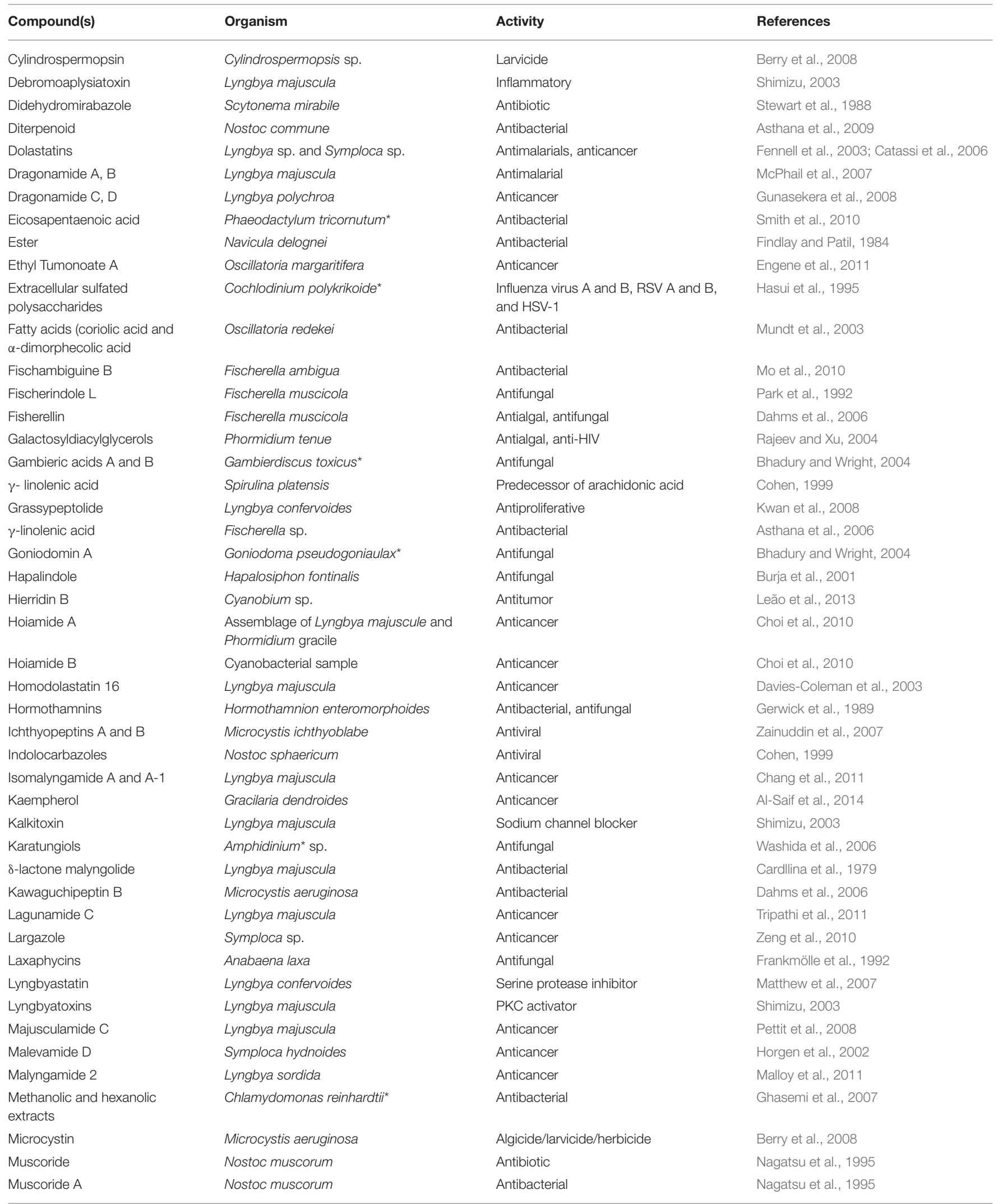


TABLE 4 | Continued

\begin{tabular}{|c|c|c|c|}
\hline Compound(s) & Organism & Activity & References \\
\hline Naienones A-C & Synechocystis sp. & Antitumoural & Nagle and Gerwick, 1995 \\
\hline Norharmane & Nostoc insulare & Antibacterial & Volk and Furkert, 2006 \\
\hline Nostocarboline & Nostoc sp. & $\begin{array}{l}\text { Antimalarial, antileishmaniasis, } \\
\text { cholinesterase inhibitor }\end{array}$ & Barbaras et al., 2008 \\
\hline Nostocine A & Nostoc spongiaeforme & Antibiotic & Hirata et al., 2003 \\
\hline Nostocycline A & Nostoc sp. & Antibacterial & Ploutno and Carmeli, 2000 \\
\hline Nostodione & Nostoc commune & Antifungal & Bhadury and Wright, 2004 \\
\hline Nostoflan & Nostoc flagelliforme & Antiviral & Hayashi et al., 2008 \\
\hline p-KG03exopolysaccharide & Gyrodinium impudicum* & Encephalomyocarditis virus & Yim et al., 2004 \\
\hline Pahayokolides & Lyngbya sp. & Antialgal/larvicidal & Gantar et al., 2008 \\
\hline Parsiguine & Fischerella ambigua & Antibacterial & Ghasemi et al., 2004 \\
\hline Palmyramide A & Lyngbya majuscula & Anticancer & Taniguchi et al., 2010 \\
\hline Phytoalexin & Scytonema ocellatum & Antifungal & Patterson and Bolis, 1997 \\
\hline Pitipeptolides C & Lyngbya majuscula & Anticancer & Montaser et al., 2011a \\
\hline Pitiprolamide & Lyngbya majuscula & Anticancer & Montaser et al., 2011b \\
\hline Polysaccharide & Navicula directa* & HSV-1 and -2 , Influenza A virus & Lee et al., 2006 \\
\hline Polyether compounds & Prorocentrum lima* and Dinophysis fortii ${ }^{\star}$ & Antifungal & Bhadury and Wright, 2004 \\
\hline Quercetin & Gracilaria dendroides & Antifungal & Al-Saif et al., 2014 \\
\hline Radiosumin & Plectonema radiosum & Enzyme inhibitor & Mooberry et al., 1995 \\
\hline Rutin & Gracilaria dendroides & Enzyme inhibitor & Al-Saif et al., 2014 \\
\hline Schizotrin A & Schizothrix sp. & Antifungal, antibacterial & Pergament and Carmeli, 1994 \\
\hline Sulfolipids & Lyngbya lagerhimii and Phormidium tenue & Anti-HIV activity & Rajeev and Xu, 2004 \\
\hline Sulfated polysaccharides & $\begin{array}{l}\text { Chlorella autotrophica* and Ellipsoidon* } \\
\text { sp. }\end{array}$ & $\begin{array}{l}\text { Viral hemorrhagic septicemia virus, } \\
\text { African swine fever virus }\end{array}$ & Fábregas et al., 1999 \\
\hline Symplocamide A & Symploca sp. & $\begin{array}{l}\text { Antimalarial, antileishmaniasis, } \\
\text { anticancer }\end{array}$ & Linington et al., 2008 \\
\hline Symplostatin 3 & Symploca sp. & Anticancer & Luesch et al., 2002 \\
\hline Tanikolide & Lyngbya majuscula & Antifungal & Singh et al., 1999 \\
\hline Tenuecyclamides & Nostoc spongiaeforme & Antibacterial and cytotoxic & Banker and Carmeli, 1998 \\
\hline Thermostable enzymes & Phormidium sp. & Catalysis of reactions & Piechula et al., 2001 \\
\hline Tjipanazoles & Tolypothrix tjipanasensis & Anticancer & Bonjouklian et al., 1991 \\
\hline Tolybyssidins & Tolypothrix byssoidea & Antifungal & Jaki et al., 2001 \\
\hline Tolyporphin & Tolypothrix nodosa & Antibiotic & Prinsep et al., 1992 \\
\hline Tolytoxin & Scytonema ocellatum & Antifungal & Patterson and Carmeli, 1992 \\
\hline Toyocamycin & Tolypothrix tenuis & Antifungal & Banker and Carmeli, 1998 \\
\hline Tubercidin toyocamycin & $\begin{array}{l}\text { Plectonema radiosum and Tolypothrix } \\
\text { tenuis }\end{array}$ & Fungicidal, cytotoxic & Stewart et al., 1988 \\
\hline Venturamide A,B & Oscillatoria sp. & Antimalarial & Linington et al., 2007 \\
\hline Veraguamides A-G & Symploca cf. hydnoides & Anticancer & Mevers et al., 2011 \\
\hline Wewakazole & Lyngbya sordida & Anticancer & Malloy et al., 2011 \\
\hline Wewakpeptins & Lyngbya semiplena & Anticancer & Han et al., 2005 \\
\hline
\end{tabular}

Organisms that are eukaryotic algae are designated with "*” mark. 
used vegetable oils. For example, the presence of alpha-linolenic and linoleic acid may partially replace the essential fatty acid contribution from rape seed and sunflower oils. The presence of LC-PUFA such as arachidonic acid, EPA, DHA, and stearidonic acid are of great interest in the evaluation of nutritional composition of an algal species to be used as food for marine organisms (Mozaffarian and Rimm, 2006; Harris et al., 2008). An alga, Gracilaria verrucosa belonging to the family rhodophyceae is one of the most exploited red seaweeds of Chilika, India and is usually known for its utilization in food industries (Gouda et al., 2013). Riahi et al. (2011) have reported that covering of mushroom growing fields with cyanobacterial cultures enhances yield, dry weight, and protein content of mushroom due to the secretion of plant growth regulators like auxins, sugars, and vitamins. Moreover, the cyanobacterium Arthrospira platensis has been reported as a rich source of protein [therefore regarded as single cell protein (SCP)], fatty acids, and feed supplements (Mishra et al., 2014). It is thought that the frequent use of Spirulina in diet may encourage the health of patients suffering from malnutrition, immune-suppression, hepatic, and neural compromise but further exploration on the antiviral impacts of this alga and its pharmaceutical applications are needed (Deo et al., 2014; Mishra et al., 2014). Due to high nutritional supplements for humans as well as animals, green algae i.e., Chlorella vulgaris, Dunaliella salina, Haematococcus pluvialis, and cyanobacterium i.e., Spirulina maxima are relevant in biotechnological fields. Spirulina platensis, due to its enrichment in pigments (Madhyastha and Vatsala, 2007), PUFAs (Sajilata et al., 2008), proteins (Colla et al., 2007; Kumar et al., 2014), vitamins, and phenolics (Ogbonda et al., 2007) had become a trademark of nutritional supplements. Chlorella is another example, which is gaining worldwide attention, because of its high demand in health food stores (Hills and Nakamura, 1978).

Besides this, the commercial importance of microalgal pigments cannot be avoided as they have become a necessary part of natural food colorant. $\beta$-carotene, which is obtained from some microalgae, is used as a food additive for enhancing: (i) coloration of fish flesh and egg yolk (specifically provides yellow color to margarine) and (ii) fertility and health of grain-fed cattle (Borowitzka, 1988). $\beta$-carotene is also used in cosmetics and food products like margarine, cheese, fruit juices, baked goods, dairy products, canned goods, and confectionary (Dufosse et al., 2005). Although, it is non-photostable and color bleach in cooking, still it has vastly gripped a potential market for microalgaederived food colorant. $\beta$-carotene, is naturally obtained from green alga Dunaliella salina, which constitutes $14 \%$ of its dry weight (Metting, 1996) and the antioxidant activity of $\beta$-carotene from Dunaliella is much higher than that of synthetic one. Another carotenoid, astaxanthin is produced by the green alga Haematococcus pluviali, which reaches up to $4-5 \%$ of dry weight and the market of astaxanthin is worth US \$200 million with an average price of US $\$ 2,500 / \mathrm{kg}$.

Carrageenan is obtained from macroalga, Kappaphycus alvarezii and supplied on a large scale in food industry. It is generally used as emulsers/stabilizers, due to their thickening and suspension forming properties in numerous foods, especially milk-based food products like ice cream, chocolate milk, puddings, jellies, evaporated milk, jams, salad dressings, dessert gels, pet foods, and meat products. Apart from their usage in foods, they are also used in medicine for their anticoagulant, antitumor, antiviral, and immunomodulation activities (Schaeffer and Krylov, 2000; Zhou et al., 2005). The agar has also its importance in preparation of gel substrate in biological culture media. Besides, these compounds, some cyanobacteria and alage are also a rich source of amino acids. For instance, Nostoc flagelliforme contains 19 amino acids and out of these eight are essential one for human and the production of these essential amino acid is $35.8-38.0 \%$ of the total amino acid (Han et al., 2004).

\section{Polyhydroxyalkanoates (PHAs): A Substitute for Non-biodegradable Plastics}

In the past few decades, the enormous uses of non-biodegradable plastics by humans have stressed almost the whole ecosystem especially in developing countries like India. The properties of PHAs are comparable to that of polypropylene (Doi, 1990; Loo and Sudesh, 2007), have attracted the attention of scientists as they are potential substitutes for non-biodegradable petrochemical-based plastics.

Microorganisms usually assimilate and store nutrients when there is high nutrient availability in surroundings. Among these stored nutrients, the lipoidic materials i.e., PHAs are accumulated in excess carbon availability (Anderson and Dawes, 1990; Nikodinovic-Runic et al., 2013). After assimilation of these carbons, they are processed biochemically and converted into monomer units (hydroxyalkanoate) and thereafter are polymerized and stored in the cell cytoplasm in form of water insoluble granules. It has been reported that two cyanobacterial strains Spirulina platensis and Synechocystis sp. accumulate $\sim 6-$ $7 \%$ hydroxyalkanoateon on dry weight basis (Campbell et al., 1982; Sudesh, 2004). Most commonly synthesized PHA by alga is poly 3-hydroxybutyrate (PHB). Since the biosynthesis efficiency for $\mathrm{PHB}$ in cyanobacteria is quite low therefore, in order to increase the production, PHB biosynthetic gene is introduced from bacterium Ralstonia eutropha into Synechococcus 7942 along with nitrogen starvation and acetate supplementation condition and production reached upto $25.6 \%$ of the dry cell weight (Takahashi et al., 1998). The metabolite production which is being enhanced by engineering the cyanobacteria has been discussed in the following section.

\section{GENETICALLY MODIFIED ORGANISMS (GMO) AND METABOLITE PRODUCTION}

The high amount of metabolite production from cyanobacteria has compelled the scientists to engineer these organisms in order to obtain maximum production. Several metabolites like alcohols, fatty metabolites (fatty acid, fatty alcohol, and fatty hydrocarbon), hydrocarbon (ethylene), carbohydrates (mannitol, lactate, and Glucosylglycerol), carboxylic acid, and terpenes obtained from cyanobacteria are applicable at commercial level and therefore to enhance their production, cyanobacteria and algae are being engineered (reviewed by Oliver et al., 2016). 
Likely, engineered Synechococcus elongatus PCC 7942 has 1.8folds higher production of 2,3-butanediol (23BD) than that of the parent strain (Oliver et al., 2013). The maximum 23BD production was $\sim 22 \mathrm{mg} / \mathrm{L} / \mathrm{h}$. Similar to this, Hirokawa et al. (2016) constructed a 1,3-propanediol biosynthetic pathway in Synechococcus elongatus PCC 7942 and observed that its average productivity was $0.9 \mathrm{mg} / \mathrm{L} / \mathrm{h}$, which constituted 288 $\mathrm{mg} / \mathrm{L}$ after 14 days. Likewise, ethanol production was enhanced $83 \%$ (productivity $11 \mathrm{mg} / \mathrm{L} / \mathrm{h}$ ) after engineering the pyruvate carboxylase enzyme in Synechocystis sp. PCC 6803 (Luan et al., 2015). The production of ethylene, an important component of polymers has been enhanced by engineering the Synechococcus elongatus PCC 7942 and Synechocystis sp. PCC 6803 and the production was improved by $64 \%(0.9 \mathrm{mg} / \mathrm{L} / \mathrm{h}$; Takahama et al., 2003; Ungerer et al., 2012; Lee et al., 2015). As the need of biofuel production is increasing, therefore, to optimize free fatty acids production in Synechococcus elongatus PCC 7942 and Synechocystis sp. PCC 6803, the alternative carbon sinks were removed as well as flux was increased for fatty acid biosynthesis, which gave the productivity of 0.1 and $0.4 \mathrm{mg} / \mathrm{L} / \mathrm{h}$, respectively (Liu et al., 2011; Ruffing and Jones, 2012). The production of fatty alcohol and fatty hydrocarbons has also been improved by employing the same engineering process. Similar to fatty acids, the production of carbohydrates, carboxylic acids, and terpenes obtained from cyanobacteria has been incresaed using the engineering process, which has been discussed in detail in review by Oliver et al. (2016). Regarding the genetic manipulation in the case of algae, some experiments have been performed with Chlamydomonas reinhardtii but no successful results have been obtained and this engineering process needs to be rectified in the case of algae.

\section{ALGAL BIOPROCESSING AND CHALLENGES}

As cyanobacteria and algae are a renewable source of drop-in fuels, feeds, fertilizers, nutritional oils, and pharmaceuticals. They can also provide waste water treatment and other remediation services and many more new applications are continuously being discovered. All these applications have to be commercialized and algal bioprocessing has been put forward as a flagship technology for driving the products or other valuable chemicals that are obtained from cyanobacteria and algae. The commercialization programme is being performed for harnessing the unequaled potential of algae to provide us with sustainable products, drive economic growth, and reduce greenhouse gas emissions. Several companies like solazyme, algenol, terra biologics etc. are heading toward this agenda but having some key points that have to be addressed by Algae biomass organization $(\mathrm{ABO})$ that include: (i) production of renewable fuel like ethanol, gasoline, diesel, and jet fuel and energy, (ii) production of more protein, feed, and oil, (iii) health and nutrition and (iv) materials and services. Outline of some companies has been addressed in the following paragraphs.

Algenol is a biotechnology company which is involved in commercializing the algae technology that had been patented for production of ethanol, gasoline, jet, and diesel fuel for a targeted cost of $\$ 1.30$ per gallon using algae, sunlight, carbon dioxide, and salt water. The ethanol obtained from patented strain is 20 times more than that of corn ethanol. The current yield is 8,000 gallons /acre/year. The production is carried out in fully closed and sealed photo bioreactors and the waste algae are converted to diesel, jet fuel, and gasoline using hydrothermal liquefaction.

Global Algae Innovations is another company which uses low cost algae production technologies. The company uses suite of algae grown in open ponds with novel, low-cost production technology in every process step. As a result, economical, sustainable production of protein and biofuel are now within reach. It also leverages the production of other algae markets such as functional foods, nutraceuticals, pigments, and aquaculture. The harvest technology of this company has $100 \%$ efficiency.

TerraVia Holdings (formerly Solazyme) is also a Biotechnology company which uses the copyrighted technology of converting low-cost plant-based sugars into high-value oils. This company shifted its focus from bio-fules to sustainable food oils and personal care products in March, 2016. However, commercialization processes have some challenges that have been discussed in detail in review by Griffiths et al. (2012). The challenges to be addressed have been briefly outlined below:

1. Increasing productivity in large-scale outdoor microalgal culture.

2. Minimizing contamination by predators and other algal species.

3. Mitigating temperature changes and water loss due to evaporation.

4. Optimizing supply of light and $\mathrm{CO}_{2}$.

5. Developing cheap and efficient reactor designs.

6. Developing cost and energy-efficient methods of harvesting dilute suspensions of small microalgal cells.

7. Decreasing the overall energy and cost requirements, particularly for pumping, gas transfer, mixing, harvesting, and dewatering.

8. Improving resource utilization and productivity through a biorefinery approach.

9. Producing valuable co-products.

10. Decreasing environmental footprint through recycling of water, energy, and nutrients.

\section{CONCLUSIONS AND FUTURE PERSPECTIVE}

Since the beginning of the civilization, biologically active compounds, which are obtained from diverse range of algae and cyanobacteria have been widely explored. Cyanobacteria and algae are rich sources of various compounds including pigments, lectins, fibers, halogenated compounds, steroids, antioxidants, vitamins, polyketides, polysaccharides, MAAs, proteins, and essential lipids. Therefore, they are widely used in different countries due to their multifunctional applications in nutraceuticals as well as in pharmaceuticals. Cyanobacterial and algal secondary metabolites possess several pharmaceutical applications such as antiviral, anticancer, and antimicrobial 
activities. Wide use of biocides has emerged as eco-friendly tactic as they are easily degradable in nature as compared to other synthetic pesticides. Undoubtedly, in the past few decades, our understanding in the field of algal metabolites has significantly improved, but there are still many steps we have to reach. We are entering in the blooming era of cyanobacteria and algae, our stage is set and it is the time, we uncover the enigma of cyanobacterial and algal metabolites. Definitely, by uncovering novel functions of algal secondary metabolites a new scenario will appear with specific reflection to humanity. This review has emphasized that cyanobacteria and algae are promising sources of structurally diverse biologically active compounds such as terpenes, alkaloids, steroids, polysaccharides, lipids, and polyphenolics which have several utilities in various industries. Nevertheless, further investigations are required for compiling secondary metabolites profile of cyanobacteria and algae in order to make them more useful for human welfare. There is a need to find out how we can convert the present days technology into a green technology for exploiting these cyanobacteria and algae. We should also think upon the strategy for disseminating this commercialization at small scale as well as at large scale. There is a need to find

\section{REFERENCES}

Abarzua, S., Jakubowski, S., Eckert, S., and Fuchs, P. (1999). Biotechnological investigation for the prevention of marine biofouling II. Blue-green algae as potential producers of biogenic agents for the growth inhibition of microfouling organisms. Botanica Mar. 42, 459-465. doi: 10.1515/BOT.1999.053

Abdo, S. M., Mona, H. H., Waleed, M. E., Rawheya, A. S. E. D., and Gamila, H. A. (2012). Antiviral activity of freshwater algae. J. Appl. Pharm. Sci. 2, 21-25. Available online at: http://imsear.li.mahidol.ac.th/bitstream/123456789/ 151107/1/japs2012v2n2p21.pdf

Adeyemi, M. M. H. (2011). A review of secondary metabolites from plant materials for post harvest storage. Int. J. Pure Appl. Sci. Technol. 6, 94-102.

Al-Saif, S. S., Abdel-Raouf, N., El-Wazanani, H. A., and Aref, I. A. (2014). Antibacterial substances from marine algae isolated from Jeddah coast of Red sea, Saudi Arabia. Saudi J. Biol. Sci. 21, 57-64. doi: 10.1016/j.sjbs.2013.06.001

Al-Tebrineh, J., Mihali, T. K., Pomati, F., and Neilan, B. A. (2010). Detection of saxitoxin-producing cyanobacteria and Anabaena circinalis in environmental water blooms by quantitative PCR. Appl. Environ. Microbiol. 76, 7836-7842. doi: 10.1128/AEM.00174-10

Ambati, R. R., Phang, S., M., Ravi, S., and Aswathanarayana, R. G. (2014). Astaxanthin: sources, extraction, stability, biological activities and its commercial applications-a review. Mar. Drugs. 12, 128-152. doi: $10.3390 / \mathrm{md} 12010128$

Anderson, A. J., and Dawes, E. A. (1990). Occurrence, metabolism, metabolic role and industrial uses of bacterial polyhydroxyalkanoates. Microbiol. Rev. 54, $450-472$.

Andrianasolo, E. H., Gross, H., Goeger, D., Musafija-Girt, M., McPhail, K., Leal, R. M., et al. (2005). Isolation of swinholide A and related glycosylated derivatives from two field collections of marine cyanobacteria. Org. Lett. 7, 1375-1378. doi: $10.1021 / 01050188 \mathrm{x}$

Anupama, and Ravindra, P. (2000). Value-added food: single cell protein. Biotechnol. Adv. 18, 459-479. doi: 10.1016/S0734-9750(00)00045-8

Ashen, J. B., Cohen, J. D., and Goff, L. J. (1999). GC-SIM-MS detection and quantification of free indole-3-acetic acid in bacterial galls on the marine alga Prionitis lanceolata (Rhodophyta). J. Phycol. 35, 493-500. doi: 10.1046/j.1529-8817.1999.3530493.x out answer to these questions like whether the production rate of metabolites is sufficient to meet out the demands in comparison to plants? Whether these metabolites could have some more beneficiary roles? Whether the changes made by bioenegineering could be employed in plant system to enhance the production from both cyanobacteria/algae and plants? Future work will no doubt reveal novel functions for secondary metabolites and the future research in this area will be very promising.

\section{AUTHOR CONTRIBUTIONS}

RS, PP, SS, JK, and MS prepared draft of this review and wrote it. $\mathrm{AB}, \mathrm{VS}$, and SP corrected and finalized review.

\section{ACKNOWLEDGMENTS}

University Grants commission is thanked for providing financial support to RS, PP, MS, and SS as D.Phil. research fellow to carry out this work. JK is thankful to the University Grants Commission for providing financial assistance as RGNF (RGNF2012-13-SC-UTT-33185: SRF) to persue D.Phil.

Asthana, R. K., Deepali, Tripathi, M. K., Srivastava, A., Singh, A. P., Singh, S. P., et al. (2009). Isolation and identification of a new antibacterial entity from the Antarctic cyanobacterium Nostoc CCC 537. J. Appl. Phycol. 21, 81-88. doi: 10.1007/s10811-008-9328-2

Asthana, R. K., Srivastava, A., Kayastha, A. M., Nath, G., and Singh, S. P. (2006). Antibacterial potential of c-linolenic acid from Fischerella sp. colonizing neem tree bark. World J. Microbiol. Biotechnol. 22, 443-448. doi: 10.1007/s11274-005-9054-8

Astley, S. B., Hughes, D. A., Wright, A. J., Elliott, R. M., and Southon, S. (2004). DNA damage and susceptibility to oxidative damage in lymphocytes: effects of carotenoids in vitro and in vivo. Br. J. Nutr. 91, 53-61. doi: 10.1079/BJN20031028

Aust, O., Stahl, W., Sies, H., Tronnier, H., and Heinrich, U. (2005). Supplementation with tomato-based products increases lycopene, phytofluene, and phytoene levels in human serum and protects against UV-light-induced erythema. Int. J. Vitam. Nutr. Res. 75, 54-60. doi: 10.1024/0300-9831. 75.1 .54

Babitha, S., and Kim, E. K. (2011). Effect of Marine Cosmeceuticals on the Pigmentation of Skin. Marine Cosmeceuticals: Trends and Prospects. Boca Raton, FL: CRC Press.

Bagu, J. R., Sykes, B. D., Craig, M. M., and Holmes, C. F. (1997). A molecular basis for different interactions of marine toxins with protein phosphatase1. Molecular models for bound motuporin, microcystins, okadaic acid, and calyculin A. J. Biol. Chem. 272, 5087-5097. doi: 10.1074/jbc.272.8.5087

Balunas, M. J., Linington, R. G., Tidgewell, K., Fenner, A. M., Ureña, L. D., Togna, G. D., et al. (2010). Dragonamide E, a modified linear lipopeptide from Lyngbya majuscula with antileishmanial activity. J. Nat. Prod. 73, 60-66. doi: $10.1021 / \mathrm{np} 900622 \mathrm{~m}$

Bandaranayake, W. M. (1998). Mycosporines: are they nature's sunscreens? Nat. Prod. Rep. 15, 159-172. doi: 10.1039/a815159y

Banker, R., and Carmeli, S. (1998). Tenuecyclamides A-D, cyclic hexapeptides from the cyanobacterium Nostoc spongiaformae var tenue. J. Nat. Prod. 61, 1248-1251. doi: 10.1021/np980138j

Barbaras, D., Kaiser, M., Brunb, R., and Gademann, K. (2008). Potent and selective antiplasmodial activity of the cyanobacterial alkaloid nostocarboline and its dimers. Bioorg. Med. Chem. Lett. 18, 4413-4415. doi: 10.1016/j.bmcl.2008.06.049 
Barchi, J. J., Moore, R. E., and Patterson, G. M. L. (1984). Acutiphycin and 20, 21-didehydroacutiphycin, new antineoplastic agents from the cyanophyte Oscillatoria acutissima. J. Am. Chem. Soc. 106, 8193-8197. doi: 10.1021/ja00338a031

Bartley, M. L., Boeing, W. J., Corcoran, A. A., Holguin, F. O., and Schaub, T. (2013). Effects of salinity on growth and lipid accumulation of biofuel microalga Nannochloropsis salina and invading organisms. Biomass Bioenerg. 54, 83-88. doi: 10.1016/j.biombioe.2013.03.026

Bedoux, G., Hardouin, K., Burlot, A. S., and Bourgougnon, N. (2014). "Bioactive components from seaweeds: cosmetic applications and future development," in Advances in Botanical Research, Sea Plants Book, Vol. 71, ed N. Bourgougnon (Amsterdam: Elsevier), 346-367.

Ben-Dor, A., Steiner, M., Gheber, L., Danilenko, M., Dubi, N., Linnewiel, K., et al. (2005). Carotenoids activate the antioxidant response element transcription system. Mol. Cancer Ther. 4, 177-186. Available online at: http:// mct.aacrjournals.org/content/4/1/177

Bennedsen, M., Wang, X., Willen, R., Wadstroem, T., and Andersen, L. P. (1999). Treatment of $H$. pylori infected mice with antioxidant astaxanthin reduces gastric inflammation, bacterial load and modulates cytokine release by splenocytes. Immunol. Lett. 70, 185-189. doi: 10.1016/S0165-2478(99)00145-5

Bentley, F. K., García-Cerdán, J. G., Chen, H. C., and Melis, A. (2013). Paradigm of monoterpene ( $\beta$-phellandrene) hydrocarbons production via photosynthesis in cyanobacteria. Bioenerg. Res. 6, 917-929. doi: 10.1007/s12155-013-9325-4

Berland, B. R., Bonin, D. J., Cornu, A. L., Maestrini, S. Y., and Marino, J. (1972). The antibacterial substances of the marine alga Stichochrysis immobilis (Chrysophyta). J. Phycol. 8, 383-392.

Bernardo, P. H., Chai, C. L., Le Guen, M., Smith, G. D., and Waring, P. (2007). Structure-activity delineation of quinones related to the biologically active calothrixin B. Bioorg. Med. Chem. Lett. 17, 82-85. doi: 10.1016/j.bmcl.2006.09.090

Berry, J. P., Gantar, M., Perez, M. H., Berry, G., and Noriega, F. G. (2008). Cyanobacterial toxins as allelochemicals with potential applications as algaecides, herbicides and insecticides. Mar. Drugs 6, 117-146. doi: $10.3390 / \mathrm{md} 6020117$

Bewley, C. A., Cai, M., Ray, S., Ghirlando, R., Yamaguchi, M., and Muramoto, K. (2004). New carbohydrate specificity and HIV-1 fusion blocking activity of the cyanobacterial protein MVL: NMR, ITC and sedimentation equilibrium studies. J. Mol. Biol. 339, 901-914. doi: 10.1016/j.jmb.2004. 04.019

Bewley, C. A., Gustafson, K. R., Boyd, M. R., Covell, D. G., Bax, A., Clore, G. M., et al. (1998). Solution structure of cyanovirin-N, a potent HIV-inactivating protein. Nat. Struct. Biol. 5, 571-578. doi: 10.1038/828

Bhadury, P., and Wright, P. C. (2004). Exploitation of marine algae: biogenic compounds for potential antifouling applications. Planta 219, 561-578. doi: 10.1007/s00425-004-1307-5

Bhatia, S., Garg, A., Sharma, K., Kumar, S., Sharma, A., and Purohit, A. P. (2011). Mycosporine and mycosporine-like amino acids: a paramount tool against ultra violet irradiation. Pharmacogn. Rev. 10, 138-146. doi: 10.4103/0973-7847.91107

Biondi, N., Piccardi, R., Margheri, M. C., Rodol, F. L., Smith, G. D., and Tredici, M. R. (2004). Evaluation of Nostoc strain ATCC 53789 as a potential source of natural pesticides. Appl. Environ. Microbiol. 70, 3313-3320. doi: 10.1128/AEM.70.6.3313-3320.2004

Bishop, W. M., and Zubeck, H. M. (2012). Evaluation of microalgae for use as nutraceuticals and nutritional supplements. J. Nutr. Food Sci. 2:147. doi: $10.4172 / 2155-9600.1000147$

Blanco-Pascual, N., Gómez-Guillén, M. C., and Montero, M. P. (2014). Integral Mastocarpus stellatus use for antioxidant edible film development. Food Hydrocolloids 40, 128-137. doi: 10.1016/j.foodhyd.2014.02.013

Blunt, J. W., Copp, B. R., Hu, W. P., Munro, M. H. G., Northcote, P. T., and Prinsep, M. R. (2009). Marine natural products. Nat. Prod. Rep. 26, 170-244. doi: 10.1039/b805113p

Böhm, G. A., Pfleiderer, W., Böger, P., and Scherer, S. (1995). Structure of a novel oligosaccharide-mycosporine-amino acid ultraviolet A/B sunscreen pigment from the terrestrial cyanobacterium Nostoc commune. J. Biol. Chem. 270, 8536-8539. doi: 10.1074/jbc.270.15.8536

Bokesch, H. R., O’Keefe, B. R., McKee, T. C., Pannell, L. K., Patterson, G. M., Gardella, R. S., et al. (2003). A potent novel anti HIV protein from the cultured cyanobacterium Scytonema varium. Biochemistry 42, 2578-2584. doi: 10.1021/bi0205698

Bolin, A. P., Macedo, R. C., Marin, D. P., Barros, M. P., and Otton, R. (2010). Astaxanthin prevents in vitro auto-oxidative injury in human lymphocytes. Cell Biol. Toxicol. 26, 457-467. doi: 10.1007/s10565-010-9156-4

Bonjouklian, R., Smitka, T. A., Doolin, L. E., Molloy, R. M., Debono, M., and Shaffer, S. A. (1991). Tjipanazoles, new antifungal agents from the blue-green alga Tolypothrix tjipanasensis. Tetrahedron 47, 7739-7750. doi: 10.1016/S0040-4020(01)81932-3

Borowitzka, M. A. (1988). "Vitamins and fine chemicals from micro-algae," in Micro-Algal Biotechnology, eds M. A. Borowitzka and L. J. Borowitzka (Cambridge: Cambridge University Press), 153-196.

Boudière, L., Michaud, M., Petroutsos, D., Rébeillé, F., Falconet, D., Bastien, O., et al. (2014). Glycerolipids in photosynthesis: composition, synthesis and trafficking. Biochim. Biophys. Acta 1837, 470-480. doi: 10.1016/j.bbabio.2013.09.007

Boyer, G. L., and Dougherty, S. S. (1988). Identification of abscisic acid in the seaweed Ascophyllum nodosum. Phytochemistry 27, 1521-1522. doi: 10.1016/0031-9422(88)80228-0

Bramley, P. M., and Mackenzie, A. (1988). "Regulation of carotenoid biosynthesis," in Current Topics in Cellular Regulation, 29th Edn., eds B. L. Horecker and E. R. Stadiman (Cambridge, MA: Academic Press), 291-343.

Brenowitz, S., and Castenholz, W. R. (1997). Long-term effects of UV and visible irradiance on natural populations of a scytonemin-containing cyanobacterium (Calothrix sp.). FEMS Microbiol. Ecol. 24, 343-352. doi: 10.1111/j.1574-6941.1997.tb00451.x

Brunner, E. (2006). Oily fish and omega 3 fat supplements. BMJ 332, 739-740. doi: 10.1136/bmj.38798.680185.47

Bui, H. T., Jansen, R., Pham, H. T., and Mundt, S. (2007). Carbamidocyclophanes, A.-E., chlorinated paracyclophanes with cytotoxic and antibiotic activity from the vietnamese cyanobacterium Nostoc sp. J. Nat. Prod. 70, 499-503. doi: $10.1021 / \mathrm{np} 060324 \mathrm{~m}$

Bultel-Poncé, V., Felix-Theodose, F., Sarthou, C., Ponge, J.-F., and Bodo, B. (2004). New pigments from the terrestrial cyanobacterium Scytonema sp. Collected on the Mitaraka inselberg, French Guyana. J. Nat. Prod. 67, 678-681. doi: $10.1021 / \mathrm{np} 034031 \mathrm{u}$

Burja, A. M., Banaigs, B., Abou-Mansour, E., Burgess, J. G., and Wright, P. C. (2001). Marine cyanobacteria-a prolific source of natural products. Tetrahedron 57, 9347-9377. doi: 10.1016/S0040-4020(01)00931-0

Bury, N. R., Codd, G. A., Wendelaar Bonga, S. E., and Flik, G. (1998). Fatty acids from the cyanobacterium Microcystis aeruginosa with potent inhibitory effects of fish gill $\mathrm{Na}+/ \mathrm{K}+$-ATPase activity. J. Exp. Biol. 201, 81-89.

Butler, A., and Carter-Franklin, J. N. (2004). The role of vanadium bromoperoxidase in the biosynthesis of halogenated marine natural products. Nat. Prod. Rep. 21, 180-188. doi: 10.1039/b302337k

Cabrita, M. T., Vale, C., and Rauter, A. P. (2010). Halogenated compounds from marine algae. Mar. Drugs 8, 2301-2307. doi: 10.3390/md8082301

Calder, P. C. (1996). Sir david cuthbertson medal lecture. Immunomodulatory and anti-inflammatory effects of n-3 polyunsaturated fatty acids. Proc. Nutr. Soc. 55, 737-774. doi: 10.1079/PNS19960069

Camera, S. L., Gouzerh, G., Dhondt, S., Hoffman, L., Frittig, B., Legrand, M., et al. (2004). Metabolic reprogramming in plant innate immunity: the contributions of phenylpropanoid and oxylipin pathways. Immunol. Rev. 198, 267-284. doi: 10.1111/j.0105-2896.2004.0129.x

Campbell, J., Stevens, S. E. J., and Balkwill, D. L. (1982). Accumulation of poly-bhydroxybutyrate in Spirulina platensis. J. Bacteriol. 149, 361-363.

Cardllina, J. H., Moore, R. E., Arnold, E. V., and Clardy, J. (1979). Structure and absolute configuration of Malyngolide, an antibiotic from the marine blue-green alga Lyngbya rnajuscula Gomont. J. Org. Chem. 44, 4039-4042. doi: 10.1021/jo01337a003

Cardozo, K. H., Guaratini, T., Barros, M. P., Falcão, V. R., Tonon, A. P., Lopes, N. P., et al. (2007). Metabolites from algae with economical impact. Comp. Biochem. Phys. C 146, 60-78. doi: 10.1016/j.cbpc.2006.05.007

Carmeli, S., Moore, R. E., and Patterson, G. M. (1990). Tolytoxin and new scytophycins from three species of Scytonema. J. Nat. Prod. 53, 1533-1542.

Carreto, J. I., and Carignan, M. O. (2011). Mycosporine-like amino acids: relevant secondary metabolites. chemical and ecological aspects. Mar. Drugs 9, 387-446. doi: $10.3390 / \mathrm{md} 9030387$ 
Carreto, J. I., Lutz, V. A., De Marco, S. G., and Carignan, M. O. (1990). "Fluence and wavelength dependence of mycosporine-like amino acid synthesis in the dinoflagellate Alexandrium excavatum," in Toxic Marine Phytoplankton, eds E. Graneli, L. Edler, and D. M. Anderson (New York, NY: Elsevier), 275-279.

Catassi, A., Cesario, A., Arzani, D., Menichinif, P., Alama, A., Bruzzo, C., et al. (2006). Characterization of apoptosis induced by marine naturalproducts in non small cell lung cancer A549 cells. Cell. Mol. Life Sci. 63, 2377-2386. doi: 10.1007/s00018-006-6264-7

Cazenave, J., Wunderlin, D. A., de Los Angeles Bistoni, M., Ame, M. V., Krause, E., Pflugmacher, S., et al. (2005). Uptake, tissue distribution and accumulation of microcystin-RR in Corydoras paleatus, Jenynsia multidentata and Odontesthes bonariensis: a field and laboratory study. Aquat. Toxicol. 75, 178-190. doi: 10.1016/j.aquatox.2005.08.002

Chaganty, S., Golakoti, T., Heltzel, C., Moore, R. E., and Yoshida, W. Y. (2004). Isolation and structure determination of cryptophycins 38, 326, and 327 from the terrestrial cyanobacterium Nostoc sp. GSV 224. J. Nat. Prod. 67, 1403-1406. doi: $10.1021 / \mathrm{np} 0499665$

Chang, T. T., More, S. V., Lu, I. H., Hsu, J. C., Chen, T. J., Jen, Y. C., et al. (2011). Isomalyngamide, A., A-1 and their analogs suppress cancer cell migration in vitro. Eur. J. Med. Chem. 46, 3810-3819. doi: 10.1016/j.ejmech.2011.05.049

Chaudhary, L., Pradhan, P., Soni, N., Singh, P., and Tiwari, A. (2014). Algae as a feedstock for bioethanol production: new entrance in biofuel world. Int. J. Chem. Tech. Res. 6, 1381-1389. Available online at: http://sphinxsai.com/2014/ CTVOL6/CT=62(1381-1389)AJ14.pdf

Chauhan, J., and Kasture, A. (2014). Antimicrobial compounds of marine algae from Indian coast. Int. J. Curr. Microbiol. Appl. Sci. 7, 526-532. doi: $10.1016 /$ j.sjbs.2013.06.001

Chen, Y. H., Tu, C. J., and Wu, H. T. (2004). Growth-inhibitory effects of the red alga Gelidium amansii on cultured cells. Biol. Pharm. Bull. 27, 180-184. doi: $10.1248 / \mathrm{bpb} .27 .180$

Chirasuwan, N., Chaiklahan, R., Ruengjitchatchawalya, M., Bunnag, B., and Tanticharoen, M. (2007). Anti HSV-1 activity of Spirulina platensis polysaccharide. Kasetsart J. Nat. Sci. 41, 311-318. Available online at: http:// kasetsartjournal.ku.ac.th/kuj_files/2008/A0804171221077799.pdf

Chisti, Y. (2007). Biodiesel from microalgae. Biotechnol. Adv. 25, 294-306. doi: 10.1016/j.biotechadv.2007.02.001

Choi, H., Pereira, A. R., Cao, Z., Shuman, C. F., Engene, N., Byrum, T., et al. (2010). The hoiamides, structurally intriguing neurotoxic lipopeptides from Papua New Guinea marine cyanobacteria. J. Nat. Prod. 73, 1411-1421. doi: $10.1021 / \mathrm{np} 100468 \mathrm{n}$

Chowdary, K. P. R., and Rao, Y. S. (2004). Mucoadhesive microspheres for controlled drug delivery. Biol. Pharm. Bull. 27, 1717-1724. doi: $10.1248 / \mathrm{bpb} .27 .1717$

Chu, W. L. (2012). Biotechnological applications of microalgae. IeJSME 6, S24-S37. Available online at: net/publication/283992977_Biotechnological_applications_of_microalgae

Coba, F. D. L., Aguilera, J., Figueroa, F. L., Galvez, M. V. D., and Herrera, E. (2009). Antioxidant activity of mycosporine-like amino acids isolated from three red macroalgae and one marine lichen. J. Appl. Phycol. 21, 161-169. doi: $10.1007 /$ s10811-008-9345-1

Cockell, C. S., and Knowland, J. (1999). Ultraviolet radiation screening compounds. Biol. Rev. 74, 311-345. doi: 10.1017/S0006323199005356

Codd, G. A., Morrison, L. F., and Metcalf, J. S. (2005). Cyanobacterial toxins: risk management for health protection. Toxicol. Appl. Pharmacol. 203, 264-272. doi: $10.1016 /$ j.taap.2004.02.016

Cohen, Z. (1999). Chemicals from Microalgae. Boca Raton, FL: CRC Press.

Coleman, R. A., Ramchunder, S. J., Moody, A. J., and Foogo, A. (2007). An enzyme in snail saliva induces herbivore-resistance in a marine alga. Funct. Ecol. 21, 101-106. doi: 10.1111/j.1365-2435.2006.01210.x

Colla, L. M., Reinehr, C. O., Reichert, C., and Costa, J. A. (2007). Production of biomass and nutraceutical compounds by Spirulina platensis under different temperature and nitrogen regimes. Bioresour. Technol. 98, 1489-1493. doi: 10.1016/j.biortech.2005.09.030

Conde, F. R., Churio, M. S., and Previtali, C. M. (2000). The photoprotector mechanism of mycosporine-like amino acids. Excited-state properties and photostability of Porphyra-334 in aqueous solution. J. Photochem. Photobiol. B Biol. 56, 139-144. doi: 10.1016/S1011-1344(00)00066-X
Connan, S., and Stengel, D. B. (2011). Impacts of ambient salinity and copper on brown algae: 2. interactive effects on phenolic pool and assessment of metal binding capacity of phlorotannin. Aquat. Toxicol. 14, 1-13. doi: 10.1016/j.aquatox.2011.03.016

Cvejic, J. H., and Rohmer, M. (2000). $\mathrm{CO}_{2}$ as main carbon source for isoprenoid biosynthesis via the mevalonate-independent methylerythritol 4-phosphate route in the marine diatoms Phaeodactylum tricornutum and Nitzschia ovalis. Phytochemistry 53, 21-28. doi: 10.1016/S0031-9422(99)00465-3

D’Agostino, G., Del Campo, J., Mellado, B., Izquierdo, M. A., Minarik, T., Cirri, L., et al. (2006). A Multicenter phase ii study of the cryptophycin analog LY355703 in patients with platinum-resistant ovarian cancer. Int. J. Gynecol. Cancer 16, 71-76. doi: 10.1111/j.1525-1438.2006.00276.x

da Costa, E., Silva, J., Mendonça, H. S., Abreu, M. H., and Domingues, M. R. (2016). Lipidomic approaches towards deciphering glycolipids from microalgae as a reservoir of bioactive lipids. Mar. Drugs 14:101. doi: 10.3390/md14050101

Dahms, H. U., Xu, Y., and Pfeiffer, C. (2006). Antifouling potential of cyanobacteria: a mini-review. Biofouling 22, 317-327. doi: 10.1080/08927010600967261

Damude, H. G., and Kinney, A. J. (2008). Enhancing plant seed oils for human nutrition. Plant Physiol. 147, 962-968. doi: 10.1104/pp.108.121681

Daniel, S., Cornelia, S., and Fred, Z. (2004). UV-A sunscreen from red algae for protection against premature skin aging. Cosmet. Toiletries Manufacture Worldw. 139-143. Available online at: https://mibellebiochemistry.com/app/ uploads/2015/03/Helioguard-365_UV-A-sunscreen-from-red-algae-forprotection-against-premature-skin-aging_CT-2004.pdf

David Nes, W. (2011). Biosynthesis of cholesterol and other sterols. Chem. Rev. 111, 6423-6451. doi: 10.1021/cr200021m

Davies-Coleman, M., Dzeha, T. M., Gray, C. A., Hess, S., Pannell, L. K., and Hendricks, D. T. (2003). Isolation of homodolastatin 16, a new cyclic depsipeptide from a Kenyan collection of Lyngbya majuscula. J. Nat. Prod. 66, 712-715. doi: 10.1021/np030014t

de Carvalho, C. C. and da Fonseca, M. M. (2006). Biotransformation of terpenes. Biotechnol. Adv. 24, 134-142. doi: 10.1016/j.biotechadv.2005.08.004

de Jesus Raposo, M. F., de Morais, A. M., and de Morais, R. M. (2015). Marine polysaccharides from algae with potential biomedical applications. Mar. Drugs 13, 2967-3028. doi: 10.3390/md13052967

De la Coba, F., Aguilera, J., and Figueroa, F. L. (2007). Use of Mycosporine Type Amino Acid Porphyra-334 as an Antioxidant. Intl Patent WO 2007/026035 A2.

Delattre, C., Fenoradosoa, A., and Michaud, P. (2011). Galactans: an overview of their most important sourcing and applications as natural polysaccharides. Braz. Arch. Biol. 54, 1075-1092. doi: 10.1590/S1516-89132011000600002

Delattre, C., Laroche, C., and Michaud, P. (2009). "Bacterial and fungal polysaccharides produced by fermentation-an overview," in Advances in Fermentation Technology, eds A. Pandey, C. Larroche, R. S. Soccol, and C. G. Dussap (New Delhi: Asiatech Publisher, Inc.), 484-521.

Delattre, C., Pierre, G., Laroche, C., and Michaud, P. (2016). Production, extraction and characterization of microalgal and cyanobacterialexopolysaccharides. Biotechnol. Adv. 34, 1159-1179 doi: 10.1016/j.biotechadv.2016.08.001

Dembitsky, M. V., and Tolstikov, G. A. (2003). Natural halogenated alkanes, cycloalkanes and their derivatives. Chem. Sustain. Dev. 11, 803-810. Available online at: http://www.medicinacomplementar.com.br/biblioteca/pdfs/Cancer/ ca-4063.pdf

Demirbas, A. (2001). Biomass resource facilities and biomass conversion processing for fuels and chemicals. Ener. Convers. Manag. 42, 1357-1378. doi: 10.1016/S0196-8904(00)00137-0

Deo, S. K., Pandey, R., Jha, S. K., Singh, J., and Sodhi, K. S. (2014). Spirulina: the single cell protein. Indo Am. J. Pharm. Res. 4, 221-2217.

De Souza, N. J., and Nes, W. R. (1968). Sterols: isolation from a Blue-Green Alga. Science 162:363. doi: 10.1126/science.162.3851.363

Devic, E., Li, D. H., Dauta, A., Henriksen, P., Codd, G. A., Marty, J. L., et al. (2002). Detection of anatoxin-a(s) in environmental samples of cyanobacteria by using a biosensor with engineered acetylcholinesterases. Appl. Environ. Microbiol. 68, 4102-4106. doi: 10.1128/AEM.68.8.4102-4106.2002

Dey, B., Lerner, D. L., Lusso, P., Boyd, M. R., Elder, J. H., and Berger, E. A. (2000). Multiple antiviral activities of cyanovirin-N: blocking of human immunodeficiency virus type 1 gp120 interaction with CD4 and coreceptor and inhibition of diverse enveloped viruses. J. Virol. 74, 4562-4569. doi: 10.1128/JVI.74.10.4562-4569.2000 
Diffey, B. L. (2009). Sunscreens as a preventative measure in melanoma: an evidence-based approach or the precautionary principle? Br. J. Dermatol. 161, 25-27. doi: 10.1111/j.1365-2133.2009.09445.x

Dillon, J. G., and Castenholz, R. W. (1999). Scytonemin, a cyanobacterial sheath pigment, protects against UVC radiation: implications for early photosynthetic life. J. Phycol. 35, 673-681. doi: 10.1046/j.1529-8817.1999.3540673.x

Dittmann, E., and Wiegand, C. (2006). Cyanobacterial toxins-occurrence, biosynthesis and impact on human affairs. Mol. Nutr. Food Res. 50, 7-17. doi: $10.1002 / \mathrm{mnfr} .200500162$

Doi, Y. (1990). Microbial Polyesters. New York, NY: Wiley.

Dragone, G., Fernandes, B., Vicente, A. A., and Teixeira, J. A. (2010). "Third generation biofuels from microalgae," in Current Research, Technology and Education Topics in Applied Microbiology and Microbial Biotechnology, ed A. Mendez-Vilas (Badajoz: Formatex), 1355-1366.

Dufosse, L., Galaup, P., Yaron, A., Arad, S. M., Blanc, P., Murthy, K. N. C., et al. (2005). Microorganisms and microalgae as sources of pigments for food use: a scientific oddity or an industrial reality? Trends Food Sci. Technol. 16, 389-409. doi: 10.1016/j.tifs.2005.02.006

Dunlap, W. C., Chalker, B. E., Bandaranayake, W. M., and Wu Won, J., J. (1998). Nature's sunscreen from the Great Barrier Reef, Australia. J. Cosmet. Sci. 20, 41-51. doi: 10.1046/j.1467-2494.1998.171734.x

Dyerberg, J., Leaf, A., and GA C. (1995). ISSFAL board statement: recommendations for the essential fatty previous termacidnext term requirement for infant formulas. J. Am. Coll. Nutr. 14:2.

Edelman, M. J., Gandara, D. R., Hausner, P., Israel, V., Thornton, D., DeSanto, J., et al. (2003). Phase 2 study of cryptophycin 52 (LY355703) in patients previously treated with platinum based chemotherapy for advanced non-small cell lung cancer. Lung Cancer 39, 197-199. doi: 10.1016/S0169-5002(02)00511-1

Edwards, D. J., Marquez, B. L., Nogle, L. M., McPhail, K., Goeger, D. E., Roberts, M. A., et al. (2004). Structure and biosynthesis of the jamaicamides, new mixed polyketide-peptide neurotoxins from the marine cyanobacterium Lyngbya majuscula. Chem. Biol. 11, 817-833. doi: 10.1016/j.chembiol.2004.03.030

El-Baz, F. K., El-Senousy, W. M., El-Sayed, A. B., and Kamel, M. M. (2013). In vitro antiviral and antimicrobial activities of Spirulina platensis extract. J. Appl. Pharm. Sci. 3, 052-056. doi: 10.7324/JAPS.2013.31209

Engene, N., Choi, H., Esquenazi, E., Byrum, T., Villa, F. A., Cao, Z., et al. (2011). Phylogeny-guided isolation of ethyl tumonoate a from the marine Cyanobacterium cf. Oscillatoria margaritifera. J. Nat. Prod. 74, 1737-1743. doi: $10.1021 / \mathrm{np} 200236 \mathrm{c}$

Fábregas, J., García, D., Fernandez-Alonso, M., Rocha, A. I., Gómez-Puertas, P., Escribano, J. M., et al. (1999). In vitro inhibition of the replication of haemorrhagic septicaemia virus (VHSV) and African swine fever virus (ASFV) by extracts from marine microalgae. Antivir. Res. 44, 67-73. doi: 10.1016/S0166-3542(99)00049-2

Fabris, M., Matthijs, M., Carbonelle, S., Moses, T., Pollier, J., Dasseville, R., et al. (2014). Tracking the sterol biosynthesis pathway of the diatom Phaeodactylum tricornutum. New Phytol. 204, 521-535. doi: 10.1111/nph.12917

Falch, B. S., Konig, G. M., Wright, A. D., Sticher, O., Ruegger, H., and Bernardinelli, G. (1993). Ambigol A and B: new biologically active polychlorinated aromatic compounds from the terrestrial blue-green alga Fischerella ambigua. J. Org. Chem. 58, 6570-6575. doi: 10.1021/jo00076a013

Faltermann, S., Zucchi, S., Kohler E Blom, J. F., Pernthaler, J., and Fent, K. (2014). Molecular effects of the cyanobacterial toxin cyanopeptolin (CP1020) occurring in algal blooms: global transcriptome analysis in zebrafish embryos. Aqua. Toxicol. 149, 33-39. doi: 10.1016/j.aquatox.2014.01.018

Favre-Bonvin, J., Bernillon, J., Salin, N., and Arpin, N. (1987). Biosynthesis of mycosporines: mycosporine glutaminol in Trichothecium roseum. Phytochemistry 26, 2509-2514. doi: 10.1016/S0031-9422(00)83866-2

Fennell, B. J., Carolan, S., Pettit, G. R., and Bell, A. (2003). Effects of the antimitotic natural product dolastatin 10 , and related peptides, on the human malarial parasite Plasmodium falciparum. J. Antimicrob. Chemother. 51, 833-841. doi: $10.1093 / \mathrm{jac} / \mathrm{dkg} 151$

Fergusson, K. M., and Saint, C. P. (2000). Molecular phylogeny of Anabaena circinalis and its identification in environmental samples by PCR. Appl. Environ. Microbiol. 66, 4145-4148. doi: 10.1128/AEM.66.9.4145-41 48.2000
Ferrari, P. F., Palmieri, D., Casazza, A. A., Aliakbarian, B., Perego, P., and Palombo, D. (2015). TNF a-induced endothelial activation is counteracted by polyphenol extract from UV-stressed cyanobacterium Arthrospira platensis. Med. Chem. Res. 24, 275-282. doi: 10.1007/s00044-014-1126-6

Ferroni, L., Klisch, M., Pancaldi, S., and Häder, D. P. (2010). Complementary UVabsorption of mycosporine-like amino acids and scytonemin is responsible for the UV-insensitivity of photosynthesis in Nostoc flagelliforme. Mar Drugs 8, 106-121. doi: 10.3390/md8010106

Findlay, J. A., and Patil, A. D. (1984). Antibacterial constituents of the diatom Navicula delognei. J. Nat. Prod. 47, 815-818. doi: 10.1021/np50035a010

Fischer, N. H. (1991). "Plant terpenoids as allelopathic agents," in Ecological Chemistry and Biochemistry of Plant Terpenoids, eds J. B. Harbourne and F. A. Tomas-Barberan (Oxford: Clarendon Press), 377.

Forin, M. C., Maume, B., and Baron, C. (1972). Sterols and triterpene alcohols of a Cyanophyceae: Spirulina platensis Geitler. C. R. Acad. Sci. Hebd. Seances. Acad. Sci. D 274, 133-136.

Frankmölle, W. P., Knübel, G., Moore, R. E., and Patterson, G. M. L. (1992). Antifungal cyclic peptides from the terrestrial blue green agla Anabaena laxa. II. Structures of laxaphycins A,B,D and E. J. Antibiot. 45, 1458-1466. doi: 10.7164/antibiotics.45.1458

Frentzen, M., Heinz, E., McKeon, T. A., and Stumpf, P. K. (1983). Specificities and selectivities of glycerol-3-phosphate acyltransferase and monoacylglycerol-3phosphate acyltransferase from pea and spinach chloroplasts. Eur. J. Biochem. 129, 629-636. doi: 10.1111/j.1432-1033.1983.tb07096.x

Froehlich, J. E., Poorman, R., Reardon, E., Barnum, S. R., and Jaworski, J. G. (1990). Purification and characterization of acyl carrier protein from two cyanobacteria species. Eur. J. Biochem. 193, 817-825. doi: 10.1111/j.1432-1033.1990.tb19405.x

Fujiki, H., Sugimura, T., and Moore, R. E. (1982). New classes of environmental tumor promoters: indole alkaloids and polyacetates. Environ. Health Perspect. 50, 85-90. doi: 10.1289/ehp.835085

Funk, C. D. (2001). Prostaglandins and leukotrienes: advances in eicosanoids biology. Science 294, 1871-1875. doi: 10.1126/science.294.5548.1871

Furukawa, Y., Moriuchi, T., and Morishima, K. (2006). Design principle and prototyping of a direct photosynthetic/metabolic biofuel cell (DPMFC). J. Micromech. Microeng. 16, 220-225. doi: 10.1088/0960-1317/16/9/S08

Gacsi, M., Antal, O., Vasas, G., Mathe, C., Borbely, G., Saker, M. L., et al. (2009). Comparative study of cyanotoxins affecting cytoskeletal and chromatin structures in CHO-K1 cells. Toxicol. In Vitro 23, 710-718. doi: 10.1016/j.tiv.2009.02.006

Gantar, M., Berry, J. P., Thomas, S., Wang, M., Perez, R., and Rein, K. (2008). Allelopathic activity among cyanobacteria and microalgae isolated from Florida freshwater habitats. FEMS Microbiol. Lett. 64, 55-64. doi: 10.1111/j.1574-6941.2008.00439.x

Gao, Q., and Garcia-Pichel, F. (2011). Microbial ultraviolet sunscreens. Nature Rev. Microbiol. 9, 791-802. doi: 10.1038/nrmicro2649

Garcia-Pichel, F., and Castenholz, R. W. (1991). Characterization and biological implications of scytonemin, a cyanobacterial sheath pigment. J. Phycol. 27, 395-409. doi: 10.1111/j.0022-3646.1991.00395.x

Garcia-Pichel, F., and Castenholz, R. W. (1993). Occurrence of UV-absorbing, mycosporine-like compounds among cyanobacterial isolates and an estimate of their screening capacity. Appl. Environ. Microbiol. 59, 163-169.

Garcia-Pichel, F., Sherry, N. D., and Castenholz, R. W. (1992). Evidence for an Ultraviolet sunscreen role of the extracellular pigment scytonemin in the terrestrial cyanobacterium Chiorogloeopsis sp. Photochem. Photobiol. 56, 17-23. doi: 10.1111/j.1751-1097.1992.tb09596.x

Gayathri, M., Kumar, P. S., Prabha, A. M. L., and Muralitharan, G. (2015). In vitro regeneration of Arachis hypogaea L., and Moringa oleifera Lam. using extracellular phytohormones from Aphanothece sp. MBDU 515. Algal Res. 7, 100-105. doi: 10.1016/j.algal.2014.12.009

Gershenzon, J., and Dudareva, N. (2007). The function of terpene natural products in the natural world. Nat. Chem. Biol. 3, 408-414. doi: $10.1038 /$ nchembio.2007.5

Gerwick, W. H., Mrozek, C., Moghaddam, M. F., and Agarwal, S. K. (1989). Novel cytotoxic peptides from the tropical marine cyanobacterium Hormothamnion enteromorphoides. Discovery, I., isolation and initial chemical and biological characterization of the hormothamnins from wild and cultured material. Experientia 45, 115-121. doi: 10.1007/BF01954842 
Gerwick, W. H., Roberts, M. A., Proteau, P. J., and Chen, J. L. (1994). Screening cultured marine microalgae for anticancer- type activity. J. Appl. Phycol. 6, 143-149. doi: 10.1007/BF02186068

Ghasemi, Y., Moradian, A., Mohagheghzadeh, A., Shokravi, S., and Morowvat, M. H. (2007). Antifungal and antibacterial activity of the microalgae collected from paddy fields of Iran: characterization of antimicrobial activity of Chlorococcus dispersus. J. Biol. Sci. 7, 904-910. doi: 10.3923/jbs.2007.904.910

Ghasemi, Y., Yazdi, M. T., Shafiee, A., Amini, M., Shokravi, S., and Zarrini, G. (2004). Parsiguine, a novel antimicrobial substance from Fischerella ambigua. Pharm. Biol. 42, 318-322. doi: 10.1080/13880200490511918

Gómez, I., Español, S., Véliz, K., and Huovinen, P. (2016). Spatial distribution of phlorotannins and its relationship with photosynthetic UV tolerance and allocation of storage carbohydrates in blades of the kelp Lessonia spicata. Mar. Biol. 163:110. doi: 10.1007/s00227-016-2891-1

Goncalves, A. G., Ducatti, D. R., Duarte, M. E., and Noseada, M. D. (2002). Sulfated and pyruvylated disaccharide alditols obtained from a red seaweed galactan: ESIMS and NMR approaches. Carbohydr. Res. 337, 2443-2453. doi: 10.1016/S0008-6215(02)00318-X

Gouda, S., Moharana, R. R., Das, G., and Patra, J. K. (2013). Free radical scavenging potential of extracts of Gracilaria verrucosa (L) (Harvey): an economically important seaweed from Chilika lake, India. Int. J. Pharm. Pharm. Sci. 6, 707-710. Available online at: http://www.ijppsjournal.com/Vol6Issue1/8348. pdf

Goulart, H. R., Kimura, E. A., Peres, V. J., Couto, A. S., Duarte, F. A. A., and Katzin, A. M. (2004). Terpenes arrest parasite development and inhibit biosynthesis of isoprenoids in Plasmodium falciparum. Antimicrob. Agents Chemother. 48, 2502-2509. doi: 10.1128/AAC.48.7.2502-2509.2004

Grant, C. S., and Louda, J. W. (2013). Scytonemin-imine, a mahogany-colored $\mathrm{UV} / \mathrm{Vis}$ sunscreen of cyanobacteria exposed to intense solar radiation. Org. Geochem. 65, 29-36. doi: 10.1016/j.orggeochem.2013.09.014

Griffiths, M. J., van Hille, R. P., and Harrison, S. T. L. (2012). Lipid productivity, settling potential and fatty acid profile of 11 microalgal species grown under nitrogen replete and limited conditions. J. Appl. Phycol. 24, 989-1001. doi: 10.1007/s10811-011-9723-y

Gromov, B. V., Vepritskii, A. A., Titota, N. N., Mamkayeva, K. A., and Alexandrova, O. V. (1991). Production of the antibiotic cyanobacterin LU-1 by Nostoc linckia CALU 892. J. Appl. Phycol. 3, 55-59. doi: 10.1007/BF00003919

Groniger, A., and Hader, D. P. (2000). Stability of mycosporine-like amino acids. Rec. Res. Dev. Photochem. Photobiol. 4, 247-252. Available online at: net/ publication/266383268_Stability_of_mycosporine-like_amino_acids

Guedes, A. C., Amaro, H. M., Barbosa, C. R., Pereira, R. D., and Malcata, F. X. (2011). Fatty acid composition of several wild microalgae and cyanobacteria, with a focus on eicosapentaenoic, docosahexaenoic and $\alpha$ linolenic acids for eventual dietary uses. Food Res. Int. 44, 2721-2729. doi: 10.1016/j.foodres.2011.05.020

Guerin, M., Huntley, M. E., and Olaizola, M. (2003). Haematococcus astaxanthin: applications for human health and nutrition. Trends Biotechnol. 21, 210-216. doi: 10.1016/S0167-7799(03)00078-7

Guihéneuf, F., Khan, A., and Tran, L. S P. (2016). Genetic engineering: a promising tool to engender physiological, biochemical, and molecular stress resilience in green microalgae. Front. Plant Sci. 7:400. doi: 10.3389/fpls.2016.00400

Gunasekera, S. P., Ross, C., Paul, V. J., Matthew, S., and Luesch, H. (2008). Dragonamides C and D linear lipopeptides from the marine cyanobacterium brown Lyngbya polychroa. J. Nat. Prod. 71, 887-890. doi: 10.1021/np0706769

Gupta, A., and Agarwal, P. (1973). Extraction, isolation, and bioassay of a gibberellin-like substance from Phormidium foveolarum. Ann. Bot. 37, 737-741. doi: 10.1093/oxfordjournals.aob.a084742

Guschina, I. A., and Harwood, J. L. (2006). Lipids and lipid metabolism in eukaryotic algae. Prog. Lipid Res. 45, 160-186. doi: 10.1016/j.plipres.2006.01.001

Gustafson, K. R., Cardellina, J. H. II, Fuller, R. W., Weislow, O. S., Kiser, R. F., Snader, K. M., et al. (1989). AIDS-antiviral sulfolipids from cyanobacteria (blue-green algae). J. Natl. Cancer Inst. 81, 1254-1258. doi: 10.1093/jnci/81.16.1254

Gutierrez, M., Suyama, T. L., Engene, N., Wingerd, J. S., Matainaho, T., and Gerwick, W. H. (2008). Apratoxin D, a potent cytotoxic cyclodepsipeptide from Papua New Guinea collections of the marine cyanobacteria Lyngbya majuscula and Lyngbya sordida. J. Nat. Prod. 71, 1099-1103. doi: 10.1021/np800121a
Halpern, A. C., and Kopp, L. J. (2005). Awareness, knowledge and attitudes to nonmelanoma skin cancer and actinic keratosis among the general public. Int. J. Dermatol. 44, 107-111. doi: 10.1111/j.1365-4632.2005.02090.x

Hammingson, J. A., Furneuax, R. H., and Murray-Brown, H. V. (1996). Biosynthesis of agar polysaccharides in Gracilaria chilensis Bird, McLachlan et Oliveira. Carbohydr. Res. 287, 101-115. doi: 10.1016/0008-6215(96) 00057-2

Han, B., Goeger, D., Maier, C. S., and Gerwick, W. H. (2005). The wewakpeptins, cyclic depsipeptides from a Papua New Guinea collection of the marine cyanobacterium Lyngbya semiplena. J. Org. Chem. 70, 3133-3139. doi: $10.1021 /$ jo0478858

Han, B., Gross, H., Goeger, D. E., Mooberry, S. L., and Gerwick, W. H. (2006) Aurilides B and C cancer cell toxins from a Papua New Guinea collection of the marine cyanobacterium Lyngbya majuscule. J. Nat. Prod. 69, 572-575. doi: 10.1021/np0503911

Han, D., Bi, Y., and Hu, Z. (2004). "Industrial production of microalgal cell-mass and secondary products - species of high potential: Nostoc," in Handbook of Microalgal Culture: Biotechnology and Applied Phycology, ed A. Richmond (Oxford: Blackwell Science), 304-311.

Hansson, L. A., Gustafsson, S., Rengefors, K., and Bomark, L. (2007). Cyanobacterial chemical warfare affects zooplankton community composition. Freshw. Biol. 52, 1290-1301. doi: 10.1111/j.1365-2427.2007.01765.x

Harris, W. S., Kris-Etherton, P. M., and Harris, K. A. (2008). Intakes of long-chain omega-3 fatty acid associated with reduced risk for death from coronary heart disease in healthy adults. Curr. Atheroscler. Rep. 10, 503-509. doi: 10.1007/s11883-008-0078-z

Hartung, W. (2010). The evolution of abscisic acid (ABA) and ABA function in lower plants, fungi and lichen. Funct. Plant Biol. 37, 806-812. doi: 10.1071/FP10058

Harvey, B. G., Wright, M. E., and Quintana, R. L. (2010). High density renewable fuels based on the selective dimerization of pinenes. Ener. Fuel 24, 267-273. doi: 10.1021/ef900799c

Harwood, J. L., and Guschina, I. A. (2009). The versatility of algae and their lipid metabolism. Biochimie 91, 679-684. doi: 10.1016/j.biochi.2008.11.004

Hashtroudi, M. S., Ghassempour, A., Riahi, H., Shariatmadari, Z., and Khanjir, M. (2013). Endogenous auxin in plant growth promoting cyanobacteriaAnabaena vaginicola and Nostoc calcicola. J. Appl. Phycol. 25, 379-386. doi: 10.1007/s10811-012-9872-7

Hasui, M., Matsuda, M., Okutani, K., and Shigeta, S. (1995). In vitro antiviral activities of sulfated polysaccharides from a marine microalga (Cochlodinium polykrikoides) against human immunodeficiency virus and other enveloped viruses. Int. J. Biol. Macromol. 17, 293-297. doi: 10.1016/0141-8130(95) 98157-T

Hayashi, K., Hayashi, T., and Kojima, I., (1996). A natural sulfated polysaccharide, calcium spirulan, isolated from Spirulina platensis: in vitro and ex vivo evaluation of anti-herpes simplex virus and anti-human immunodeficiency virus activities. AIDS Res. Hum. Retroviruses 12, 1463-1471. doi: 10.1089/aid.1996.12.1463

Hayashi, K., Kanekiyo, K., Ohta, Y., Lee, J. B., Takenaka, H., and Hayashi, T. (2008). Anti influenza A virus activity of an acidic polysaccharide from a blue green alga Nostocflagelliforme. Planta Med. 74:PA34. doi: 10.1055/s-0028-10 84032

He, H., Rodgers, R. P., Marshall, A. G., and Hsu, C. S. (2011). Algae polar lipids characterized by online liquid chromatography coupled with hybrid linear quadrupole ion trap/fourier transform ion cyclotron resonance mass spectrometry. Ener. Fuels 25, 4770-4775. doi: 10.1021/ef201061j

Helbling, E. W., Menchi, C. F., and Villafanae, V. E. (2002). Bioaccumulation and role of UV-absorbing compounds in two marine crustacean species from Patagonia, Argentina. Photochem. Photobiol. Sci. 1, 820-825. doi: 10.1039/B206584C

Hellier, P., Al-Haj, L., Talibi, M., Purton, S., and Ladommatos, N. (2013). Combustion and emissions characterization of terpenes with a view to their biological production in cyanobacteria. Fuel 111, 670-688. doi: 10.1016/j.fuel.2013.04.042

Hemscheidt, T., Puglisi, M. P., Larsen, L. K., Patterson, G. M. L., Moore, R. E., Rios, J. L., et al. (1994). Structure and biosynthesis of Borophycin, a new boeseken complex of boric acid from a marine strain of the blue-green alga Nostoc linckia. J. Org. Chem. 59, 3467-3471. doi: 10.1021/jo00091a042 
Hibbeln, J. R., and Salem, N. (1995). Dietary polyunsaturated fatty acids and depression: when cholesterol does not satisfy. Am. J. Clin. Nutr. 62, 1-9.

Higuera-Ciapara, I., Félix-Valenzuela, L., and Goycoolea, F. M. (2006). Astaxanthin: a review of its chemistry and applications. Crit. Rev. Food Sci. Nutr. 46, 185-196. doi: 10.1080/10408690590957188

Hill, D. R., Hladun, S. L., Scherer, S., and Potts, M. (1994). Water stress proteins of Nostoc commune (Cyanobacteria) are secreted with UV-A/B-absorbing pigments and associate with 1,4- $\beta$-D-xylanxylanohydrolase activity. J. Biol. Chem. 269, 7726-7734.

Hills, C., and Nakamura, H. (1978). Food from Sunlight. Boulder Creek, CA: World Hunger Research Publ.

Hirano, A., Ueda, R., Hirayama, S., and Ogushi, Y. (1997). $\mathrm{CO}_{2}$ fixation and ethanol production with microalgal photosynthesis and intracellular anaerobic fermentation. Energy 22, 137-142. doi: 10.1016/S0360-5442(96)00123-5

Hirata, K., Yoshitomi, S., Dwi, S., Iwabe, O., Mahakhant, A., Polchai, J., et al. (2003). Bioactivities of nostocine A produced by a freshwater cyanobacterium Nostoc spongiaforme TISTR 8169. J. Biosci. Bioeng. 95, 512-517. doi: 10.1016/S1389-1723(03)80053-1

Hirata, T., Tanaka, M., Ooike, M., Tsunomura, T., and Sakaguchi, M. (2000). Antioxidant activities of phycocyanobilin prepared from Spirulina platensis. J. Appl. Phycol. 12, 435-439. doi: 10.1023/A:1008175217194

Hirokawa, Y., Maki, Y., Tatsuke, T., and Hanai, T. (2016). Cyanobacterial production of 1,3-propanediol directly from carbon dioxide using a synthetic metabolic pathway. Metab. Eng. 34, 97-103. doi: 10.1016/j.ymben.2015.12.008

Hirsch, R., Hartung, W., and Gimmler, H. (1989). Abscisic acid content of algae under stress. Bot. Acta 102, 326-334. doi: 10.1111/j.1438-8677.1989.tb00113.x

Ho, S. H., Chen, C. Y., Lee, D. J., and Chang, J. S. (2010). Perspectives on microalgal $\mathrm{CO}_{2}$ emission mitigation systems-a review. Biotechnol. Adv. 29, 189-198. doi: 10.1016/j.biotechadv.2010.11.001

Ho, S. H., Huang, S. W., Chen, C. Y., Hasunuma, T., Kondo, A., and Chang, J. S. (2013). Bioethanol production using carbohydrate-rich microalgae biomass as feedstock. Bioresour. Technol. 135, 191-198. doi: 10.1016/j.biortech.2012.10.015

Ho, S. H., Ye, X., Hasunuma, T., Chang, J. S., and Kondo, A. (2014). Perspectives on engineering strategies for improving biofuel production from microalgae-a critical review. Biotechnol. Adv. 32, 1448-1459. doi: 10.1016/j.biotechadv.2014.09.002

Hodge, L., Salome, C. M., Peat, J. K., Haby, M. M., Xuan, W., and Woolcock, A. J. (1996). Consumption of oily fish and childhood asthma risk. Med. J. Aust. 164, $137-140$.

Hölzl, G., and Dörmann, P. (2007). Structure and function of glycoglycerolipids in plants and bacteria. Prog. Lipid Res. 46, 225-243. doi: 10.1016/j.plipres.2007.05.001

Horgen, F. D., Kazmierski, E. B., Westenburg, H. E., Yoshida, W. Y., and Schuer, P. J. (2002). Malevamide D: isolation and structure determination of an Isodolastat in $\mathrm{H}$ analogue from the marine cyanobacterium Symploca hydnoides. J. Nat. Prod. 65, 487-491. doi: 10.1021/np010560r

Horrocks, L. A., and Yeo, Y. K. (1999). Health benefits of docosahexaenoic acid (DHA). Pharmacol. Res. 40, 211-225. doi: 10.1006/phrs.1999.0495

Hossain, Z., Kurihara, H., Hosokawa, M., and Takahashi, K. (2005). Growth inhibition and induction of differentiation and apoptosis mediated by sodium butyrate in Caco-2 cells with algal glycolipids. In Vitro Cell Dev. Biol. Anim. 41, 154-159. doi: 10.1290/0409058.1

Hughes, C., Franklin, D. J., and Malin, G. (2011). Iodomethane production by two important marine cyanobacteria: Prochlorococcus marinus (CCMP 2389) and Synechococcus sp. (CCMP 2370). Mar. Chem. 125, 19-25. doi: 10.1016/j.marchem.2011.01.007

Humpage, A. R., Fenech, M., Thomas, P., and Falconer, I. R. (2000). Micronucleus induction and chromosome loss in transformed human white cells indicate clastogenic and aneugenic action of the cyanobacterial toxin, Cylindrospermopsin. Mutat. Res. Genet. Toxicol. Environ. Mutagen. 472, 155-161. doi: 10.1016/S1383-5718(00)00144-3

Huskens, D., Ferir, G., Vermeire, K., Kehr, J. C., Balzarini, J., Dittmann, E., et al. (2010). Microvirin, a novel alpha(1,2)-mannose-specific lectin isolated fromMicrocystis aeruginosa, has anti-HIV-1 activity comparable with that of cyanovirin-N but a much higher safety profile. J. Biol. Chem. 285, 24845-24854. doi: 10.1074/jbc.M110.128546
Hussain, A., and Hasnain, S. (2010). Phytostimulation and biofertilization in wheat by cyanobacteria. J. Ind. Microbiol. Biotechnol. 38, 85-92. doi: $10.1007 /$ s10295-010-0833-3

Hussain, A., and Hasnain, S. (2011). Comparative assessment of the efficacy of bacterial and cyanobacterial phytohormones in plant tissue culture. World J. Microbiol. Biotechnol. 28, 1459-1466. doi: 10.1007/s11274-0110947-4

Hussain, A., Hamayun, M., and Shah, S. T. (2013). Root colonization and phytostimulation by phytohormones producing entophytic Nostoc sp. AH-12. Curr. Microbiol. 67, 624-630. doi: 10.1007/s00284-013-0408-4

Hussain, A., Krischke, M., Roitsch, T., and Hasnain, S. (2010). Rapid determination of cytokinins and auxin in cyanobacteria. Curr. Microbiol. 61, 361-369. doi: $10.1007 /$ s00284-010-9620-7

Ibànez, E., and Cifuentes, A. (2013). Benefits of using algae as natural sources of functional ingredients. J. Sci. Food Agric. 93, 703-709. doi: 10.1002/jsfa.6023

Ishibashi, F., Park, S., Kusano, T., and Kuwano, K. (2005). Synthesis and algicidal activity of (+)-cyanobacterin and its stereoisomer. Biosci. Biotechnol. Biochem. 69, 331-396. doi: 10.1271/bbb.69.391

Ishibashi, M., Moore, R. E., Patterson, G. M. L., Xu, C., and Clardy, J. (1986). Scytophycins, cytotoxic and antimycotic agents from the cyanophyte Scytonema pseudohofmanni. J. Org. Chem. 51, 5300-5306. doi: $10.1021 /$ jo00376a 047

Isman, M. B. (2006). The role of botanical insecticides, deterrents and repellents in modern agriculture and an increasingly regulated world. Annu. Rev. Entomol. 51, 45-66. doi: 10.1146/annurev.ento.51.110104.151146

Jaki, B., Orjala, J., and Sticher, O. (1999). A novel extracellular diterpenoid with antibacterial activity from the cyanobacterium Nostoc Commune. J. Nat. Prod. 62, 502-503. doi: 10.1021/np980444x

Jaki, B., Zerbe, O., Heilmann, J., and Sticher, O. (2001). Two novel cyclic peptides with antifungal activity from the cyanobacterium Tolypothrixbyssoidea (EAWAG 195). J. Nat. Prod. 64, 154-158. doi: 10.1021/np000297e

Jea, J. Y., Park, P. J., Kim, E. K., Park, J. S., Yoon, H. D., Kim, K. R., et al. (2009). Antioxidant activity of enzymatic extracts from the brown seaweed Undaria pinnatifida by electron spin resonance spectroscopy. Food Sci. Technol. 42, 874-878. doi: 10.1016/j.lwt.2008.10.012

Jennings, R. (1969). Cytokinins as endogenous growth regulators in the algae Ecklonia (Phaeophyta) and Hypnea (Rhodophyta). Aust. J. Biol. Sci. 22, 621-628. doi: 10.1071/BI9690621

Jennings, R. C. (1968). Gibberellins as endogenous growth regulators in green and brown algae. Planta 80, 34-42. doi: 10.1007/BF00387187

Jepson, M. A., Clark, M. A., and Hirst, B. H. (2004). M cell targeting by lectins: a strategy for mucosal vaccination and drug delivery. Adv. Drug Deliv. Rev. 56, 511-525. doi: 10.1016/j.addr.2003.10.018

Jha, R. K., and Zi-rong, X. (2004). Biomedical compounds from marine organisms. Mar. Drugs 2, 123-146. doi: 10.3390/md203123

Jiao, G., Yu, G., Zhang, J., and Ewart, H. S. (2011). Chemical structures and bioactivities of sulfated polysaccharides from marine algae. Mar. Drugs 9, 196-223. doi: 10.3390/md9020196

Jiménez, J. I., and Scheuer, P. J. (2001). New lipopeptides from the caribbean cyanobacterium Lyngbya majuscula. J. Nat. Prod. 64, 200-203. doi: $10.1021 /$ np000462q

John, R. P., Anisha, G. S., Nampoothiri, K. M., and Pandey, A. (2011). Micro and macroalgal biomass: a renewable source for bioethanol. Bioresour. Technol. 102, 186-193. doi: 10.1016/j.biortech.2010.06.139

Ju, C., Van de Poel, B., Cooper, E. D., Thierer, J. H., Gibbons, T. R., Delwiche, C. H., et al. (2015). Conservation of ethylene as a plant hormone over 450 million years of evolution. Nat. Plants 1, 1-7. doi: 10.1038/nplants.2014.4

Jüttner, F. (2001). Liberation of 5,8,11,14,17-eicosapentaenoic acid and other polyunsaturated fatty acids from lipids as a grazer defense reaction in epilithic diatom biofilms. J. Phycol. 37, 744-755. doi: 10.1046/j.1529-8817.2001. 00130.x

Kaczmarzyk, D., and Fulda, M. (2010). Fatty acid activation in cyanobacteria mediated by acyl-acyl carrier protein synthetase enables fatty acid recycling. Plant Physiol. 152, 1598-1610. doi: 10.1104/pp.109.148007

Kaneko, S., and Tabata, T. (1997). Complete genome structure of the unicellular cyanobacterium Synechocystis sp. PCC6803. Plant Cell Physiol. 38, 1171-1176. doi: 10.1093/oxfordjournals.pcp.a029103 
Kannaujiya, V. K., Richa, and Sinha, R. P. (2014). Peroxide scavenging potential of ultraviolet-B-absorbing mycosporine-like amino acids isolated from a marine red alga Bryocladia sp. Front. Environ. Sci. 2:26. doi: 10.3389/fenvs.2014.00026

Karthikeyan, N., Prasanna, R., Nain, L., and Kaushik, B. D. (2007). Evaluating the potential of plant growth promoting cyanobacteria as inoculants for wheat. Eur. J. Soil Biol. 43, 23-30. doi: 10.1016/j.ejsobi.2006.11.001

Kaspar, S. M. (1994). Terpen-biosynthese in Ginkgo Biloba: Eine Überraschende Geschichte. Dissertation, Diss. Naturwiss. ETH Zürich. doi: 10.3929/ethz-a-001435803

Keeling, C. I., and Bohlmann, J. (2012). "Plant terpenoids," in Natural Products in Chemical Biology, 1st Edn., ed N. Civjan (New York, NY: Wiley), 121-142.

Kentzer, T., and Mazur, H. (1991). Abscisic acid as endogenous inhibitor of the marine diatom Coscinodiscus granii. Acta Physiol. Plant 13, 153-157.

Khan, Q. A., Lu, J., and Hecht, S. M. (2009). Calothrixins, a new classof human DNA topoisomerase I poisons. J. Nat. Prod. 72, 438-442. doi: $10.1021 / \mathrm{np} 8007232$

Kılınç, B., Koru, E., Turan, G., Tekogul, H., and Cirik, S. (2013). Seaweeds for Food and Industrial Applications. Rijeka: INTECH Open Access Publisher.

Kim, M. S., Baek, J. S., Yun, Y. S., Sim, S. J., Park, S., and Kim, S. C. (2006). Hydrogen production from Chlamydomonas reinhardtii biomass using a two-step conversion process: anaerobic conversion and photosynthetic fermentation. Int. J. Hydrogen Ener. 31, 812-816. doi: 10.1016/j.ijhydene.2005.06.009

Kim, S. K., Ravichandran, Y. D., Khan, S. B., and Kim, Y. T. (2008). Prospective of the cosmeceuticals derived from marine organisms. Biotechnol. Bioprocess. Eng. 13, 511-523. doi: 10.1007/s12257-008-0113-5

Kim, S., Yamaoka, Y., Ono, H., Kim, H., Shim, D., Maeshima, M., et al. (2013). AtABCA9 transporter supplies fatty acids for lipid synthesis to the endoplasmic reticulum. Proc. Natl. Acad. Sci. U.S.A. 110, 773-778. doi: 10.1073/pnas.1214159110

Kirby, J., and Keasling, J. D. (2009). Biosynthesis of plant isoprenoids: perspectives for microbial engineering. Annu. Rev. Plant Biol. 60, 335-355. doi: 10.1146/annurev.arplant.043008.091955

Kiyota, H., Okuda, Y., Ito, M., Hirai, M. Y., and Ikeuchi, M. (2014). Engineering of cyanobacteria for the photosynthetic production of Limonene from $\mathrm{CO}_{2}$. J. Biotechnol. 185, 1-7. doi: 10.1016/j.jbiotec.2014.05.025

Klisch, M., and Häder, D. P. (2008). Mycosporine-like amino acids and marine toxins- the common and the different. Mar. Drugs 6, 147-163. doi: 10.3390/md6020147

Kobayashi, M., Hirai, N., Kurimura, Y., Ohigashi, H., and Tsuji, Y. (1997). Abscisic acid-dependent algal morphogenesis in the unicellular green alga Haematococcus pluvialis. Plant Growth Regul. 22, 79-85. doi: 10.1023/A:1005862809711

Koehn, E. F., Lomgley, R. E., and Reed, J. K. (1992). Microcolins, A., and B, new immunosuppressive peptide from the bluegreen algae Lyngbya majuscula. J. Nat. Prod. 55, 613-619. doi: 10.1021/np50083a009

Kohlhase, M., and Pohl, P. (1988). Saturated and unsaturated sterols of nitrogenfixing blue-green algae (cyanobacteria). Phytochemistry 27, 1735-1740. doi: 10.1016/0031-9422(88)80434-5

Koskinen, A. M., and Rapoport, H. (1985). Synthetic and conformational studies on anatoxin-a-a potent acetylcholine agonist. J. Med. Chem. 28, 1301-1309. doi: $10.1021 / \mathrm{jm} 00147 \mathrm{a} 032$

Kraan, S. (2012). "Algal polysaccharides, novel applications and outlook," in Carbohydrates - Comprehensive Studies on Glycobiology and Glycotechnology, ed C.-F. Chang (Croatia: InTech), 489-532.

Kreslavsky, V. D., Kobzar, E. F., and Muzafarov, E. N. (1997). Effect of red radiation, kinetin and linuron on growth and ethylene production in Chlorella. Biol. Plant 39, 427-430. doi: 10.1023/A:10010925 29160

Kroes, R., Schaefer, E. J., Squire, R. A., and Williams, G. M. (2003). A review of the safety of DHA45-oil. Food Chem. Toxicol. 41, 1433-1446. doi: 10.1016/S0278-6915(03)00163-7

Kujbida, P., Hatanaka, E., Campa, A., Colepicolo, P., and Pinto, E. (2006). Effects of microcystins on human polymorphonuclear leukocytes. Biochem. Biophys. Res. Commun. 341, 273-277. doi: 10.1016/j.bbrc.2005.12.177

Kumar, C. S., Ganesan, P., Suresh, P. V., and Bhaskar, N. (2008). Seaweeds as a source of nutritionally beneficial compounds - a review. J. Food Sci. Technol. $45,1-13$.
Kumar, D., Dhar, D. W., Pabbi, S., Kumar, N., and Walia, S. (2014). Extraction and purification of C-phycocyanin from Spirulina platensis (CCC540). Indian J. Plant Physiol. 19, 184-188. doi: 10.1007/s40502-0140094-7

Kumar, J., Parihar, P., Singh, R., Singh, V. P., and Prasad, S. M. (2016). UV$\mathrm{B}$ induces biomass production and nonenzymatic antioxidant compounds in three cyanobacteria. J. Appl. Phycol. 28, 131-140. doi: 10.1007/s10811-0150525-5

Kumar, S., Hahn, F. M., Baidoo, E., Kahlon, T. S., Wood, D. F., McMahan, C. M., et al. (2012). Remodeling the isoprenoid pathway in tobacco by expressing the cytoplasmic mevalonate pathway in chloroplasts. Metab. Eng. 14, 19-28. doi: 10.1016/j.ymben.2011.11.005

Kwan, J. C., Rocca, J. R., Abboud, K. A., Paul, V. J., and Luesch, H. (2008). Total structure determination of grassypeptolide, a new marine cyanobacterial cytotoxin. Org. Lett. 10, 789-792. doi: 10.1021/ol702946d

La Barre, S., Roullier, C., and Boustie, J. (2014). "Mycosporine-like amino acids (MAAs) in biological photosystems," in Outstanding Marine Molecules: Chemistry, Biology, Analysis, eds S. La Barre and J.-M. Kornprobst (Weinheim: Wiley-VCH Verlag GmbH and Co. KGaA), 333-360. doi: 10.1002/9783527681501.ch15

Lam, S. K., and Ng, T. B. (2011). Lectins: production and practical applications. Appl. Microbiol. Biotechnol. 89, 45-55. doi: 10.1007/s00253-010-2892-9

Landsberg, J. H. (2002). The effects of harmful algal blooms on aquatic organisms. Rev. Fish. Sci. 10, 113-390. doi: 10.1080/20026491051695

Larsen, L. K., Moore, R. E., and Patterson, G. M. (1994). Beta-carbolines from the blue-green alga Dichothrix baueriana. J. Nat. Prod. 57, 419-421. doi: $10.1021 / \mathrm{np} 50105 \mathrm{a} 018$

Lau, S. C. K., and Qian, P. Y. (2000). Inhibitory effect of phenolic compounds and marine bacteria on larval settlement of the barnacle Balanus amphitrite Darwin. Biofouling 16, 47-58. doi: 10.1080/08927010009378429

Leão, P. N., Vitor, R., Gonçalves, P. B., Viana, F., Lage, O. M., Gerwick, W. H., et al. (2013). Chemoecological screening reveals high bioactivity in diverse culturable Portuguese marine cyanobacteria. Mar Drugs. 11, 1316-1135. doi: $10.3390 / \mathrm{md} 11041316$

Le Bail, A., Billoud, B., Kowalczyk, N., Kowalczyk, M., Gicquel, M., Le Panse, S., et al. (2010). Auxin metabolism and function in the multicellular brown alga Ectocarpus siliculosus. Plant Physiol. 153, 128-144. doi: 10.1104/pp.109.1 49708

Le Gall, H., Philippe, F., Domon, J. M., Gillet, F., Pelloux, J., and Rayon, C. (2015). Cell wall metabolism in response to abiotic stress. Plants 4, 112-166. doi: 10.3390/plants4010112

Lee, J.-B., Hayashi, K., Hirata, M., Kuroda, E., Suzuki, E., Kubo, Y., et al. (2006). Antiviral sulfated polysaccharide from Navicula directa, a diatom collected from deep-sea water in Toyama Bay. Biol. Pharmaceut. Bull. 29, 2135-2139. doi: $10.1248 / \mathrm{bpb} .29 .2135$

Lee, J. M., Lee, H., Kang, S., and Park, W. J. (2016). Fatty acid desaturases, polyunsaturated fatty acid regulation, and biotechnological advances. Nutrients 8:23. doi: $10.3390 /$ nu8010023

Lee, T. C., Xiong, W., Paddock, T., Carrieri, D., Chang, F., Chiu, H.-F., et al. (2015). Engineered xylose utilization enhances bio-products productivity in the cyanobacterium Synechocystis sp. PCC 6803. Metab. Eng. 30, 179-189. doi: 10.1016/j.ymben.2015.06.002

Levin, E. Y., and Bloch, K. (1964). Absence of sterols in blue-green algae. Nature 202, 90-91. doi: 10.1038/202090a0

Li, E. P. H., Min, H. J., Belk, R., Kimura, J., and Bahl, S. (2008). Skin lightening and beauty in four Asian cultures. Adv. Consum. Res. 35, 444-449. Available online at: http://www.acrwebsite.org/volumes/13415/volumes/v35/NA-35

Li, Q., Du, W., and Liu, D. (2008). Perspectives of microbial oils for biodiesel production. Appl. Microbiol. Biotechnol. 80, 749-756. doi: 10.1007/s00253-008-1625-9

Linington, R. G., Edwards, D. J., Shuman, C. F., McPhail, K. L., Matainaho, T., and Gerwick, W. H. (2008). Symplocamide A, a potent cytotoxin and chymotrypsin inhibitor from the marine cyanobacterium Symploca sp. J. Nat. Prod. 71, 22-27. doi: $10.1021 / \mathrm{np} 070280 \mathrm{x}$

Linington, R. G., González, J., Ureña, L. D., Romero, L. I., Ortega-Barría, E., and Gerwick, W. H. (2007). Venturamides A, and B: antimalarial constituents of the Panamanian marine cyanobacterium Oscillatoria sp. J. Nat. Prod. 70, 397-401. doi: $10.1021 / \mathrm{np} 0605790$ 
Liu, X., and Curtiss, R. III. (2012). Thermorecovery of cyanobacterial fatty acids at elevated temperatures. J. Biotechnol. 161, 445-449. doi: 10.1016/j.jbiotec.2012.08.013

Liu, X., Sheng, J., and Curtiss, R. III. (2011). Fatty acid production in genetically modified cyanobacteria. Proc. Natl. Acad. Sci. U.S.A. 108, 6899-6904. doi: 10.1073/pnas.1103014108

Lobner, D., Piana, P. M., Salous, A. K., and Peoples, R. W. (2007). -NMethylamino-Lalanine enhances neurotoxicity through multiple mechanisms. Neurobiol. Dis. 25, 360-366. doi: 10.1016/j.nbd.2006.10.002

Loo, C. Y., and Sudesh, K. (2007). Polyhydroxyalkanoates: bio-based microbial plastics and their properties. MPJ 2, 31-57. Available online at: 228650294 Polyhydroxyalkanoates_Bio-based_microbial_plastics_and_their_properties/ links/09e415061604adc31900

Lu, Y., Tarkowská, D., Turecková, V., Luo, T., Xin, Y., Li, J., et al. (2014). Antagonistic roles of abscisic acid and cytokinin in oleaginous microalga Nannochloropsis oceanica upon nitrogen- depletion expand the evolutionary breadth of phytohormone function. Plant J. 80, 52-68. doi: 10.1111/tpj. 12615

Luan, G., Qi, Y., Wang, M., Li, Z., Duan, Y., Tan, X., et al. (2015). Combinatory strategy for characterizing and understanding the ethanol synthesis pathway in cyanobacteria cell factories. Biotechnol. Biofuels 8:184. doi: 10.1186/s13068-015-0367-Z

Luesch, H., Yoshida, W. Y., Moore, R. E., Paul, V. J., Mooberry, S. L., and Corbett, T. H. (2002). Symplostatin 3, a new dolastatin 10 analogue from the marine cyanobacterium Symploca sp. VP452. J. Nat. Prod. 65, 16-20. doi: $10.1021 / \mathrm{np} 010317 \mathrm{~s}$

Luukkainen, R., Sivonen, K., Namikoshi, M., Fardig, M., Rinehart, K. L., and Niemela, S. L. (1993). Isolation and identification of eight microcystins from thirteen Oscillatoria agardhii strains and structure of a new microcystin. Appl. Environ. Microbiol. 59, 2204-2209.

Ma, L. X., and Led, J. J. (2000). Determination by high field NMR spectroscopy of the longitudinal electron relaxation rate in $\mathrm{Cu}(\mathrm{II})$ plastocyanin form Anabaena variabilis. Am. Chem. Soc. 122, 7823-7824. doi: 10.1021/ja000746x

Machado, I. M., and Atsumi, S. (2012). Cyanobacterial biofuel production. J. Biotechnol. 162, 50-56. doi: 10.1016/j.jbiotec.2012.03.005

MacMillan, J. B., and Molinski, T. F. (2002). Caylobolide A, a unique 36-membered macrolactone from a Bahamian Lyngbya majuscule. Org. Lett. 4, 1535-1153. doi: 10.1021/ol025759p

Madhyastha, H. K., and Vatsala, T. M. (2007). Pigment production in Spirulina fussiformis in different photophysical conditions. Biomol. Eng. 24, 301-305. doi: 10.1016/j.bioeng.2007.04.001

Mahmood, N. A., and Carmichael, M. W. (1986). Paralytic shellfish poisons produced by the fresh-water cyanobacterium Aphanizomenon-flos-aquae $\mathrm{NH}$ 5. Toxicon 24, 175-186. doi: 10.1016/0041-0101(86)90120-0

Maier, T., and Korting, H. C. (2005). Sunscreens-which and what for? Skin Pharmacol. Physiol. 18, 253-262. doi: 10.1159/000087606

Malathi, T., Babu, M. R., Mounika, T., Snehalatha, D., and Rao, B. D. (2014). Screening of cyanobacterial strains for antibacterial activity. Phykos 44, 6-11. Available online at: http://phykosindia.com/paper3vol44no2.pdf

Malloy, K. L., Villa, F. A., Engene, N., Matainaho, T., Gerwick, L., and Gerwick, W. H. (2011). Malyngamide 2, an oxidized lipopedtide with nitric oxide inhibiting activity from a Papua New Guinea marine cyanobacterium. J. Nat. Prod. 74, 95-98. doi: 10.1021/np1005407

Mandal, S., and Rath, J. (2014). Extremophilic Cyanobacteria for Novel Drug Development, Vol. 7. Berlin: Springer.

Manley, L., Goodwin, K., and North, W. J. (1992). Laboratory production of bromoform, methylene bromide, and methyl iodide by macroalgae and distribution in nearshore southern California waters. Limnol. Oceanogr. 37, 1652-1659. doi: 10.4319/lo.1992.37.8.1652

Maor, R. (2010). Compositions and Methods for Increasing Oil Content in Algae. Google Patents WO2010113149A1. Available online at: https://www.google. com/patents/WO2010113149A1

Marinho-Soriano, E., and Bourret, E. (2003). Effects of season on the yield and quality of agar from Gracilaria species (Gracilariaceae Rhodophyta). Bioresour. Technol. 90, 329-333. doi: 10.1016/S0960-8524(03)00112-3

Markou, G., and Nerantzis, E. (2013). Microalgae for high-value compounds and biofuels production: a review with focus on cultivation under stress conditions. Biotechnol. Adv. 31, 1532-1542. doi: 10.1016/j.biotechadv.2013 07.011

Marsšálek, B., Zahradníčková, H., and Hronková, M. (1992). Extracellular abscisic acid produced by cyanobacteria under salt stress. J. Plant Physiol. 139, 506-508. doi: 10.1016/S0176-1617(11)80503-1

Martin-Creuzburg, D., and Von Elert, E. (2009). Good food versus bad food: the role of sterols and polyunsaturated fatty acids in determining growth and reproduction of Daphnia magna. Aquatic Ecol. 43, 943-950. doi: 10.1007/s10452-009-9239-6

Mata, T. M., Martins, A. A., and Caetano, N. S. (2010). Microalgae for biodiesel production and other applications: a review. Renewable Sustain. Ener. Rev. 14, 217-232. doi: 10.1016/j.rser.2009.07.020

Matsui, K., Nazifi, E., Hirai, Y., Wada, N., Matsugo, S., and Sakamoto, T. (2012). The cyanobacterial UV-absorbing pigment scytonemin displays radical-scavenging activity. J. Gen. Appl. Microbiol. 58, 137-144. doi: 10.2323/jgam.58.137

Matsunaga, S., Moore, R. E., Niemczura, W. P., and Carmichael, W.W. (1989). Anatoxin-a(s), a potent anticholinesterase from Anabaena flos-aquae. J. Am. Chem. Soc. 111, 8021-8023. doi: 10.1021/ja00202a057

Matthew, S., Ross, C., Rocca, J. R., Paul, V. J., and Luesch, H. (2007). Lyngbyastatin 4 , a dolastatin 13 analogue with elastase and chymotrypsin inhibitory activity from the marine cyanobacterium Lyngbya conferoides. J. Nat. Prod. 70, 124-127. doi: $10.1021 / \mathrm{np} 060471 \mathrm{k}$

Matthew, S., Schupp, P. J., and Luesch, H. (2008). Apratoxin, E., a cytotoxic peptolide from a Guamanian collection of the marine cyanobacterium Lyngbya bouillonii. J. Nat. Prod. 71, 1113-1116. doi: 10.1021/np70 0717s

Mazhar, S., Cohen, J. D., and Hasnain, S. (2013). Auxin producing nonheterocystous cyanobacteria and their impact on the growth and endogenous auxin homeostasis of wheat. J. Basic Microbiol. 53, 996-1003. doi: 10.1002/jobm.201100563

Mazur, H., Konop, A., and Synak, R. (2001). Indole-3-acetic acid in the culture medium of two axenic green microalgae. J. Appl. Phycol. 13, 35-42. doi: 10.1023/A:1008199409953

McFeeters, R. L., Xiong, C., O’Keefe, B. R., Bokesch, H. R., McMahon, J. B., Ratner, D. M., et al. (2007). The novel fold of scytovirin reveals a new twist for antiviral entry inhibitors. J. Mol. Biol. 369, 451-461. doi: 10.1016/j.jmb.2007. 03.030

McKendry, P. (2002). Energy production from biomass (part 2): conversion technologies. Bioresour. Technol. 83, 47-54. doi: 10.1016/S0960-8524(01)00119-5

McPhail, K. L., Correa, J., Linington, R. G., González, J., Ortega-Barría, E., Capson, T. L., et al. (2007). Antimalarial linear lipopeptides from a panamanian strain of the marine cyanobacterium Lyngbya majuscula. J. Nat. Prod. 70, 984-988. doi: $10.1021 / \mathrm{np} 0700772$

Medina, R. A., Goeger, D. E., Hills, P., Mooberry, S. L., Huang, N., Romero, L. I., et al. (2008). Coibamide A, a potent antiproliferative cyclic depsipeptide from the Panamanianmarine cyanobacterium Leptolyngbyasp. J. Am. Chem. Soc. 130, 6324-6325. doi: 10.1021/ja801383f

Metcalf, J., and Codd, G. (2012). "Cyanotoxins," in Ecology of Cyanobacteria II, ed B. A. Whitton (Berlin: Springer), 651-675.

Metting, F. B. (1996). Biodiversity and application of microalgae. J. Ind. Microbiol. 17, 477-489. doi: 10.1007/BF01574779

Mevers, E., Liu, W. T., Engene, N., Mohimani, H., Byrum, T., Pevzner, P. A., et al. (2011). Cytotoxic veraguamides, alkynyl bromide-containing cyclic depsipeptides from the marine cyanobacterium cf. Oscillatoria margaritifera. J. Nat. Prod. 74, 928-936. doi: 10.1021/np200077f

Miao, S. C., Anderson, R. J., and Allen, T. M. (1990). Cytotoxic metabolites from the sponge Ianthella basta collected in Papua New Guinea. J. Nat. Prod. 53, 1441-1446. doi: 10.1021/np50072a007

Minicante, S. A., Michelet, S., Bruno, F., Castelli, G., Vitale, F., Sfriso, A., et al. (2016). Bioactivity of phycocolloids against the mediterranean protozoan Leishmania infantum: an inceptive study. Sustainability 8:1131. doi: 10.3390/su8111131

Mishra, P., Singh, V. P., and Prasad, S. M. (2014). Spirulina and its nutritional importance: a possible approach for development of functional food. Biochem. Pharmacol. 3:e171. doi: 10.4172/2167-0501.1000e171 
Misra, S., and Kaushik, B. D. (1989). Growth promoting substances of cyanobacteria II. Detection of amino acids, sugars and auxins. Proc. Indian Sci. Acad. B 55, 499-504.

Misurcova, L., Orsavova, J., and Ambrozova, J. V. (2015). "Algal polysaccharides and health," in Polysaccharides Bioactivity and Biotechnology, eds K. G. Ramawat and J. M. Merillon (Cham: Springer International Publishing Switzerland), 110-144.

Mo, S., Krunic, A., Pegan, S. D., Franzblau, S. G., and Orjala, J. (2009). An antimicrobial guanidine-bearing sesterterpene from the cultured cyanobacterium Scytonema sp. J. Nat. Prod. 72, 2043-2045. doi: $10.1021 / \mathrm{np} 900288 \mathrm{x}$

Mo, S., Krunic, A., Santaerio, B. D., Franzblau, S. G., and Orjala, J. (2010). Hapalindole-related alkaloids from the cultured cyanobacterium Fischerella ambigua. Phytochemistry 71, 2116-2123. doi: 10.1016/j.phytochem.2010.09.004

Mochimaru, M., Masukawa, H., and Takaichi, S. (2005). The cyanobacterium Anabaena sp. PCC 7120 has two distinct b-carotene ketolases: CrtO for echinenone and CrtW for ketomyxol synthesis. FEBS Lett. 579, 6111-6114. doi: 10.1016/j.febslet.2005.09.081

Moheimani, N. R. (2013). Long-term outdoor growth and lipid productivity of Tetraselmis suecica, Dunaliella tertiolecta, and Chlorella sp. (Chlorophyta) in bag photobioreactors. J. Appl. Phycol. 25, 167-176. doi: 10.1007/s10811-012-9850-0

Montaser, R., Abboud, K. A, Paul, V. J., and Luesch, H. (2011b). Pitiprolamide, a proline-rich dolastatin 16 analogue from the marine cyanobacterium Lyngbya majuscula from Guam. J. Nat. Prod. 74, 109-112. doi: 10.1021/np1006839

Montaser, R., Paul, V. J., and Luesch, H. (2011a). Pitipeptolides C-F, antimycobacterial cyclodepsipeptides from the marine cyanobacterium Lyngbya majuscula from Guam. Phytochemistry 72, 2068-2074. doi: 10.1016/j.phytochem.2011.07.014

Mooberry, S. L., Stratman, K., and Moore, R. E. (1995). Tubercidin stabilizes microtubules against vinblastine-induced depolymerization, a taxol-like effect. Cancer Lett. 96, 261-266. doi: 10.1016/0304-3835(95)03940-X

Moon, S. S., Chen, J. L., Moore, R. E., and Patterson, G. M. L. (1992). Calophycin, a fungicidal cyclic decapeptide from the terrestrial blue green alga Calothrix fusca. J. Org. Chem. 57, 1097-1103. doi: 10.1021/jo00030a013

Moore, R. E., Corbett, T. H., Patterson, G. M. L., and Valeriote, F. A. (1996). The search for new antitumor drugs from blue green algae. Curr. Pharm. Design 2, 317-330.

Moore, R. E., Patterson, G. M. L., and Carmichael, W. W. (1988). "New pharmaceuticals from cultured blue green algae," in Biomedical Importance of Marine Organisms, ed D. G. Fautin (San Francisco, CA: California Academy of Sciences), 143-150.

Moore, R. E., Yang, X. Q. G., and Patterson, G. M. L. (1987). Fontonamide and anhydrohapaloxindole $\mathrm{A}$, two new alkaloids from the blue-green algae Hapalosiphon fontinalis. J. Org. Chem. 52, 3773-3777. doi: 10.1021/jo002 $26 a 009$

Mozaffarian, D., and Rimm, E. B. (2006). Fish intake, contaminants, and human health - evaluating the risks and the benefits. JAMA 296, 1885-1899. doi: 10.1001/jama.296.15.1885

Muhlroth, A., Li, K., Rokke, G., Winge, P., Olsen, Y., and Hohmann-Marriott, M. F. (2013). Pathway of lipid metabolism in marine algae, co-expression network, bottlenecks and candidate genes for enhanced production of EPA and DHA in species of Chromista. Mar. Drugs 11, 4662-4697. doi: 10.3390/md11114662

Mukund, S., and Sivasubramanian, V. (2014). Anticancer activity of Oscillatoria terebriformis, cyanobacteria in human lung cancer cell line A549. IJABPT 5, 34-45. Available online at: http://imsear.li.mahidol.ac.th/bitstream/123456789/ 167811/1/ijabpt2014v5n2p34.pdf

Mukund, S., Muthukumaran, M., and Sivasubramanian, V. (2014). In-silico studies on cyanobacterial metabolites against lung cancer EGFR protein. Int. J. Inst. Pharm. Life Sci. 4, 89-98. Available online at: https://www.academia.edu/ 9835976/

Mulkidjanian, A. Y., Koonin, E. V., Makarova, K. S., Mekhedov, S. L., Sorokin, A., Wolf, Y. I., et al. (2006). The cyanobacterial genome core and the origin of photosynthesis. Proc. Natl. Acad. Sci. U.S.A. 103, 13126-13131. doi: $10.1073 /$ pnas.0605709103

Munawer, K. M., and Mazharuddin, K. M. (2011). Enhancement of engineering in production of phenolic compounds (antioxidants) in Spirulina plantensis under different IAA regimes. Int. J. Eng. Sci. Technol. 3, 3004-3009.
Mundt, S., Kreitlow, S., and Jansen, R. (2003). Fatty acids with antibacterial activity from the cyanobacterium Oscillatoria redekei HUB 051. J. Appl. Phycol. 15, 263-267. doi: 10.1023/A:1023889813697

Münkel, R., Schmid-Staiger, U., Werner, A., and Hirth, T. (2013). Optimization of outdoor cultivation in flat panel airlift reactors for lipid production by Chlorella vulgaris. Biotechnol. Bioeng. 110, 2882-2893. doi: 10.1002/bit.24948

Mynderse, J. S., Moore, R. E., Kashiwagi, M., and Norton, T. R. (1977). Antileukemia activity in the Osillatoriaceae: isolation of debromoaplysiatoxin from Lyngbya. Science 196, 538-540. doi: 10.1126/science.403608

Nadal, N. G. M. (1971). Sterols of Spirulina maxima. Phytochemistry 10, 2537-2538. doi: 10.1016/S0031-9422(00)89903-3

Nagatsu, A., Kajitani, H., and Sakakibara, J. (1995). Muscoride A: a new oxazole peptide alkaloid from freshwater cyanobacterium Nostoc muscorum. Tetrahedron Lett. 36, 4097-4100. doi: 10.1016/0040-4039(95)00724-Q

Nagle, D. G., and Gerwick, W. H. (1995). Nakienones A-C and nakitriol new cytotoxic cyclic Cqq metabolites from an Okinawan cyanobacterial (Synechocystis sp.) overgrowth of coral. Tetrahedron Lett. 36, 849-852. doi: 10.1016/0040-4039(94)02397-T

Nakai, S., Yamada, S., and Hosomi, M. (2005). Anti-cyanobacterial fatty acids released from Myriophyllum spicatum. Hydrobiologia 543, 71-78. doi: 10.1007/s10750-004-6822-7

Nakamura, H., Kobayashi, J., and Hirata, Y. (1982). Separation of mycosporinelike amino acids in marine organisms using reverse-phase high performance liquid chromatography. J. Chromatogr. A 250, 113-118. doi: 10.1016/S0021-9673(00)95219-1

Nakanishi, A., Aikawa, S., Ho, S. H., Chen, C. Y., Chang, J. S., Hasunuma, T., et al. (2014). Development of lipid productivities under different $\mathrm{CO}_{2}$ condition of marine microalgae Chlamydomonas sp. JSC4. Bioresour. Technol. 152, 247-252. doi: 10.1016/j.biortech.2013.11.009

Namikoshi, M., Murakami, T., Watanabe, M. F., Oda, T., Yamada, J., Tsujimura, S., et al. (2003). Simultaneous production of homoanatoxin-a, anatoxin-a, and a new nontoxic 4-hydroxyhomoanatoxin-a by the cyanobacterium Raphidiopsis mediterranea Skuja. Toxicon 42, 533-538. doi: 10.1016/S0041-0101(03)00233-2

Naumann, I., Darsow, K. H., Walter, C., Lange, H. A., and Buchholz, R. (2007). Identification of sulfoglycolipids from the alga Porphyridium purpureum by matrix-assisted laser desorption/ionisation quadrupole ion trap time-offlight mass spectrometry. Rapid Commun. Mass Spectrom. 21, 3185-3192. doi: $10.1002 / \mathrm{rcm} .3190$

Neelam, K., O’Gorman, N., Nolan, J., O’Donovan, O., Wong, H. B., Au Eong, K., G., et al. (2005). Measurement of macular pigment: Raman spectroscopy versus heterochromatic flicker photometry. Invest. Opthalmol. Vis. Sci. 46, 1023-1032. doi: 10.1167/iovs.04-1032

Negri, A. P., and Jones, G. J. (1995). Bioaccumulation of paralytic shellfish poisoning (PSP) toxins from the cyanobacterium Anabaena circinalis by the freshwater mussel Alathyria condola. Toxicon 33, 667-678. doi: 10.1016/0041-0101(94)00180-G

Neumann, C., Bain, P., and Shaw, G. (2007). Studies of the comparative in vitro toxicology of the cyanobacterial metabolite deoxycylindrospermopsin. J. Toxicol. Environ. Health 70, 1679-1686. doi: 10.1080/15287390701434869

Nichkova, M., Fu, X., Yang, Z., Zhong, P., Sanborn, J. R., Chang, D., et. al. (2009). Immunochemical screening of pesticides (simazine and cypermethrin) in orange oil. J. Agr. Food Chem. 57, 5673-5679. doi: 10.1021/jf900652a

Nikodinovic-Runic, J., Guzik, M., Kenny, S. T., Babu, R., Werker, A., and Connor, K. E. O. (2013). Chapter four - carbon-rich wastes as feedstocks for biodegradable polymer (Polyhydroxyalkanoate) production using bacteria. Adv. Appl. Microbiol. 84, 139-200. doi: 10.1016/B978-0-12-407673-0.00004-7

Nishimura, M., and Koyama, T. (1977). The occurrence of stanols in various living organisms and the behavior of sterols in contemporary sediments. Geochim. Cosmochim. Acta 41, 379-385. doi: 10.1016/0016-7037(77)90265-4

Nowicka, B., and Kruk, J. (2010). Occurrence, biosynthesis and function of isoprenoid quinones. Biochim. Biophys. Acta 1797, 1587-1605. doi: 10.1016/j.bbabio.2010.06.007

Ogbonda, K. H., Aminigo, R. E., and Abu, G. O. (2007). Influence of temperature and $\mathrm{pH}$ on biomass production and protein biosynthesis in a putative Spirulina sp. Bioresour. Technol. 98, 2207-2211. doi: 10.1016/j.biortech.2006.08.028

Ohta, S., Ono, F., Shiomi, Y., Nakao, T., Aozasa, O., Nagate, T., et al. (1998). Antiherpes simplex virus substances produced by the marine green alga, Dunaliella primolecta. J. Appl. Phycol. 10, 349-356. doi: 10.1023/A:1008065226194 
Oliver, J. W., Machado, I. M., Yoneda, H., and Atsumi, S. (2013). Cyanobacterial conversion of carbon dioxide to 2,3-butanediol. Proc. Natl. Acad. Sci. U.S.A. 110, 1249-1254. doi: 10.1073/pnas.1213024110

Oliver, N. J., Rabinovitch-Deere, C. A., Carroll, A. L., Nozzi, N. E., Case, A. E., and Atsumi, S. (2016). Cyanobacterial metabolic engineering for biofuel and chemical production. Curr. Opin. Chem. Biol. 35, 43-50. doi: 10.1016/j.cbpa.2016.08.023

Olson, J. A. (1993). "Molecular actions of carotenoids. In carozenoids in human health," in Annals of the New York Academy of Science 691, eds L. M. Canfield, N. Krinsky, and J. A. Olson (New York, NY: New York Academy of Sciences), $156-166$.

Oren, A., and Gunde-Cimerman, N. (2007). Mycosporines and mycosporine-like amino acids: UV protectants or multipurpose secondary metabolites? FEMS Microbiol. Lett. 269, 1-10. doi: 10.1111/j.1574-6968.2007.00650.x

Paniagua-Michel, J., Olmos-Soto, J., and Acosta, M. (2012). "Pathways of carotenoid biosynthesis in bacteria and microalgae," in Microbial Carotenoids from Bacteria and Microalgae: Methods and Protocols, Methods in Molecular Biology, Vol. 892, ed J.-L. Barredo (Berlin: Springer-Humana Press Holanda), $1-12$.

Paoletti, C., Pushparaj, B., Florenzano, G., Capella, P., and Lercker, G. (1976). Unsaponifiable matter of green and blue-green algal lipids as a factor of biochemical differentiation of their biomasses: I. Total unsaponifiable and hydrocarbon fraction. Lipids 11, 258-265. doi: 10.1007/BF02544051

Papendorf, O., König, G. M., and Wright, A. D. (1998). Hirridin B and 2,4-dimethoxy-6 heptadecylphenol, secondary metabolites from the cyanobacterium Phormidium ectocarpi with antiplasmodial activity. Phytochemistry 49, 2383-2386. doi: 10.1016/S0031-9422(98)00440-3

Park, A., Moore, R. E., and Patterson, G. M. L. (1992). Fischerindole L., a new isonitrile from the terrestrial blue green alga Fischerella muscicola. Tetrahedron Lett. 33, 3257-3260. doi: 10.1016/S0040-4039(00)92061-6

Park, W., Yoo, G., Moon, M., Kim, C., W., Choi, Y., E., and Yang, J. (2013). Phytohormone supplementation significantly increases growth of Chlamydomonas reinhardtii cultivated for biodiesel production. Appl. Biochem. Biotechnol. 171, 1128-1142. doi: 10.1007/s12010-013-0386-9

Parmar, A., Singh, N. K., Pandey, A., Gnansounou, E., and Madamwara, D. (2011). Cyanobacteria and microalgae: a positive prospect for biofuels. Bioresour. Technol. 102, 10163-10172. doi: 10.1016/j.biortech.2011.08.030

Pattanaik, B., and Lindberg, P. (2015). Terpenoids and their biosynthesis in cyanobacteria. Life 5, 269-293. doi: 10.3390/life5010269

Patterson, G. M. L., and Bolis, C. M. (1997). Fungal cell-wall polysaccharides elicit an antifungal secondary metabolite (phytpalexin) in the cyanobacterium Scytonema ocellatum. J. Phycol. 33, 54-60. doi: 10.1111/j.0022-3646.1997.00054.x

Patterson, G. M., and Carmeli, S. (1992). Biological effects of tolytoxin (6-hydroxy7-O-methylscytophin b), a potent bioactive metabolite from cyanobacteria. Arch. Microbiol. 157, 406-410. doi: 10.1007/BF00249096

Patterson, G. M. L., Larsen, L. K., and Moore, R. E. (1994). Bioactive natural products from blue-green algae. J. Appl. Phycol. 6, 151-157. doi: $10.1007 / \mathrm{BF} 02186069$

Patterson, J. T. (1971). Microbiological assessment of surfaces. Int. J. Food. Sci. Technol. 6, 63-72. doi: 10.1111/j.1365-2621.1971.tb01593.x

Pereira, L., Critchley, A. T., Amado, A. M., and Ribeiro-Claro, P. J. A. (2009). A comparative analysis of phycocolloids produced by underutilized versus industrially utilized carrageenophytes (Gigartinales, Rhodophyta). J. Appl. Phycol. 21, 599-605. doi: 10.1007/s10811-009-9447-4

Pergament, I., and Carmeli, S. (1994). Schizotrin A: a novel antimicrobial cyclic peptide from a cyanobacterium. Tetrahedron Lett. 35, 8473-8476. doi: 10.1016/S0040-4039(00)74436-4

Perry, J., Gillan, F. T., and Johns, R. B. (1978). Lipid composition of a prochlorophyte. J. Phycol. 14, 369-371. doi: 10.1111/j.1529-8817.1978. tb00315.x

Pettit, G. R., Hogan, F., Xu, J. P., Tan, R., Nogawa, T., Cichacz, Z., et al. (2008). Antineoplastic agents. 536. New sources of naturally occurring cancer cell growth inhibitors from marine organisms, terrestrial plants, and microorganisms (1a,). J. Nat. Prod. 71, 438-444. doi: 10.1021/np700738k

Piechula, S., Waleron, K., S'wiatek, W, and Biedrzycka, I., Podhajska, A. J. (2001). Mesophilic cyanobacteria producing thermophilic restriction endonucleases. FEMS Microb. Lett. 198, 135-140. doi: 10.1111/j.1574-6968.2001.tb10632.x
Piironen, V., Lindsay, D. G., Miettinen, T. A., Toivo, J., and Lampi, A. M. (2000). Plant sterols: biosynthesis, biological function and their importance to human nutrition. J. Sci. Food Agric. 80, 939-966. doi: 10.1002/(SICI)10970010(20000515)80:7<939::AID-JSFA644>3.0.CO;2-C

Piotrowska-Niczyporuk, A., and Bajguz, A. (2014). The effect of natural and synthetic auxins on the growth, metabolite content and antioxidant response of green alga Chlorella vulgaris (Trebouxiophyceae). Plant Growth Regul. 73, 57-66. doi: 10.1007/s10725-013-9867-7

Pisciotta, J. M., Zou, Y., and Baskakov, I. V. (2010). Light-dependent electrogenic activity of cyanobacteria. PLOS ONE 5:e10821. doi: 10.1371/journal.pone.0010821

Plouguerné, E., da Gama, B. A. P., Pereira, R. C., and Barreto-Bergter, E. (2014). Glycolipids from seaweeds and their potential biotechnological applications. Front. Cell Infect. Microbiol. 4:174. doi: 10.3389/fcimb.2014.00174

Ploutno, A., and Carmeli, S. (2000). Nostocyclyne A. a novel antimicrobial cyclophane from the cyanobacterium Nostoc sp. J. Nat. Prod. 63, 1524-1526. doi: 10.1021/np0002334

Portwich, A., and Garcia-Pichel, F. (2003). Biosynthetic pathway of mycosporines (mycosporine-like amino acids) in the cyanobacterium Chlorogloeopsis sp. strain PCC 6912. Phycologia 42, 384-392. doi: 10.2216/10031-8884-42-4-384.1

Prasanna, R. A., Sood, A., Jaiswal, S., Nayak, S., Gupta, V., and Chaudhary, V. (2010). Rediscovering cyanobacteria as valuable sources of bioactive compounds (review). Appl. Biochem. Microb. 46, 119-134. doi: $10.1134 / \mathrm{S} 0003683810020018$

Prinsep, M. R., Moore, R. E., Levine, I. A., and Patterson, G. M. (1992). Westiellamide, a bistratamide-related cyclic peptide from the blue-green alga Westiellopsis prolifica. J. Nat. Prod. 55, 140-142. doi: 10.1021/np50079a022

Prochazkova, T., Sychrova, E., Javurkova, B., Vecerkova, J., Kohoutek, J., Lepsova-Skacelova, O., et al. (2017). Phytoestrogens and sterols in waters with cyanobacterial blooms - Analytical methods and estrogenic potencies. Chemosphere 170, 104-112. doi: 10.1016/j.chemosphere.2016. 12.006

Pulido, P., Perello, C., and Rodriguez-Concepcion, M. (2012). New insights into plant isoprenoid metabolism. Mol. Plant. 5, 964-967. doi: 10.1093/mp/sss088

Raja, A., Vipin, C., and Aiyappan, A. (2013). Biological importance of marine algae- an overview. Int. J. Curr. Microbiol. Appl. Sci. 2, 222-227.

Rajeev, K. J., and Xu, Z. (2004). Biomedical compounds from marine organisms. Mar. Drugs 2, 123-146. doi: 10.3390/md203123

Rao, A. R., Ravishankar, G. A., and Sarada, R. (2012). Cultivation of green alga Botryococcus braunii in raceway, circular ponds under outdoor conditions and its growth, hydrocarbon production. Bioresour. Technol. 123, 528-533. doi: 10.1016/j.biortech.2012.07.009

Rasmussen, H. E., Blobaum, K. R., Park, Y. K., Ehlers, S. J., Lu, F., and Lee, J. Y. (2008). Lipid extract of Nostoc commune var. sphaeroides Kützing, a bluegreen alga, inhibits the activation of sterol regulatory element binding proteins in HepG2 cells. J. Nutr. 138, 476-481.

Rastogi, R. P., and Incharoensakdi, A. (2014). Characterization of UVscreening compounds, mycosporine-like amino acids, and scytonemin in the cyanobacterium Lyngbya sp. CU2555. FEMS Microbiol Ecol. 87, 244-256. doi: 10.1111/1574-6941.12220

Rastogi, R. P., and Madamwar, D. (2016). Cyanobacteria synthesize their own UV-sunscreens for photoprotection. Bioenergetics 5:138. doi: $10.4172 / 2167-7662.1000138$

Rastogi, R. P., and Sinha, R. P. (2009). Biotechnological and industrial significance of cyanobacterial secondary metabolites. Biotechnol. Adv. 27, 521-539. doi: 10.1016/j.biotechadv.2009.04.009

Rastogi, R. P., Richa, Sinha, R. P., Singh, S. P., and Häder, D. P. (2010). Photoprotective compounds from marine organisms. J. Indus. Microbiol. Biotechnol. 37, 537-558. doi: 10.1007/s10295-010-0718-5

Rastogi, R. P., Sinha, R. P., and Incharoensakdi, A. (2013). Partial characterization, UV-induction and photoprotective function of sunscreen pigment, scytonemin from Rivularia sp. HKAR-4. Chemosphere 93, 1874-1878. doi: 10.1016/j.chemosphere.2013.06.057

Rastogi, R. P., Sonani, R. R., and Madamwar, D. (2014). The highenergy radiation protectant extracellular sheath pigment scytonemin and its reduced counterpart in the cyanobacterium Scytonema sp. R77DM. Bioresource Technol. 171, 396-400. doi: 10.1016/j.biortech.2014. 08.106 
Rastogi, R. P., Sonani, R. R., and Madamwar, D. (2015). Cyanobacterial sunscreen scytonemin: role in photoprotection and biomedical research. Appl. Biochem. Biotechnol. 176, 1551-1563. doi: 10.1007/s12010-015-1676-1

Rath, B., and Priyadarshani, I. (2013). Antibacterial and antifungal activity of marine cyanobacteria from Odisha coast. Int. J. Curr. Trends Res. 2, 248-251.

Ratledge, C. (2004). Fatty acid biosynthesis in microorganisms being used for single cell oil production. Biochimie 86, 807-815. doi: 10.1016/j.biochi.2004.09.017

Raveh, A., and Carmeli, S. (2007). Antimicrobial ambiguines from the cyanobacterium Fischerella sp. collected in Israel. J. Nat. Prod. 70, 196-201. doi: 10.1021/np060495r

Reitz, R. C., and Hamilton, J. G. (1968). The isolation and identification of two sterols from two species of Blue-green Algae. Comp. Eiochem. Physiol. 25, 401-416. doi: 10.1016/0010-406X(68)90349-6

Reshef, V., Mizrachi, E., Maretzki, T., Silberstein, C., Loya, S., Hizi, A., et al. (1997). New acetylated known glycolipids from cyanobacteria with potential to inhibit the reverse transcriptase of HIV-1. J. Nat. Prod. 60, 1251-1260. doi: $10.1021 / \mathrm{np} 970327 \mathrm{~m}$

Riahi, H., Eskash, A., and Shariatmadari, Z. (2011). "Effect of bacterial and cyanobacterial culture on growth, quality and yield of Agaricus bisporus," Proceedings of the 7th International Conference on Mushroom Biology and Mushroom Products (ICMBMP7) Section: Waste Conversion, Substrates and Casing (Arcachon), 406-411.

Rice-Evans, C. A., Miller, N. J., and Paganga, G. (1997). Antioxidant properties of phenolic compounds. Trends Plant Sci. 2, 152-159. doi: 10.1016/S1360-1385(97)01018-2

Rittmann, B. E. (2008). Opportuni- ties for renewable bioenergy using microorganisms. Biotechnol. Bioeng. 100, 203-212. doi: 10.1002/bit. 21875

Rock, C. D., and Zeevaart, J. A. (1991). The aba mutant of Arabidopsis thaliania is impaired in epoxy-carotenoid biosynthesis. Proc. Natl. Acad. Sci. U.S.A. 88, 7496-7499. doi: 10.1073/pnas.88.17.7496

Rothrock, M. J. Jr., and Garcia-Pichel, F. (2005). Microbial diversity of benthic mats along a tidal desiccation gradient. Environ. Microbiol. 7, 593-601. doi: 10.1111/j.1462-2920.2005.00728.x

Rudiger, H., and Gabius, H. J. (2001). Plant lectins: occurrence, biochemistry, functions and application. Glycoconj. J. 18, 589-613. doi: 10.1023/A:1020687518999

Ruffing, A. M., and Jones, H. D. (2012). Physiological effects of free fatty acid production in genetically engineered Synechococcus elongatus PCC 7942. Biotechnol. Bioeng. 109, 2190-2219. doi: 10.1002/bit.24509

Rupilius, W., and Ahmad, S. (2006). The changing world of oleochemicals. Palm Oil Dev. 44, 15-28. Available online at: www.americanpalmoil.com/ ContentPages/18698804.pdf

Sajilata, M. G., Singhal, R. S., and Kamat, M. Y. (2008). Fractionation of lipids and purification of ã-linolenicacid (GLA) from Spirulina platensis. Food Chem. 109, 580-586. doi: 10.1016/j.foodchem.2008.01.005

Salvador, L. A., Paul, V. J., and Luesch, H. (2010). Caylobolide, B., a macrolactone from symplostatin 1-producing marine cyanobacteria Phormidium spp. from Florida. J. Nat. Prod. 73, 1606-1609. doi: 10.1021/np100467d

Sanchez, S., and Demain, A. L. (2008). Metabolic regulation and overproduction of primary metabolites. Microb. Biotechnol. 4, 283-319. doi: 10.1111/j.1751-7915.2007.00015.x

Santoyo, S., Rodríguez-Meizoso, I., Cifuentes, A., Jaime, L., García-Blairsy Reinac, G., Señorans, F. J., et al. (2009). Green processes based on the extraction with pressurized fluids to obtain potent antimicrobials from Haematococcus pluvialis microalgae. LWT Food Sci. Technol. 42, 1213-1218. doi: 10.1016/j.lwt.2009.01.012

Sarkar, N., Ghosh, S. K., Bannerjee, S., and Aikat, K. (2012). Bioethanol production from agricultural wastes: an overview. Renewable Ener. 37, 19-27. doi: 10.1016/j.renene.2011.06.045

Sato, M., Masuda, Y., Kirimura, K., and Kino, K. (2007). Thermostable ATP regeneration system using polyphosphate kinase from Thermosynechococcus elongatus BP-1 for d-amino acid dipeptide synthesis. J. Biosci. Bioeng. 103, 179-184. doi: 10.1263/jbb.103.179

Sayanova, O. V., and Napier, J. A. (2004). Eicosapentaenoic acid: biosynthetic routes and the potential for synthesis in transgenic plants. Phytochemistry 65, 147-158. doi: 10.1016/j.phytochem.2003 10.017

Schaeffer, D. J., and Krylov, V. S. (2000). Anti-HIVactivity of extracts and compounds from algae and cyanobacteria. Ecotoxicol. Environ. Saf. 45, 208-227. doi: 10.1006/eesa.1999.1862

Scherer, S., Chen, T. W., and Böger, P. (1988). A new UV-A/B protecting pigment in the terrestrial cyanobacterium Nostoc commune. Plant Physiol. 88, 1055-1057. doi: 10.1104/pp.88.4.1055

Schoenwaelder, M. E. A., and Wiencke, C. (2000). Phenolic compounds in the embryo development of several northern hemisphere fucoids. Plant Biol. 2, 24-33. doi: 10.1055/s-2000-9178

Schwartz, R. E., Hirsch, C. F., Sesin, D. F., Flor, J. E., Chartain, M., Fromtling, R. E., et al. (1990). Fromtling, Pharmaceuticals from cultured algae. Indus. Microbiol. 5, 113-124. doi: 10.1007/BF01573860

Seckbach, J., and Ikan, R. (1972). Sterols and chloroplast structure of Cyanidium caldarium. Plant Physiol. 49, 457-459. doi: 10.1104/pp.49. 3.457

Seino, Y., Miki, T., Kiyonari, H., Abe, T., Fujimoto, W., Kimura, K., et al. (2008). Isx participates in the maintenance of vitamin A metabolism by regulation of beta-carotene 15,15'-monooxygenase (Bcmo1) expression. J. Biol. Chem. 283, 4905-4911. doi: 10.1074/jbc.M707928200

Seite, S., and Fourtanier, A. M. (2008). The benefit of daily photoprotection. J. Am. Acad. Dermatol. 58, S160-S166. doi: 10.1016/j.jaad.2007.04.036

Semary, N. A. E., and Fouda, M. (2015). Anticancer activity of Cyanothece sp. strain extracts from Egypt: first record. Asian Pac. J. Trop. Biomed. 5, 992-995. doi: 10.1016/j.apjtb.2015.09.004

Sergeeva, E., Liaimer, A., and Bergman, B. (2002). Evidence for production of the phytohormone indole-3-acetic acid by cyanobacteria. Planta 215, 229-238. doi: 10.1007/s00425-002-0749-x

Shah, M. M., Liang, Y., Cheng, J. J., and Daroch, M. (2016). Astaxanthin-producing green microalga Haematococcus pluvialis: from single cell to high value commercial products. Front. Plant Sci. 7:531. doi: 10.3389/fpls.2016.00531

Shahidi, F., and Zhong, Y. (2010). Novel antioxidants in food quality preservation and health promotion. Eur. J. Lipid Sci. Technol. 112, 930-940. doi: 10.1002/ejlt.201000044

Shaieb, F. A., Issa, A. A., and Meragaa, A. (2014). Antimicrobial activity of crude extracts of cyanobacteria Nostoc commune and Spirulina platensis. Arch. Biomed. Sci. 2, 34-41. Available online at: http://journals.tmkarpinski.com/ index.php/abms/article/view/221

Shih, S.R., Ho, M. S., Lin, K. H., Wu, S.L., Chen, Y. T., Wu, C. N., et al. (2000). Genetic analysis of enterovirus 71 isolated from fatal and non-fatal cases of hand, foot and mouth disease during an epidemic in Taiwan 1998. Virus Res. 68, 127-136. doi: 10.1016/S0168-1702(00)00162-3

Shilpa, K. K., Varun, K. K., and Lakshmi, B. S. (2010). An alternate method of natural drug production: eliciting secondary metabolite production using plant cell culture. J. Plant Sci. 5, 222-247. doi: 10.3923/jps.2010.222.247

Shimizu, M., and Tomoo, T. (1994). Anti-inflammatory constituents of topically applied crude drugs. Constituents V. and anti-inflammatory effect of Aoki, Aucuba japonica THUNB. Biol. Pharm. Bull. 17, 665-667. doi: $10.1248 / \mathrm{bpb} .17 .665$

Shimizu, Y. (2003). Microalgal metabolites.Curr. Opin. Microbiol. 6, 236-243. doi: 10.1016/S1369-5274(03)00064-X

Shin, H. J., Matsuda, H., Murakami, M., and Yamaguchi, K. (1997). Aeruginosins 205A and -B, serine protease inhibitory glycopeptides from the cyanobacterium Oscillatoria agardhii (NIES-205). J. Org. Chem. 62, 1810-1813. doi: 10.1021/jo961902e

Sieburth, J. M. (1960). Acrylic acid, an 'antibiotic' principle inPhaeocystis blooms in Antarctic waters. Science 132, 676-677. doi: 10.1126/science.132.3428.676

Siegenthaler, P. A., and Murata, N. (eds.). (1998). Lipids in Photosynthesis: Structure, Function and Genetics, Vol. 6. Kluwer Academic Publishers.

Sijtsma, L., and Swaaf, M. E. (2004). Biotechnological production and applications of the n-3 polyunsaturated fatty acid docosahexaenoic acid. Appl. Microbiol. Biotechnol. 64, 146-153. doi: 10.1007/s00253-003-1525-y

Silva-Stenico, M. E., Silva, C. S. P., Lorenzi, A. S., Shishido, T. K., Etchegaray, A., Lira, S. P., et al. (2011). Non-ribosomal peptides produced by Brazilian cyanobacterial isolates with antimicrobial activity. Microbiol. Res. 166, 161-175. doi: 10.1016/j.micres.2010.04.002 
Silva-Stenico, M. E., Silva, C. S., Lorenzi, A. S., Shishido, T. K., Etchegaray, A., Lira, S. P., et al. (2014). Non-ribosomal peptides produced by Brazilian cyanobacterial isolates with antimicrobial activity. Microbiol. Res. 166, 161-175. doi: 10.1016/j.micres.2010.04.002

Silvestro, D., Andersen, T. G., Schaller, H., and Jensen, P. E. (2013). Plant sterol metabolism. D7-sterol-C5-desaturase (STE1/DWARF7), D5,7-sterol-D7reductase (DWARF5) and D24-sterol-D24-reductase (DIMINUTO/DWARF1) show multiple subcellular localizations in Arabidopsis thaliana (Heynh) L. PLoS ONE 8:e56429. doi: 10.1371/journal.pone.0056429

Simmons, T. L., Andrianasolo, E., McPhail, K., Flatt, P., and Gerwick, W. H. (2005). Marine natural products as anticancer drugs. Mol. Cancer Ther. 4, 333-342.

Simmons, T. L., McPhail, K. L., Ortega-Barría, E., Mooberry, S. L., and Gerwick, W. H. (2006). Belamide, A., a new antimitotic tetrapeptide from a Panamanian marin cyanobacterium. Tetrahedron. Lett. 47, 3387-3390. doi: 10.1016/j.tetlet.2006.03.082

Simopoulos, A. P. (1991). Omega-3 fatty acids in health and disease and in growth and development. Am. J. Clin. Nutr. 54, 438-463.

Simopoulos, A. P., Bazán, N. G., and Karger, S. (2009). Omega-3 Fatty Acids, the Brain and Retina. Basel: Karger.

Singh, B., and Sharma, R. A. (2015). Plant terpenes: defense responses, phylogenetic analysis, regulation and clinical applications. 3 Biotech. 5, 129-151. doi: 10.1007/s13205-014-0220-2

Singh, I. P., Milligan, K. E., and Gerwick, W. H. (1999). Tanikolide, a toxic and antifungal lactone from the marine cyanobacterium Lyngbya majuscula. J. Nat. Prod. 62, 1333-1335. doi: 10.1021/np990162c

Singh, S. C., Sinha, R. P., and Häder, D. P. (2002). Role of lipids and fatty acids in stress tolerance in cyanobacteria. Acta Protozool. 41, 297-308. Available online at: http://wwwl.nencki.gov.pl/pdf/ap/ap620.pdf

Singh, S. P., Hader, D. P., and Sinha, R. P. (2010). Cyanobacteria and ultraviolet radiation (UVR) stress: mitigation strategies.Age Res. Rev 9, 79-90. doi: 10.1016/j.arr.2009.05.004

Singh, S. P., Kumari, S., Rastogi, R. P., Singh, K. L., and Sinha, R. P. (2008). Mycosporine-like amino acids (MAAs): chemical structure, biosynthesis and significance as UV-absorbing/screening compounds. Ind. J. Exp. Biol. 46, 7-17.

Singh, U. P., Sarma, B. K., and Singh, D. P. (2003). Effect of plant growth promoting rhizobacteria and culture filtrate of Sclerotium rolfsii on phenolic and salicylic acid contents in Chickpea (Cicer arietinum). Curr. Microbiol. 46, 131-140. doi: 10.1007/s00284-002-3834-2

Sinha, R. P., Singh, S. P., and Häder, D. P. (2007). Database on mycosporines and mycosporine-like amino acids (MAAs) in fungi, cyanobacteria, macroalgae, phytoplankton and animals. J. Photochem. Photobiol. B Biol. 89, 29-35. doi: 10.1016/j.jphotobiol.2007.07.006

Siow, R. S., Teoh, S., Teo, S. S., Shukor, M. Y. A., Phang, S. M., and Ho, C-L. (2013). Molecular cloning and characterization of GDP-mannose3,5-epimerase from Gracilaria changii. J. Appl. Phycol. 25, 1309-1318. doi: 10.1007/s10811-013-9987-5

Smit, A. J. (2004). Medicinal and pharmaceutical uses of seaweed natural products: a review. J. Appl. Phycol. 16, 245-262. doi: 10.1023/B:JAPH.0000047783.36600.ef

Smith, V. J., Desbois, A. P., and Dyrynda, E. A. (2010). Conventional and unconventional antimicrobials from fish, marine invertebrates and microalgae. Mar. Drugs 8, 1213-1262. doi: 10.3390/md8041213

Solomons, N. W., and Bulux, J. (1994). Plant sources of pro-vitamin A and human nutriture. Nutr. Rev. 51, 199-204. doi: 10.1111/j.1753-4887.1993.tb03103.x

Steinhoff, F. S., Karlberg, M., Graeve, M., Wulff, A. (2014). Cyanobacteria in Scandinavian coastal waters - a potential source for biofuels and fatty acids? Algal. Res. 5, 42-51. doi: 10.1016/j.algal.2014.05.005

Stengel, D. B., Connan, S., and Popper, Z. A. (2011). Algal chemodiversity and bioactivity: sources of natural variability and implications for commercial application. Biotechnol. Adv. 29, 483-501. doi: 10.1016/j.biotechadv. 2011.05.016

Stevenson, C. S., Capper, E. A., Roshak, A. K., Marquez, B., Grace, K., Gerwick, W. G., et al. (2002). Scytonemin, a marine natural product inhibitor of kinases key in hyperproliferative inflammatory diseases. Inflamm. Res. 51, 112-114. doi: $10.1007 / \mathrm{BF} 02684014$

Stewart, I., Webb, P. M., Schluter, P. J., and Shaw, G. R. (2006). Recreational and occupational field exposure to freshwater cyanobacteria-a review of anecdotal and case reports, epidemiological studies and the challenges for epidemiologic assessment. Environ. Health 5:6. doi: 10.1186/1476-069X-5-6
Stewart, J. B., Bomemann, V., Chen, J. L., Moore, R. E., Caplan, F. R., Karuso, H., et al. (1988). Cytotoxic, fungicidal nucleosides from bluegreen algae belonging to the Scytonemataceae. J. Antibiot. 41, 1048-1056. doi: 10.7164/antibiotics.41.1048

Stirk, W. A., Balint, P., Tarkowska, D., Novak, O., Maroti, G., Ljung, K., et al. (2014). Effect of light on growth and endogenous hormones in Chlorella minutissima (Trebouxiophyceae). Plant Physiol. Biochem. 79, 66-76. doi: 10.1016/j.plaphy.2014.03.005

Stirk, W. A., Bálint, P., Tarkowská, D., Novákc, O., Strnad, M., Ördög, V., et al. (2013). Hormone profiles in microalgae: gibberellins and brassinosteroids. Plant Physiol. Biochem. 70, 348-353. doi: 10.1016/j.plaphy.2013.05.037

Stirk, W. A., Novák, O., Hradecká, V., Pěnčík, A., Rolčík, J., Strnad, M., et al. (2009). Endogenous cytokinins, auxins and abscisic acid in Ulva fasciata (Chlorophyta) and Dictyota humifusa (Phaeophyta): towards understanding their biosynthesis and homoeostasis. Eur. J. Phycol. 44, 231-240. doi: 10.1080/09670260802573717

Stirk, W. A., Ordog, V., Staden, J. V., and Jager, K. (2002). Cytokinins and auxin-like activity in Cyanophyta and microalgae. J. Appl. Phycol. 14, 215-221. doi: 10.1023/A:1019928425569

Stirk, W. A., Staden, J. V., Novak, O., Doležal, K, Strnad, M., Dobrev, P. I., et al. (2011). Changes in endogenous cytokinin concentrations in Chlorella (Chlorophyceae) in relation to light and the cell cycle. J. Phycol. 47, 291-301. doi: 10.1111/j.1529-8817.2010.00952.x

Stolz, P., and Obermayer, B. (2005). Manufacturing microalgae for skin care. Cosmet. Toiletries 120, 99-106. Available online at: http://www. cosmeticsandtoiletries.com/formulating/function/active/2078882.html

Strichartz, G., Rando, T., Hall, S., Gitschier, J., Hall, L., Magnani, B., et al. (1986). On the mechanism by which saxitoxin binds to and blocks sodium channels. Ann. N.Y. Acad. Sci. 479, 96-112. doi: 10.1111/j.1749-6632.1986.tb15564.x

Sudesh, K. (2004). Microbial polyhydroxyalkanoates (PHAs): an emerging biomaterial for tissue engineering and therapeutic applications. Med. J. Malaysia 59, 55-56.

Suh, H. J., Lee, H. W., and Jung, J. (2003). Mycosporine glycine protects biological systems against photodynamic damage by quenching singlet oxygen with a high efficiency. Photochem. Photobiol. 78, 109-113. doi: 10.1562/0031-8655(2003)078<0109:mgpbsa>2.0.co;2

Suh, S. S., Hwang, J., Park, M., Seo, H. H., Kim, H. S., Lee, J. H., et al. (2014). Antiinflammation activities of mycosporine-like amino acids (MAAs) in response to UV radiation suggest potential anti-skin aging activity. Mar. Drugs 12, 5174-5187. doi: 10.3390/md12105174

Takahama, K., Matsuoka, M., Nagahama, K., and Ogawa, T. (2003). Construction and analysis of a recombinant cyanobacterium expressing a chromosomally inserted gene for an ethylene-forming enzyme at the psbAI locus. J. Biosci. Bioeng. 95, 302-305. doi: 10.1016/S1389-1723(03)80034-8

Takahashi, H., Miyake, M., Tokiwa, Y., and Asada, Y. (1998). Improved accumulation of poly-3-hydroxybutyrate by a recombinant cyanobacterium. Biotechnol. Lett. 20, 183-186.

Takano, S., Nakanishi, A., Uemura, D., and Hirata, Y. (1979). Isolation and structure of a $334 \mathrm{~nm}$ UV absorbing substance, porphyra-334 from the red alga Porphyra tenera Kjellman. Chem. Lett. 8, 419-420. doi: 10.1246/cl. 1979.419

Talebi, A. F., Mohtashami, S. K., Tabatabaei, M., Tohidfar, M., Bagheri, A., Zeinalabedini, M., et al. (2013). Fatty acids profiling: a selective criterion for screening microalgae strains for biodiesel production. Algal Res. 2, 258-267. doi: 10.1016/j.algal.2013.04.003

Tan, X., Yao, L., Gao, Q., Wang, W., Qi, F., and Lu, X. (2011). Photosynthesis driven conversion of carbon dioxide to fatty alcohols and hydrocarbons in cyanobacteria. Metab. Eng. 13, 169-176. doi: 10.1016/j.ymben.2011.01.001

Taniguchi, M., Nunnery, J. K., Engene, N., Esquenazi, E., Byrum, T., Dorrestein, P. C., et al. (2010). A cyclic depsipeptide from a palmyra atoll collection of the marine cyanobacterium Lyngbya majuscula. J. Nat. Prod. 73, 393-398. doi: 10.1021/np900428h

Tarakhovskaya, E. R., Maslov, Y. I., and Shishova, M. F. (2007). Phytohormones in Algae. Russ. J. Plant Physiol. 54, 163-170. doi: 10.1134/S10214437070 20021

Tate, J. J., Gutierrez-Wing, M. T., Rusch, K. A., and Benton, M. G. (2013). The effects of plant growth substances and mixed cultures on growth and metabolite production of green algae Chlorella sp.: a review. J. Plant Growth Regul. 32, 417-428. doi: 10.1007/s00344-012-9302-8 
Taylor, M. S., Stahl-Timmins, W., Redshaw, C. H., and Osborne, N. J. (2014). Toxic alkaloids in Lyngbya majuscula and related tropical marine cyanobacteria. Harmful Algae 31, 1-8. doi: 10.1016/j.hal.2013.09.003

Teruya, T., Sasaki, H., Fukazawa, H., and Suenaga, K. (2009). Bisebromoamide, a potent cytotoxic peptide from the marine cyanobacterium Lyngbya sp.: isolation, stereostructure, and biological activity. Org. Lett. 11, 5062-5065. doi: $10.1021 / \mathrm{ol} 9020546$

Teshima, S. I., and Kanazawa, A. (1972). Bioconversion of cholesterol to 7-cholestenol in a chiton. Nippon Suisan Gakk. 44, 1265-1268. doi: $10.2331 /$ suisan.44.1265

Thomas, N. V., and Kim, S. K. (2011). Potential pharmacological applications of polyphenolic derivatives from marine brown algae. Environ. Toxicol. Pharmacol. 32, 325-335. doi: 10.1016/j.etap.2011.09.004

Thomas, N. V., and Kim, S. K. (2013). Beneficial effects of marine algal compounds in cosmeceuticals. Mar. Drugs 11, 146-164. doi: 10.3390/md11010146

Tian, B., Wang, Y., Zhu, Y., Lu, X., Huang, K., Shao, N., et al. (2006). Synthesis of the photorespiratory key enzyme serine: glyoxylate aminotransferase in Chlamydomonas reinhardtii is modulated by the light regime and cytokinin. Physiol. Plant. 127, 571-582. doi: 10.1111/j.1399-3054.2006.00691.x

Tidgewell, K., Clark, B. T., and Gerwick, W. H. (2010). Comprehensive Natural Products Chemistry, 2nd Edn., eds B. Moore and P. Crews (Oxford: Pergamon Press), 141-188.

Tominaga, N., Takahata, M., and Tominaga, H. (1993). Effects of $\mathrm{NaCl}$ and $\mathrm{KNO}_{3}$ concentrations on the abscisic acid content of Dunaliella sp. (Chlorophyta). Hydrobiologia 267, 163-168. doi: 10.1007/BF00018798

Tonon, T., Harvey, D., Larson, T., R., and Graham, I. A. (2002). Long chain polyunsaturated fatty acid production and partitioning to triacylglycerols in four microalgae. Phytochemistry 61, 15-24. doi: 10.1016/S0031-9422(02)00201-7

Torokne, A., Asztalos, M., Bankine, M., Bickel, H., Borbely, G., Carmeli, S., et al. (2004). Interlaboratory comparison trial on cylindrospermopsin measurement. Anal. Biochem. 332, 280-284. doi: 10.1016/j.ab.2004.05.036

Torres, F. A. E., Passalacqua, T. G., Velásque, A. M. A., de Souza, R. A., Colepicolo, P., and Graminha, M. A. S. (2014). New drugs with antiprotozoal activity from marine algae: a review. Rev. Bras. Farmacogn. 24, 265-276. doi: 10.1016/j.bjp.2014.07.001

Tripathi, A., Puddick, J., Prinsep, M. R., Rottmann, M., Chan, K. P., Chen, D. Y., et al. (2011). Lagunamide, C., a cytotoxic cyclodepsipeptide from the marine cyanobacterium Lyngbya majuscula. Phytochemistry 72, 2369-2375. doi: 10.1016/j.phytochem.2011.08.019

Tsavkelova, E. A., Klimova, S. Y., Cherdyntseva, T. A., and Netrusov, A. I. (2006). Hormones and hormone-like substances of microorganisms: a review. Appl. Biochem. Microbiol. 42, 229-235. doi: 10.1134/S000368380603001X

Ueno, Y., Kurano, N., and Miyachi, S. (1998). Ethanol production by dark fermentation in the marine green alga, Chlorococcum littorale. J. Ferment. Bioeng. 86, 38-43.

Ungerer, J., Tao, L., Davis, M., Ghirardi, M., Maness, P. C., and Yu, J. (2012). Sustained photosynthetic conversion of CO2 to ethylene in recombinant cyanobacterium Synechocystis 6803. Energy Environ. Sci. 5:8998. doi: $10.1039 / \mathrm{c} 2 \mathrm{ee} 22555 \mathrm{~g}$

Vairappan, C. S., Suzuki, M., Abe, T., and Masuda, M. (2001). Halogenated metabolites with antibacterial activity from the Okinawan Laurencia species. Phytochemistry 58, 517-523. doi: 10.1016/S0031-9422(01)00260-6

Valerio, E., Pereira, P., Saker, M. L., Franca, S., and Tenreiro, R. (2005). Molecular characterization of Cylindrospermopsis raciborskii strains isolated from Portuguese freshwaters. Harmful Algae 4, 1044-1052. doi: 10.1016/j.hal.2005.03.002

Vijayakumar, S., and Menakha, M. (2015). Pharmaceutical applications of cyanobacteriad. J. Acute Med. 5, 15-23. doi: 10.1016/j.jacme.2015.02.004

Vílchez, C., Forján, E., Cuaresma, M., Bédmar, F., Garbayo, I., and Vega, J. M. (2011). Marine carotenoids: biological functions and commercial applications. Mar. Drugs 9, 319-333. doi: 10.3390/md9030319

Vogt, T. (2010). Phenylpropanoid biosynthesis. Mol. Plant 3, 2-20. doi: $10.1093 / \mathrm{mp} / \mathrm{ssp} 106$

Volk, R. B., and Furkert, F. H. (2006). Antialgal, antibacterial and antifungal activity of two metabolites produced and excreted by cyanobacteria during growth. Microbiol. Res. 161, 180-186. doi: 10.1016/j.micres.2005.08.005
Volka, R. B., and Furkert, F. H. (2006). Antialgal, antibacterial and antifungal activity of two metabolites produced and excreted by Cyanobacteria during growth. Microbiol. Res. 161, 180-186. doi: 10.1016/j.micres.2005.08.005

Volkman, J. K. (2003). Sterols in microorganisms. Appl. Microbiol. Biotechnol. 60, 495-506. doi: 10.1007/s00253-002-1172-8

Voß, U., Bishopp, A., Farcot, E., and Bennett, M. J. (2014). Modelling hormonal response and development. Trends Plant Sci. 19, 311-319. doi: 10.1016/j.tplants.2014.02.004

Wada, N., Sakamoto, T., and Matsugo, S. (2013). Multiple roles of photosynthetic and sunscreen pigments in cyanobacteria focusing on the oxidative stress. Metabolites 3, 463-483. doi: 10.3390/metabo3020463

Wagner, J. R., Motchnik, P. A., Stocker, R., Sies, H., and Ames, B. N. (1993). The oxidation of blood plasma and low density lipoprotein components by chemically generated singlet oxygen. J. Biol. Chem. 268, 18502-18506.

Wang, H. M., Chen, C. Y., and Wen, Z. H. (2011). Identifying melanogenesis inhibitors from Cinnamomum subavenium with in vitro and in vivo screening systems by targeting the human tyrosinase. Exp. Dermatol. 20, 242-248. doi: 10.1111/j.1600-0625.2010.01161.x

Wang, J., Yang, H., and Wang, F. (2014). Mixotrophic cultivation of microalgae for biodiesel production: status and prospects. Appl. Biochem. Biotech. 172, 3307-3329. doi: 10.1007/s12010-014-0729-1

Wang, T., Jonsdottir, R., Liu, H., Gu, L., Kristinsson, H. G., Raghavan, S., et al. (2012). Antioxidant capacities of phlorotannins extractedfrom the brown algae Fucus vesiculosus. J. Agric. Food Chem. 60, 5874-5883. doi: 10.1021/jf3003653

Wang, Z., and Benning, C. (2012). Chloroplast lipid synthesis and lipid trafficking through ER-plastid membrane contact sites. Biochem Soc Trans. 40, 457-463. doi: $10.1042 /$ BST20110752

Ward, O. P, and Singh, A. (2005). Omega-3/6 fatty acids: alternative sources of production. Process Biochem. 40, 3627-3652. doi: 10.1016/j.procbio.2005.02.020

Washida, K., Koyama, T., Yamada, K., Kitab, M., and Uemura, D. (2006). Karatungiols, A., and B, two novel antimicrobial polyol compounds, from the symbiotic marine dinoflagellate Amphidinium sp. Tetrahedron Lett. 47, 2521-2525. doi: 10.1016/j.tetlet.2006.02.045

Watanabe, T., and Kondo, N. (1976). Ethylene evolution in marine algae and a proteinaceous inhibitor of ethylene biosynthesis from red alga. Plant Cell Physiol. 17, 1159-1166.

Wertz, K., Hunziker, P., B., Seifert, N., Riss, G., Neeb, M., Steiner, G., et al. (2005). beta-carotene interferes with ultraviolet light A-induced gene expression by multiple pathways. J. Invest. Dermatol. 124, 428-434. doi: 10.1111/j.0022-202X.2004.23593.x

Whitehead, K., and Hedges, J. I. (2005). Photodegradation and photosensitization of mycosporine-like amino acids. J. Photochem. Photobiol. B Biol. 80, 115-121. doi: 10.1016/j.jphotobiol.2005.03.008

Wiegand, C., and Pflugmacher, S. (2005). Ecotoxicological effects of selected cyanobacterial secondary metabolites: a short review. Toxicol. Appl. Pharmacol. 203, 201-218. doi: 10.1016/j.taap.2004.11.002

Wrasidlo, W., Mielgo, A., Torres, V. A., Barbero, S., Stoletov, K., Suyama, T. L., et al. (2008). The marine lipopeptide somocystinamide A triggers apoptosis via caspase 8. Proc. Natl. Acad. Sci. U.S.A. 105, 2313-2318. doi: 10.1073/pnas.0712198105

Xia, L., Ge, H., Zhou, X., Zhang, D., and Hu, C. (2013). Photoautotrophic outdoor two-stage cultivation for oleaginousmicroalgae Scenedesmus obtusus XJ-15. Bioresour. Technol. 144, 261-267. doi: 10.1016/j.biortech.2013.06.112

Yim, J. H., Kim, S. J., Ahn, S. H., Lee, C. K., Rhie, K. T., and Lee, H. K. (2004). Antiviral effects of sulfated exopolysacchride from the marine microalga Gyrodinium impudicum strain KG03. Mar. Biotechnol 6, 17-25. doi: 10.1007/s10126-003-0002-z

Yokoya, N. S., Strik, W. A., Staden, J. V., Novak, O., Tureckova, V., Pencik, A., et al. (2010). Endogenous cytokinins, auxins, and abscisic acid in red algae from Brazil. J. Phycol. 46, 1198-1205. doi: 10.1111/j.1529-8817.2010.00898.x

Yordanova, Z. P., Lakimova, E. T., Cristescu, S. M., Harren, F. J. M., KapchinaToteva, V. M., and Woltering, E. J. (2010). Involvement of ethylene and nitric oxide in cell death in mastoparan-treated unicellular alga Chlamydomonas reinhardtii. Cell Biol. Int. 34, 301-308. doi: 10.1042/CBI20090138

Yoshida, K., Igarashi, E., Mukai, M., Hirata, K., and Miyamoto, K. (2003). Induction of tolerance to oxidative stress in the green alga, 
Chlamydomonas reinhardtii, by abscisic acid. Plant Cell Environ. 26, 451-457. doi: 10.1046/j.1365-3040.2003.00976.x

Yoshida, K., Igarashi, E., Wakatsuki, E., Miyamoto, K., and Hirata, K. (2004). Mitigation of osmotic and salt stresses by abscisic acid through reduction of stress-derived oxidative damage in Chlamydomonas reinhardtii. Plant Sci. 167, 1335-1341. doi: 10.1016/j.plantsci.2004.07.002

Yoshiki, M., Tsuge, K., Tsuruta, Y., Yoshimura, T., Koganemaru, K., Sumi, T., et al. (2009). Production of new antioxidant compound from mycosporinelike amino acid, porphyra-334 by heat treatment. Food Chem. 113, 1127-1132. doi: 10.1016/j.foodchem.2008.08.087

Yuan, H., Zhang, J., Nageswaran, D., and Li, L. (2015). Carotenoid metabolism and regulation in horticultural crops. Horti. Res. 2:15036. doi: 10.1038/hortres.2015.36

Zahradnıckova, H., Budijovice, C., and Polinska, M. (1991). High-performance thin-layer chromatographic and high-performance liquid chromatographic determination of abscisic acid produced by cyanobacteria. J. Chromatogr. A 555, 239-245. doi: 10.1016/S0021-9673(01)87184-3

Zainuddin, E. N., Mentel, R., Wray, V., Jansen, R., Nimtz, M., Lalk, M., et al. (2007). Cyclic depsipeptides, ichthyopeptins A and B, from Microcystis ichthyoblabe. J. Nat. Prod. 70, 1084-1088. doi: 10.1021/np060303s

Zeng, X., Yin, B., Hu, Z., Liao, C., Liu, J., Li, S., et al. (2010). Total synthesis and biological evaluation of largazole and derivatives with promising selectivity for cancers cells. Org. Lett. 12, 1368-1371. doi: 10.1021/ol100308a
Zhou, G. F., Xin, H., Sheng, W., Sun, Y., Li, Z., and Xu, Z. (2005). In vivo growthinhibition of $\mathrm{S} 180$ tumor by mixture of 5 -Fu and low molecular lambda carrageenan from Chondrus ocellatus. Pharmacol. Res. 51, 153-157. doi: 10.1016/j.phrs.2004.07.003

Zhou, G., Sheng, W., Yao, W., and Wang, C. (2006). Effect of low molecular [lambda]-carrageenan from Chondrus ocellatus on antitumor H-22 activity of 5-Fu. Pharmacol. Res. 53, 129-134. doi: 10.1016/j.phrs.2005.09.009

Ziemert, N., Ishida, K., Weiz, A., Hertweck, C., and Dittmann, E. (2010). Exploiting the natural diversity of microviridin gene clusters for discovery of novel tricyclic depsipeptides. Appl. Environ. Microbiol. 76, 3568-3574. doi: 10.1128/AEM.02858-09

Conflict of Interest Statement: The authors declare that the research was conducted in the absence of any commercial or financial relationships that could be construed as a potential conflict of interest.

Copyright $\odot 2017$ Singh, Parihar, Singh, Bajguz, Kumar, Singh, Singh and Prasad. This is an open-access article distributed under the terms of the Creative Commons Attribution License (CC BY). The use, distribution or reproduction in other forums is permitted, provided the original author(s) or licensor are credited and that the original publication in this journal is cited, in accordance with accepted academic practice. No use, distribution or reproduction is permitted which does not comply with these terms. 